Portland State University

PDXScholar

1988

Direct and Indirect Costs of Tinnitus: Factors for Decisionmaking

Gloria E. Reich

Portland State University

Follow this and additional works at: https://pdxscholar.library.pdx.edu/open_access_etds Let us know how access to this document benefits you.

Recommended Citation

Reich, Gloria E., "Direct and Indirect Costs of Tinnitus: Factors for Decisionmaking" (1988). Dissertations and Theses. Paper 1169.

https://doi.org/10.15760/etd.1168

This Dissertation is brought to you for free and open access. It has been accepted for inclusion in Dissertations and Theses by an authorized administrator of PDXScholar. Please contact us if we can make this document more accessible: pdxscholar@pdx.edu. 


\title{
DIRECT AND INDIRECT \\ COSTS OE TINNITUS: \\ FACTORS FOR DECISIONMAKING
}

by

GLORIA E. REICH

A dissertation submitted in partial fulfillment of the requirements for the degree of

\author{
DOCTOR OF PHILOSOPHY \\ in \\ URBAN STUDIES
}

Portland State University

(C) 1988 
TO THE OFFICE OF GRADUATE STUDIES:

The members of the Committee approve the dissertation of Gloria E. Reich presented March 15, 1988.

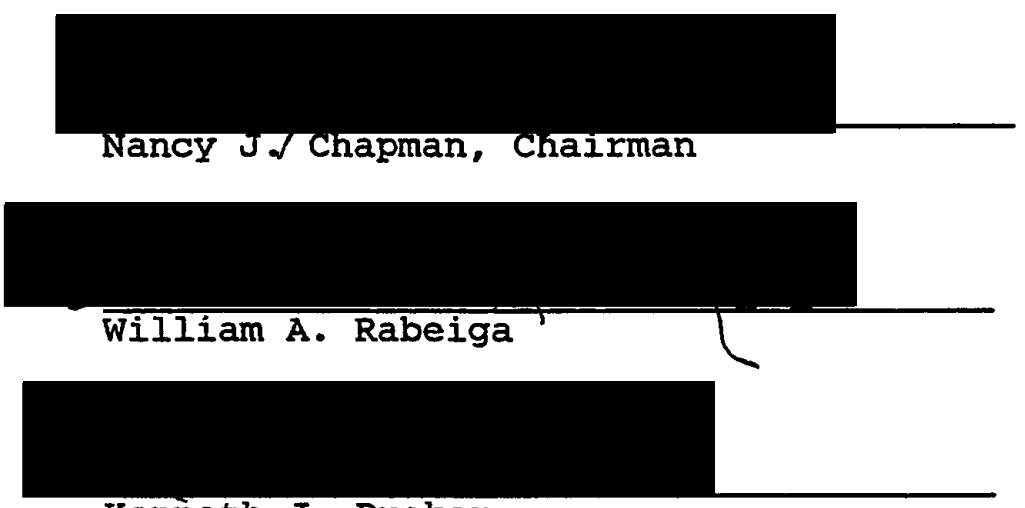

Kenneth J. Dueker

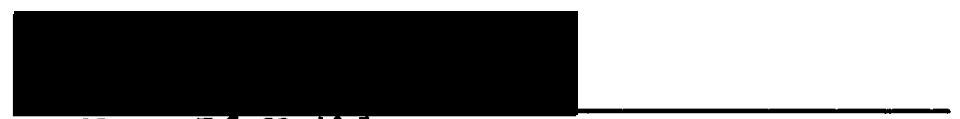

Mary Bd Meikle

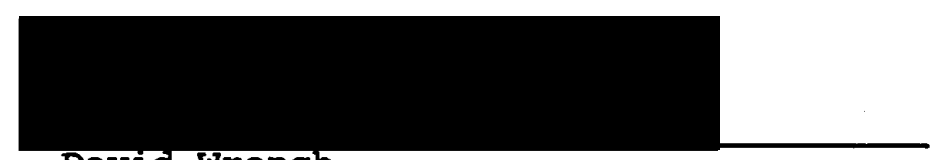

David Wrench

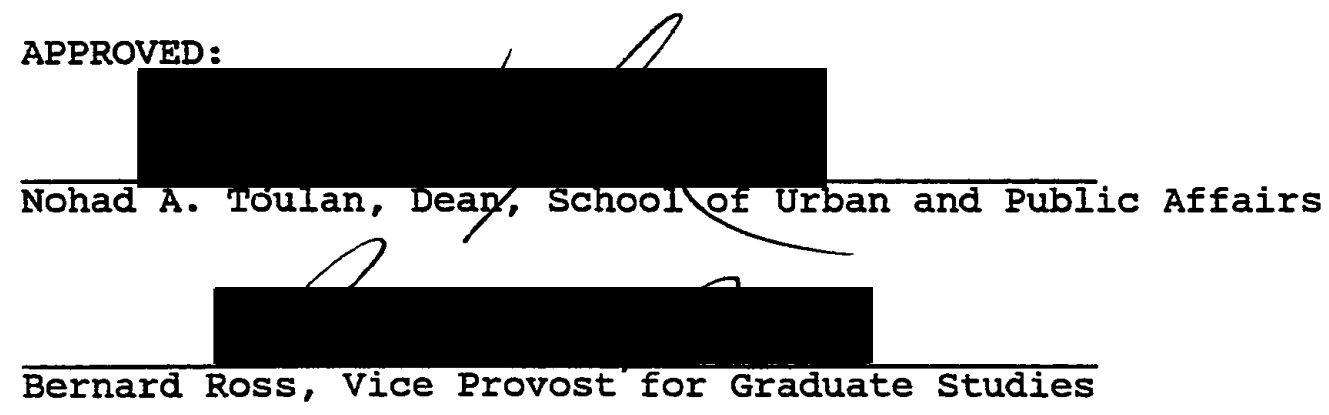


AN ABSTRACT OF THE DISSERTATION OF Gloria E. Reich for the Doctor of Philosophy in Urban Studies presented March 15, 1988.

Title: Direct and Indirect Costs of Tinnitus: Factors for Decisionmaking.

APPROVED BY MEMBERS OF THE DISSERTATION COMMITTEE:

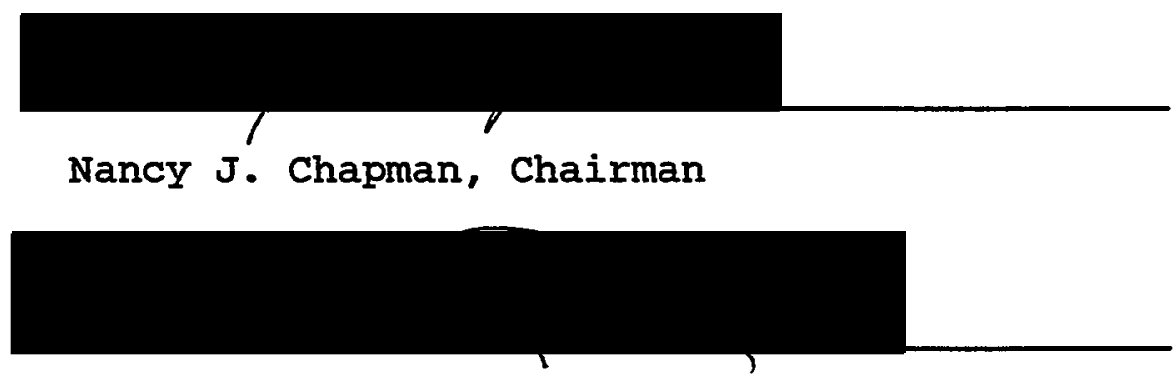

William A. Rabeiga

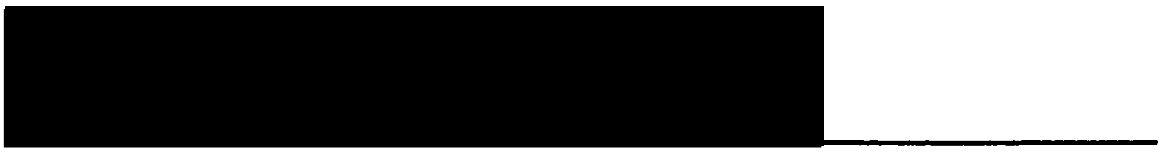

Kenneth J. Dueker

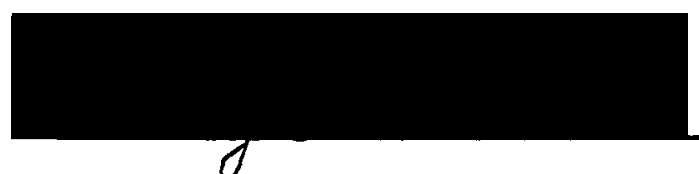

Mary B. Meikle

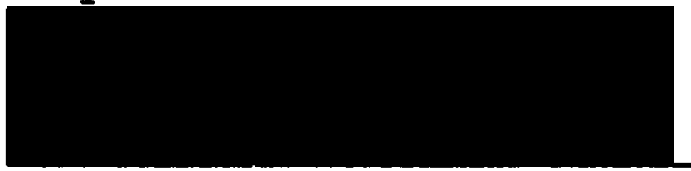

David Wrench 
This study investigates the psychological, social and economic costs of tinnitus to affected individuals. A conceptual framework for tinnitus is presented which includes the possible causes of tinnitus, the perception of severity of tinnitus, mediators or agents that can change the perception of tinnitus, tinnitus treatments, and the social and economic effects of tinnitus. Three main factors were studied: 1) whether tinnitus costs can be predicted from perceived severity and other characteristics of tinnitus, 2) whether a scale can be developed to provide information about the subjective measurement of tinnitus severity, and 3) how many people have severe tinnitus. Information from tinnitus sufferers was collected through the use of a mail survey distributed to members of tinnitus self-help groups and to people seeking information about their tinnitus from the American Tinnitus Association. Group I comprised 171 self-help group members, and Group II comprised 84 new inquirers. Estimates of the cost of tinnitus were derived for the combined respondent groups.

In testing the hypotheses it was found that tinnitus costs increased as the perception of severity increased, and that the variables age, sex, psychological problems, income and general health are related to tinnitus costs. A three item scale for rating the perception of tinnitus severity was developed. Reliability testing indicated that the scale would provide data usable in research but that it would not 
be a strong enough indicator to be used alone as a decision criterion. The scale, when used in conjunction with medical, audiological, and dental evaluations can contribute to the definition of severity.

Using the available data about tinnitus prevalence this study presented an estimate of more than 5\% of civilian and non-institutionalized Americans suffering from severe tinnitus in 1985, and more than $20 \%$ experiencing milder tinnitus. Information for obtaining this estimate was derived from U. S. census reports, National Health Interviews, Hearing and Ear Examination Findings, census studies from Great Britain, and smaller studies. 


\section{ACKNOWLEDGMENTS}

Appreciation is given to those people who aided and encouraged me in my doctoral studies. Particular thanks to my colleagues at the Oregon Hearing Research Center without whose inspiration none of this would have been possible. Thanks also to those people suffering from tinnitus who were willing to share their experience and firsthand knowledge by participating in this survey research. 
TABLE OF CONTENTS

\section{PAGE}

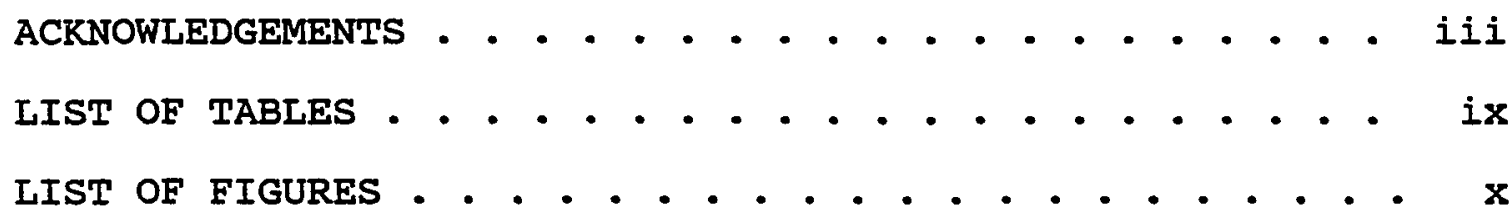

CHAPTER

I INTRODUCTION . . . . . . . . . . . . . 1

Statement of the Problem . . . . . . . 1

Goals of this study . . . . . . 1

Definition of tinnitus . . . . . . . 2

The etiology of tinnitus . . . . . . . 3

Treatments for tinnitus $\quad$. . . . . 4

Masking . . . . . . . . . . 5

Biofeedback . . . . . . . . 6

Dental treatment ........ 6

Drug treatment, allergies, diet . . . 6

Summary and discussion . . . . . . . 8

An argument for intervention . . 10

II MEASURING THE COSTS OF TINNITUS . . . . . . . 12

Social and psychological costs . . . . 12

The perception of tinnitus -- the

patient's view . . . . . . . . 12 
The perception of tinnitus - the professional view . . . . . . .

How point of view influences

accounts of tinnitus . . . . . . 15

The impact of tinnitus on emotional

well being . . . . . . . . . 16

The impact on social interaction . . 21

Evaluation of social relationships $\cdot 23$

Economic costs of tinnitus . . . . . . 24

Assessment of chronic conditions . . 26

Problems in measurement . . . . . 28

General techniques and analytical

systems . . . . . . . . . . 28

The accounting model for costs . . 30

Measuring costs of illness . . . 31

Using legal decisions to establish

valuations . . . . . . . . . 32

Prevalence of tinnitus . . . . . . . 34

Sources of Information . . . . . 34

The National Health Interview

Survey . . . . . . . . . 40

The National Health Examination

Survey .. . . . . . . 42

The Health Records Survey . . 44

Other sources of tinnitus

information . . . . . . . 45 
Information from abroad . . . 46

Problems obtaining data concerning

the prevalence of tinnitus. . . . 48

How the question was asked . . . . 51

Tinnitus in children . . . . . . . 55

Estimates of tinnitus in adults . . . . 56

Prevalence estimates for tinnitus in the

United States 1985 . . . . . . 60

Estimating incidence . . . . . . . . 62

III FACTORS THAT INFLUENCE INDIVIDUAL COSTS . . . . . . 65

Severity .............. 65

Personal and demographic factors . . . . . 72

IV CONCEPTUAL FRAMEWORK, RESEARCH QUESTIONS, \& HYPOTHESES . . . . . . . . . . . . 74

Conceptual Framework for Tinnitus . . . . . 74

Possible causes of tinnitus . . . . . 76

Possible mediators or agents of change . $\quad 77$

Perception of the tinnitus problem . . . 78

Tinnitus outcomes . . . . . . . . 79

Treatments . . . . . . . . . 81

Research Questions . . . . . . . . 83

Summary of the Problem . . . . . . . 85

The hypotheses for study . . . . . . . 85

V METHODS . . . . . . . . . . . . . . . . . 87

The survey method . . . . . . . . . . 87

Sample selection . . . . . . . . . . 88 
vii

Sample size consideration . . . . . 93

Sampling Bias Considerations . . . . . 93

variables used in the study . . . . . . . 95

Demographic and personal variables . . . 96

Measures of severity . . . . . . 96

Measures of psychological and social cost 97

Measures of economic cost . . . . . . 97

Other variables relevant to tinnitus . . 102

Data analysis . . . . . . . . . 103

VI RESULTS . . . . . . . . . . . 105

Characteristics of the sample . . . . 105

Differences between the two samples and

their subsequent combination . . . . 105

Demographic features . . . . . . . 107

Characteristics relating to tinnitus and hearing loss . . . . . . . . . 112

Social and psychological costs of tinnitus . 115

Development of a severity measurement scale . . . . . . . . . 115

Descriptive data for severity . . 116

Correlates of severity . . . . 119

Estimating the reliability of the

severity scale . . . . . . 120

Gender differences . . . . . . . 123

Age and socioeconomic differences. . . . 127

Economic costs of tinnitus . . . . . . 132 
viii

Accounting model for tinnitus . . . . 132

Costs by age and sex . . . . . . 136

Costs by income and education . . . 138

Costs by severity level . . . . . 138

Costs by severity and income . . . 139

Predictors of tinnitus costs . . . . . . . 140

Explanatory analysis of causal

relationships . . . . . . . 140

VII DISCUSSION . . . . . . . . . . . . . . . 154

Introduction . . . . . . . . . . . . 154

The attempt to set monetary values for

tinnitus costs............ 154

Relating individual costs to society . . . . 156

Prevalence of tinnitus . . . . . . 156

Tinnitus severity . . . . . . . . 157

The effects of other variables on tinnitus . 158

Implications for policymaking and further

research . . . . . . . . . . 162

SELECTED BIBLIOGRAPHY. . . . . . . . . . . . . . 165

REEERENCE NOTES. • • . . . . . . . . . . . . 176

APPENDICES . . . . . . . . . . . . . . . . . . . . . . . . . . . .

A Questionnaire . . . . . . . . . . . 178

B Database Structure . . . . . . . . . . .186

C Severity Scale . . . . . . . . . . . . . 187 


\section{LIST OF TABLES}

TABLE

PAGE

I Possible sources of data for prevalence information about tinnitus and hearing impairment in the U.S. . . . . . . . . 37

II Prevalence of hearing impairment and tinnitus as reported in vital and health statistics publications . . . . . . . . 38

III Annual family income . . . . . . . . . 110

IV Awareness of tinnitus . . . . . . . . . . 113

V Reliability analysis for severity scale. . . . 122

VI Number reporting at each severity scale level by age . . . . . . . . . . . . . . . 129

VII Number reporting at each severity scale level by income . . . . . . . . . . . . . . 130

VIII Number reporting at each severity scale level by education . . . . . . . . . . . . 131

IX Accounting model for tinnitus costs . . . . 134

$\mathrm{X}$ Past year tinnitus costs by age and sex . . . 137

$\mathrm{XI}$ Past year tinnitus costs by income and socioeconomic status . . . . . . . . . . . 138

XII Past year tinnitus costs by severity level . . 139 
XIII Past year tinnitus costs by severity and income levels . . . . . . . . . . . 140

XIV Path model for tinnitus costs, decomposition of effects - saturated model . . . . . . . 149

XV Path model for tinnitus costs, decomposition of effects - trimmed model . . . . . . . 150 XVI Correlation matrix for path analysis . . . . 151 


\section{LIST OF FIGURES}

FIGURE

PAGE

1 Conceptual framework for tinnitus . . . . . 75

2 ATA membership and self-help groups 1985 . . 90

3 Tinnitus survey data comparing 2 groups on 15 variables . . . . . . . . . . 106

4 Age distribution of tinnitus survey population 108

5 Educational levels achieved by adults in survey . . . . . . . . . . . . 109

6 Income distribution for tinnitus survey . . 111

7 How long tinnitus has been a problem . . . . 114

8 Percent of group choosing indicated severity item level . . . . . . . . . . 117

9 Percent of group choosing indicating interference-with-life item level . . . 118

10 Percent at each severity item level by sex . . 125

11 Percent at each severity scale level by sex. • 126

12 Path model for tinnitus - saturated . . . . . 145

13 Pat:h model for tinnitus - trimmed . . . . 148 
CHAPTER I

INTRODUCTION

Statement of the Problem

Tinnitus, ringing in the ears or head noises, is a problem that has been recognized throughout history (Stephens, 1985). Many people experience tinnitus but fewer suffer from tinnitus to the degree that their lives are disrupted. Societies have always been called on to make decisions about tinnitus but often without the benefit of comprehensive empirical knowledge.

In attempting to understand the magnitude of the problem of tinnitus both in terms of the sufferer and in terms of society, information is needed about the effects of tinnitus on the individual, and about the costs incurred seeking relief for tinnitus.

\section{Goals of this study}

The goals of the present study are:

1) To estimate the psychological, social and economic costs of tinnitus to affected individuals, and to draw on the available literature to arrive at a prevalence estimate for tinnitus.

2) To attempt to determine which factors influence individual costs. Since the perception of severity 
is an important factor for estimating costs, its measurement will be explored as a subtopic.

Information that will be developed to meet these goals will relate to describing the population of tinnitus sufferers. Descriptive statistics will be used to characterize the tinnitus sufferer in terms of how tinnitus affects their health care expenditures and their psychological well-being. General demographic information will be utilized for the purpose of comparing this population to the general population.

\section{Definition of tinnitus}

It is necessary to have a clear picture of just what tinnitus is as a context for this research. This section will address the following issues: 1) the presence or absence of an objective means of assessing whether or not tinnitus exists and its severity, 2) the causation of tinnitus, and 3) the treatments available.

Tinnitus is the perception of sound when no external cause for that sound is present. It is commonly called ringing in the ears or head noises. The type of tinnitus that is under consideration in this study is sometimes referred to as subjective ideopathic tinnitus which means that it is a sound which can be heard only by the person who has it, and that it arises from unknown origins. Another type of tinnitus, commonly referred to as objective tinnitus, can be heard both by the afflicted person and by others 
usually through a stethoscope. It has been suggested that objective tinnitus may be of either muscular or vascular origin, (Virtanen, 1983) and is found in less than one percent of patients who complain of tinnitus (Longridge, 1979). In addition to defining tinnitus in terms of what it is one must also consider the dilemma about how to characterize it. Medical professionals tend to regard tinnitus as a 'symptom' (Douek, Note 1), while those who suffer from tinnitus are more likely to identify it as an illness or a disease and therefore, a major issue.

\section{The etiology of tinnitus}

Tinnitus is thought to originate from many causes. For example, noise is suspected as one of the primary causes of tinnitus. The Tinnitus Clinic at the Oregon Health Sciences University reports that $66 \%$ of their tinnitus patients report having been exposed to loud noise, (Meikle \& Walsh, 1984). Tinnitus is also thought to accompany various forms of hearing loss. Physicians have reported that a high percentage of patients with hearing loss, perhaps as high as 85 percent, also have tinnitus, (Fowler, 1948). Dentists report an association between tinnitus and dysfunctioning of the temporomandibular joint (Summer, 1987). Damage to the hair cells of the cochlea or damaged neurotransmitter function along the auditory pathway has also been cited as a cause of tinnitus (Tonndorf, 1981). Stress is implicated in tinnitus both as a cause and as an outcome (Ambrosino, 1981). 
When a specific cause is not identifiable for tinnitus, and that is most of the time, it is a matter of conjecture where the causative damage lies. Thus, at this point it is not possible to make clear recommendations for the allocation of societal resources for preventing tinnitus other than those programs associated with noise prevention.

\section{Treatments for tinnitus}

The multiplicity of causes for tinnitus also leads people to seek treatment in a variety of quarters. Depending on a person's experience and beliefs a great variety of health professionals might be contacted. This great variety of health professionals, all trained to deliver aid according to the established methods in their particular profession, also helps to explain why there are so many different treatments that are being used in the attempt to relieve tinnitus. Without more information about the efficacy of present treatments it is difficult to make decisions regarding resource allocation for the development of new treatments or for making current treatments more accessible. Information of this type is generally obtained through followup studies of clinic patients and is beyond the scope of this study.

Currently the first course of action for a person suffering from tinnitus is to see an ear specialist who can perform tests to determine whether or not the tinnitus is signalling a medically treatable condition. This first step 
is very important because in a very small number of cases tinnitus may be the only symptom of something as potentially life threatening as a brain tumor. Once such medical causes have been ruled out the patient is free to pursue treatment to bring about symptomatic relief for the bothersome noise.

Masking. At present the most effective relief procedure for the largest number of tinnitus patients is masking. Masking is the substitution of a more pleasing external sound for the internal sound of tinnitus (Hazell, 1987). Maskers for tinnitus have been produced for about 10 years and have been successfully used with thousands of patients (Johnson, Note 2). Maskers look like conventional hearing aids but instead of amplifying sound they emit a composed sound designed to cover-up the patient's internal sound. Another form of masker is called a Tinnitus Instrument. The tinnitus instrument is a hearing aid and masker combined within the same unit (Vernon \& Schleuning, 1978). The concept that the presence of another sound can help tinnitus has been referred to and utilized throughout history (Stephens, 1987). Sometimes this has been achieved with environmental sound and sometimes with sound introduced externally such as musical sounds, and sometimes with the improvement of the persons ability to hear sound through hearing amplification. Hearing aids alone provide masking by amplifying environmental sounds and allowing a person to focus on those sounds rather than on their tinnitus. Other forms of masking include bedside 
devices that emit sounds of rain, wind and ocean waves; tape cassettes that play sounds of waterfalls, birds, music, jungle noises and almost anything else that can be recorded and listened to in place of one's tinnitus.

Biofeedback. Another frequently used form of tinnitus treatment is biofeedback. When a tinnitus patient is experiencing a great amount of stress it is sometimes suggested that a type of stress reduction therapy be utilized. Biofeedback training can help a tinnitus patient learn to relax and to adopt a healthier attitude toward the tinnitus (House, 1978). If the patient can react toward the tinnitus by ignoring it or by considering it merely a nuisance then the tinnitus ceases to be a problem.

Dental treatment. Some tinnitus appears to be related to dental problems such as malocclusion resulting from temporomandibular joint dysfunction. Dentists specializing in TMJ report that some tinnitus patients have benefitted from the use of a dental splint or other therapies designed to alleviate the TMJ problem. (Summer, 1987)

Drug treatment, allergies, diet. Another medical approach assesses the patient's allergic reactions to foods and other common airborne allergens. If the tinnitus changes in response to the withholding of certain foods and/or treatment with anti-histimines then a course of treatment for the allergies may alleviate the tinnitus symptoms as well (Hoover, 1987). There are drugs that affect tinnitus in some 
patients. One of these drugs, Lidocaine, intravenously administered, was found to reduce or stop tinnitus in most patients. (Melding, Goodey, \& Thorne, 1978) This ability to change or stop tinnitus is a temporary phenomenon and so far there has not been a drug available that has had the desired effect along with the ability to be used over a long time period. Other drugs have been tried for tinnitus relief. The problem with most reports of specific drug effectiveness for tinnitus is that the numbers of patients treated are usually very small and the monitoring of the tinnitus is not well controlled. Sometimes drugs prescribed for tinnitus have severe side effects, such as the anti-convulsants, and some work only when the tinnitus can be attributed to certain origins. For example, Vaso-dilators are sometimes given to patients who are thought to have tinnitus related to circulatory problems. Other regimes, such as those requiring massive doses of vitamins, with or without special diets, are difficult to assess. The patient may experience better general health because of improved nutrition thus having more physical resources to utilize in coping with tinnitus. on the other hand people with severe malnourishment such as prisoners of war have not been found to experience hearing problems as a result of that malnutrition. (Brumnett, Note 3 ) The emotional and psychological factors of a person's tinnitus influence all forms of treatment that may be initiated. It is often necessary to combine various forms of 
treatment in order to help an individual. For example, a person might be successfully masked but require some stress management therapy to overcome behaviors that have been established during the time he was suffering. One of the newer areas of tinnitus management focuses on 'tinnitus patient management' utilizing techniques such as individual counseling, group therapy, cognitive therapy, and behavior modification to achieve an effective coping style on the part of the patient (Sweetow, 1987).

These are only some of the more common treatments or interventions for tinnitus. Others are in use that may be helpful for certain individuals.

\section{Summary and discussion}

Tinnitus is still an unsolved problem. Basic research into causation has yet to provide definitive results. This lack of information has caused much speculation about what treatments and services are required. Decisions to appropriate money for the development and evaluation of treatments require that society have information about the number of individuals affected and the cost to them of specialized treatment or services. Decisions must also be made relating to the education and training of health professionals in order that they may be able to utilize research information and administer treatments. The information that will be developed in this study will provide knowledge about how many individuals are afflicted with 
tinnitus, the effect of tinnitus on the individual, and about how these effects relate to severity perception.

Other decisions to consider include those relating to the appropriate level of investment in prevention and service delivery. Prevention may take the form of informing the public about how they may protect themselves from agents or events that produce tinnitus, or mandating safeguards in situations over which an individual has no control. For those who already have tinnitus, help may take the form of programs designed to facilitate coping with it.

The general thesis underlying this study is that tinnitus is a potential stressor in addition to its role as a medical symptom and can interfere with living what is considered a normal life. A normal life, in this context, is defined as the perception by the individual that he or she is able to carry out the functions of everyday living without having to modify a daily routine because of tinnitus. In reflecting about what is meant by a normal life one must consider that people react to illness or dysfunction in different ways. Some are able to cope with the fact that their body is performing in less than an optimal way and some interpret these malfunctions as threatening. Those who can cope with a chronic, non-life-threatening problem, may have a normal lifestyle, but people suffering from tinnitus, and unable to cope with it, may only appear to lead normal lives, and may be desperate in their desire for relief. 
An argument for intervention. Any intervention program has both an outcome and a cost. Tinnitus interventions utilize resources in attempting to alleviate the distress felt by tinnitus sufferers. There are divergent points of view about the allocation of resources for conditions such as tinnitus. Some, usually those who suffer or who have an interest in tinnitus treatment, have the feeling that the quality of life is beyond monetary concern, that anything and everything should be done to prevent or alleviate tinnitus. Those holding the opposite point of view argue that tinnitus is not a life threatening condition and is of minor importance because, they say, people can learn to live with it. These people do not think it important either to allocate money for research or for prevention. It is important, therefore, to be able to analyse the economic cost burden of tinnitus in order to provide sufficient evidence to recommend societal investment in research, prevention, and treatment of tinnitus.

Past attempts to quantify the numbers of tinnitus sufferers, and, in fact to quantify the severity of the condition itself, have been fragmented and as a result the information that has been relied upon for estimates and for statements of significance has been confusing at best and woefully inadequate at the worst. The following chapters will explore some of the characteristics of tinnitus, information about how tinnitus severity has been measured, 
how the prevalence of tinnitus has been estimated, attempts that have been made to develop health indicators for measuring the effects of disease, and information about how the costs associated with other health problems and with chronic illness have been measured. 
CHAPTER II

\section{MEASURING THE COSTS OF TINNITUS}

\section{Social and psychological costs}

Before social and psychological costs can be measured it is necessary to attempt to understand the differing points of view about tinnitus that exist between patients and professionals. These differing points of view are not clearly defined because not all patients feel one way and all professionals another. Previous studies about tinnitus have reflected, for the most part, the professional view. In the present work, using survey techniques, the patients' view will be presented.

The perception of tinnitus -- the patient's view. It is necessary at this point to clarify some of the differences in the way tinnitus is commonly perceived. A suffering tinnitus patient perceives himself as having an illness, tinnitus. Some of the most troublesome moments for tinnitus sufferers, therefore, come when they sense that the professional who is attending them considers their problem insignificant.

A letter from a patient (FB, Note 4) says "...the ringing has been in a non-stop crescendo, and there seems to be no relief in sight. My life has become a horror story since I cannot find any peace and it has become impossible 
for me to function normally. I have been to numerous ENT (Ear Nose and Throat) specialists who have prescribed various medications, have ordered various tests including audiograms and tympanograms, and have undergone biofeedback. Nothing has helped. I have been submerged into depression because my quality of life is altogether gone. I cannot even concentrate at work."

The perception of tinnitus - the professional view. The physician's training leads him to look at tinnitus as a sign that something is wrong with the auditory system. When testing reveals nothing of a medical nature that can be corrected the tinnitus may lose much of its importance for him. For many physicians, it no longer has a meaning clinically.

Tinnitus commonly has no readily apparent source and thus, like pain and mental illness, is difficult for nonsufferers to understand. The patient may have to endure accusations of malingering, hypochondria, or laziness, while at the same time he may be trying to cope with the lack of empathy shown by his family and physician. If tinnitus is causing stress and disruption in his life then it truly becomes a debilitating condition for him. It is not surprising that he may become very resentful of the physician who counsels him to learn to live with it without giving him any help or guidance in how to do so. Sometimes an attempt is made to relieve the patient's suffering through the use of 
tranquilizing agents but these may provoke a new set of problems that can include a dependence on drugs as well as drug-related side effects. More importantly, a perceptual change may occur in the therapists view by which the auditory problem is translated into a "mind" problem; not infrequently, psychiatric treatment is suggested when standard medical treatment fails.

These subtle differences in the way professionals and laymen speak about tinnitus reflect an underlying problem of attitudes toward tinnitus evaluation and treatment. That problem is that the health providers treat what they perceive is the patient's problem, not necessarily what the patient perceives as the problem. In the case of an easily identifiable illness, where cause and effect can be shown, an issue such as this would not be important. If a patient had a broken leg as a result of a fall, the treating physician could show the patient what the problem was by presenting the $x-r a y$ and pointing out the injury, and treatment could commence with a reasonable expectation of visible success. Tinnitus patients are likely to expect more from the physician than a simple course of treatment. The problem is usually totaliy subjective and often difficult for the patient to explain. The health professional is expected to understand and to be able to treat a condition that eludes any standard definition or remedy. 
Even those physicians most involved in tinnitus research appear to have a different view of tinnitus than the layman who suffers from it. At the Ciba Symposium on Tinnitus in 1981, Ellis Douek remarked, "The greatest error that might ensue would be to forget this symptomatic nature and to consider tinnitus as a disease. The dangers that this produces in management are grave." The question to consider is when does tinnitus cease being merely a symptom or warning of auditory disorder and become a chronic disorder in its own right, something that is difficult to live with? Shulman and Goldstein, (1984) propose that the physician's goals in treating tinnitus patients are the exclusion of causal disease entities and then control or treatment of the tinnitus based upon an objective neurotologic classification system.

How point of view influences accounts of tinnitus. These subtle differences in attitude are also reflected in the allocation of societal resources for research about tinnitus. Collection of data about tinnitus in the National Health Interview Surveys appears to have been influenced by the way in which the problem is perceived. Earlier discussions in this study have pointed out that in the professional point of view questions about tinnitus tend to be secondary to questions about hearing or deafness. This situation has created a problem in data gathering because tinnitus is generally perceived by the public as a separate 
affliction from deafness. It also may be that when questions about tinnitus are embedded in a list of other questions they are disregarded, and therefore ought to be asked separately . The impact of tinnitus on emotional well being. Not surprisingly, tinnitus patients often experience feelings of hopelessness when told there is nothing that can be done to relieve tinnitus. (House, 1978) Whether or not this is true for that individual may or may not have been determined, but the seeds of helpless behavior have been planted with this simple statement. The person who passively accepts that verdict may lose hope for the future. That person may also feel inadequate to cope with the problem (after all, the best medical resources cannot seem to deal effectively with it!) and can even imagine that it prevents him or her from attaining whatever life goals have been envisioned. These problems in living are confronted frequently by those who work with tinnitus patients. Sometimes the patient volunteers such information and sometimes the problems are observed by the clinicians who are called on for help. occasionally problems of adjustment become severe enough that the patients themselves seek psychiatric counseling (House, 1981)

In a 1986 article Jakes remarked that "Psychological therapy can remove the 'problem', not of the tinnitus (which as we know is not a problem in itself) but of the patient finding it annoying and being unable to accept it." 
Various psychological problems have been observed in relation to hearing loss. Personality changes may occur that are thought to result from how the person perceives himself in his environment. Myklebust (1960) points out that in studying the psychological effects of hearing loss, we must be aware of the sensory function of hearing. He defines hearing as the basic contact, and alerting sense and refers to it as the primary sense for background 'scanning'. When this function is impaired, the individual is forced to attend to all sounds, (both important and unimportant). This is a significant perceptual reorganization and one that may cause significant fatigue as well as confusion. Ramsdell (1960) also addressed this issue when he wrote about the three psychological levels of hearing. Level 1, language comprehension, is the symbolic level. Level 2 is the sign or signal warning level. Level 3 is the auditory background level. This primitive level of hearing where one reacts to sounds that are in the background of the senses, establishes the foundation for conscious experience. This constant reaction to the environment couples the individual with the living, active world. When a person is deprived of this primitive function, whether or not he realizes it, he may feel insecure or depressed or have a flat or deadened affect. Tinnitus can increase the difficulties of the hearingimpaired because it too, interferes with language 
comprehension, confuses signal auditory messages, and alters the auditory background level.

Many patients who are troubled by tinnitus also report having psychological difficulties. These negative reactions, to a great extent, are similar to those experienced by people with hearing impairment. However, there are also patients who have normal hearing and who suffer greatly from tinnitus and its associated stress. It is easy to understand why listening to a constant noise over which one has no control is tiring. What is not understood about tinnitus by people who don't have it is that a person who hears these internal noises is constantly checking to see if his tinnitus is a "real" noise or not. Tinnitus patients repeatedly comment that they answer the telephone when it hasn't rung, or that they go around the house checking various pieces of electrical equipment which might inadvertantly have been left running.

"Tinnitus is a stress" (Ambrosino, 1981). Some tinnitus patients have been so distressed that they have committed suicide to escape the noise. Selye (1974) characterizes stress as the nonspecific response of the body to any demand made upon it. In the case of tinnitus this demand could relate to the need for constant reasurrance about where the noise is coming from. When the body is chronically in this state of readiness to respond, (such as running to answer the telephone) its adaptability is diminished and the person 
involved is less flexible to cope with the everyday problems of living. The problem that has just been described presents tinnitus as a stressor, that is, something that causes stress.

In other situations, stress is described as the cause of the tinnitus. Some patients describe their tinnitus as having arisen from an extremely stressful situation. One letter received in the ATA office explained that tinnitus had started for that patient at the moment that her husband informed her of her brother's death. Another aspect of the problem is that other stressful agents can exacerbate an existing tinnitus. That situation may be similar to situations with pain. Think of having a minor pain such as a headache and then having your boss angry with you for something or your kids misbehaving; the pain seems worse in these situations than if you had the same headache and were enjoying a pleasant walk in the country. When the stressful situation, either caused by the tinnitus or contributing to the tinnitus, becomes unbearable, the patient is likely to exhibit behaviors that are disorganized or pathological. One of the most common psychopathologies clinically observed in tinnitus patients is depression (Johnson, Note 5). Feelings of hopelessness, self-pity, inadequacy, along with a dependence on others to solve problems, withdrawal from social situations, and increased frequency of other illnesses are examples of these depression-related states. 
The significance a patient attaches to his or her tinnitus is an important factor in the manner in which the patient relates to the problem. Tinnitus can be little more than a nuisance to a person who iis well adjusted but can be a major source of preoccupation to someone already having problems with living (Johnson, Note 5). The stress is undoubtedly compounded by the presence of hearing loss, but sometimes it is the patient with little or no hearing loss who becomes most anxious about having tinnitus. When a patient becomes overly concerned about the tinnitus, a vicious circle can be initiated where the anxiety exacerbates the tinnitus; the patient becomes more anxious and the tinnitus, in response to increasing stress levels, seems to worsen.

Frankenhaeuser \& Patkai (1964) have shown that when people perform tasks requiring sustained concentration under distracting conditions, their continuation of these tasks will result in a depletion of the energy reserves and cause fatigue even though hormones to sustain these reserves are still being secreted at the same level. It is possible that the sustained annoyance of the stress of tinnitus may account for the inability to endure long periods of concentration and fatigue that is reported in correspondence from many tinnitus patients (Mahr, Note 6 ).

Many individuals who experience tinnitus do not appear to suffer from psychological effects attributable to tinnitus. In fact, most seem able to cope fairly adequately 
with the problem. It is therefore necessary to ask, why do certain individuals exhibit poor psychological adjustment to tinnitus? It is possible that chronic problems such as tinnitus exacerbate preexisting psychological problems. If the situation worsens, the tinnitus may serve as a focus for phobic fears, obsessive ruminations, depression and a variety of hostile or guilt feelings. (House, 1978)

In summary, it has been noted that tinnitus is stressful and may often give rise to feelings of anxiety. The body reacts as though it were being constantly tormented by a situation that is difficult to tolerate. If this situation exceeds a person's capacity for coping, then a pathological state is likely to result. It is well known that response to stress is highly individual. Tolerable stress for one person may be intolerable distress, discomfort and incapacity for another (Ambrosino, 1981).

If illnesses affected only those suffering from them there would be somewhat less reason to commit the resources of society to search for cures. But such is not the case. Illness touches family members, friends, colleagues, health providers, insurance companies, courts of law, legislators; everyone is involved. Some scornful viewers of tinnitus have called it trivial; not a disease; not life threatening. Yet for those who suffer, it is engulfing; disabling; and sometimes distressing to the point of suicide. 
The impact on social interaction. Many tinnitus sufferers report that social situations are difficult for them. Sometimes social difficulties are exacerbated by the patient's hearing loss but usually the tinnitus is identified as the reason for a person's lack of ability to understand conversation or to extract meaningful content from an oral presentation. Considerable attention has been paid to a hearing-impaired person's ability to discriminate words in noise but little is known about the effort that a tinnitus patient must expend in order to discriminate words in the presence of his internal noise. Clinical observations from the Tinnitus Clinic at the oregon Hearing Research Center indicate that tinnitus patients do have reduced tolerance for situations requiring either acute hearing or tolerance of noise. (Johnson, Note 7) This may appear to be a conflicting statement. It is not. A quiet environment may cause the tinnitus patient to be more aware of the internal sound. Patients frequently report that if they try very hard to hear something the tinnitus seems to get louder and louder. On the other hand, in a noisy situation a person's tinnitus will also seem to get louder and louder to compete with the external noise.

Even an outgoing and otherwise well adjusted person may find it easier to withdraw socially than to try to explain their particular difficulties to others. Such withdrawal has serious implications, for it is known that the ability to 
function socially influences a person's self-confidence (Carmen, 1983):

Although specific indicators of successful adaptation or adjustment to tinnitus have not yet been established it is clear they should include being able to carry on a normal range of social activities, including those involving family, work and leisure-time interactions with others.

The evaluation of social relationships. When an attempt is made to assess the effect of tinnitus on social relationships and the social role there are three areas to study. Stanley and Rattray (1978) define social severance as the rupture of relationships between (1) people, or (2) between people and places, or (3) between people and institutions. Social bonds are the relationships that people have with other people. Tinnitus may disrupt personal relationships by making communication more difficult. For example, people with tinnitus sometimes perceive that they are not hearing as well in social situations. Social disruption includes social severance and other factors which dislocate a person's identity, pattern of life or psychological well being. In these instances, tinnitus may cause a person to worry about their social status if they are unable to carry on their normal daily work and other activity, or interact poorly with friends or withdraw from certain social situations like church-going or club attendance where friendships and neighborhood behavior 
patterns are established. In applying a cost-benefit approach to social severance an attempt is made to identify who gains and who loses as a consequence of the problem in question. One can measure the actual costs involved, the disruption costs of severing personal and environmental relationships, measure the reduction in employment opportunities, make an assessment of behavior changes, and measure changes in attitude (Downs, 1970; Fried, 1967).

\section{Economic costs of tinnitus}

It is desirable and important to be able to make some statements about the impact of tinnitus upon the individual and upon society. In order to devise a measurement framework for assessing the cost of tinnitus one can look to similar studies of the valuation of life and suffering, and to studies about illness cost estimates for other chronic conditions. The framework for measuring illness costs is usually constructed with information that can be easily quantified. One can count the numbers of deaths attributed to a specific disease, or the number of people residing in nursing homes with specific diagnoses. However when an affliction, such as tinnitus, is widespread and variable in its impact upon the individual the attempt to measure costs becomes highly complex.

Medical sociologists have been interested in the problems of evaluating the costs of illnesses for the last several decades. Nearly 20 years ago the U. S. Department of 
Health, Education, and Welfare published a booklet (Rice, 1966) in their Health Economics Series about estimating the cost of illness.

The Rice (1966), study estimated illness costs both directly, through expenditures, and indirectly, through mortality and morbidity losses, and losses to society (Gross National Product loss). These measures were further broken down by sex, circumstances of residence (whether or not institutionalized), and factors of employment. Even though the Rice catagorization is inappropriate for assessing the costs of tinnitus, research on the costs of some other chronic problems might produce some indications of how the problem may be tackled.

Additionally, the Rice framework utilized the 'International Classification of Diseases Adapted' code which lumps together into one category all diseases of the nervous system and sense organs. If one wished to use this work to make rough comparisons of direct expenditures and costs, then tinnitus, as part of the category, 'nervous systems and sense organ diseases', would share the costs of this category with communicative disorders and a whole variety of nervous system disorders. But, one of the problems with trying to use this framework to assess the costs of tinnitus is that tinnitus is a symptom which can be associated with almost any other hearing problem. This creates difficulty in assigning costs to it specifically, and sometimes tinnitus occurs in the 
absence of any measurable hearing problem. Tinnitus may be associated with medical problems, dental problems, psychoneurotic disorders, nutritional or allergy problems, or other ill-defined conditions making it difficult if not impossible to draw an accurate picture or specify a complete model for measurement.

Assessment of chronic conditions. Some of the same techniques that were used to measure social severance have been utilized to measure the impact on one's life of having a chronic health condition. These techniques may also be helpful in the assessment of tinnitus.

Ehrlich (1983) in writing about the outcomes of Rheumatoid Arthritis notes a number of conditions that appear to have parallels in tinnitus. The first of these parallels is that tinnitus treatment, if it is to achieve any sort of effect on the patient, needs to be carefully tailored to the individual needs of the patient. The implication is that the doctor-patient relationship must be a great deal more than if the patient were presenting with an illness such as pneumonia where the identification and eradication of the causal organism can be done using treatment techniques that are the same for everyone. Further, chronic illnesses that lack specific treatments are particularly complicated to deal with and often require a multidisciplinary approach in order to achieve even partial success in their alleviation. This can and does often involve the judgements of several people 
concerning potential treatment and increases dollar cost accordingly.

Meenan, Yehlin, Henke, Curtis, \& Epstein, (1978) detailed the costs of rheumatoid arthritis, compiling their data from reports of patients in order to reveal previously hidden costs of this condition. They were able to create a picture for policy makers and health practitioners that more fully reflects the costs of arthritis.

Five clinical practices in the San Francisco area provided them with names of potentially eligible patients for the survey. The 50 people selected furnished information about their age, sex, occupation, disease characteristics, marital status, and education. The study team additionally was able to review medical records in order to supplement the survey and assign those costs directly attributable to arthritis. Psychological effects were measured based on five indices: 1) marital status, 2) family structure, 3) family employment, 4) change of residence, and 5) reports of major psychological problems. These effects were found in all socioeconomic classes, and there was a relationship between the magnitude of economic losses and the number of such effects noted. These psychological factors were not able to be converted into dollar amounts, instead, they were simply recorded as positive responses in those cases where they could be shown to be mainly due to the effects of the illness. Insurance and indirect costs were estimated by 
determining health insurance coverage and transfer payments. Transfer payments in this study included disability income, welfare payments, and payments for aid to dependent children. Medical costs were tabulated for patients grouped according to the American Rheumatism Association's Functional Class Index for arthritis (a four-level index based on describing the progressive stages of the disease). An effort was made to relate direct and indirect costs to individuals' income and social class.

Problems in measurement. The psychological measures used to classify arthritis patients in the Meenan study suggest that effects on interpersonal relationships, employment characteristics, and psychological problems may be important indications of the effect of chronic illness on the individual. Arthritis is a more visible, physical problem than tinnitus. The invisibility itself causes much of the distress perceived by tinnitus sufferers who often state that no one else either understands or cares about their affliction. In the study to be described below, information will be gathered concerning the psychological problems experienced by individuals with tinnitus, in order to try to relate such problems to tinnitus costs.

General techniques and analytical systems. Economic costs of tinnitus may accrue through diminished productivity of the sufferer or through goods and services utilized in its treatment. The first cost is indirect, it is not 
specifically tied to the problem but rather to the decreased overall effectiveness of the afflicted individual. These costs are more difficult to measure, especially as the affected population spans all age groups. More easily measured are the actual costs of treatment; even here, however, confusion may arise because of coincidental treatment for other disorders that may make it difficult to assign costs solely to tinnitus treatment.

One model for measuring costs calls for the specification of all possible ingredients utilized in a therapeutic intervention and placing a value on each one. $A$ model for tinnitus cost measurement then would necessarily include specifying costs for all forms of treatment used to alleviate the problem, as well as all costs incurred simply as a result of having the problem. The most straightforward way to obtain such data is to ask the people who are afflicted with tinnitus to provide it by answering a structured questionnaire.

Economists, according to Mishan (1976) scorn the use of questionnaire data although he advocates its use to capture quantitative information and for elusive qualitative information. Economists prefer to rely on what a person does rather than on what he or she says of their own behavior. Other social scientists, however, do rely heavily on survey data and can often draw a recognizable image of a person, and his expected behavior in a particular situation. These 
portraits can be helpful in assessing the utilization of societal resources for tinnitus in three ways: 1) to determine priorities by reporting the number of cases of tinnitus requiring special help, 2) to evaluate the severity of tinnitus in the individuals involved, for to evaluate the efficacy of treatments utilized to alleviate their tinnitus), and 3) to allocate appropriate funds for research and development of treatments for tinnitus as well as for education and programs designed to prevent tinnitus. Economic analyses can go beyond the simple application of cost-benefit studies. In this attempt to measure the costs of having tinnitus the main focus is not the direct costs so much as it is the indirect, human costs involved. Medical services are the most identifiable costs but they do not give a complete picture of the impact of tinnitus on the individual. Better understanding of the problems associated with having tinnitus can lead to improved working conditions, enriched social interactions, and superior medical treatment. The accounting model for costs. Merely counting cases does not determine the socio-economic impact of the problem. What is needed is an assessment of the overall cost to society. Social cost valuation tries to put a monetary value on the 'goods' or 'bads' that people experience. If a person has a steady job, that might be considered a 'good' and some positive dollar value could be assigned to it. Conversely, if a person suffers some chronic disease, that might be 
considered a 'bad' and again one would try to assign some negative dollar amount to it so that comparisons might be made. Mooney (1978), calls this kind of valuation 'the accounting approach'. The present study will develop an accounting model for tinnitus costs in which the amounts spent for treatment, drugs, and devices will be combined with the estimates of lost income and the cost of household services.

Measuring costs of illness. The past two decades have seen dramatically increased interest in the measurement of economic costs of illness. For the most part these studies have involved health conditions that represent the major causes of death, or the substantial reduction of life expectancy. More recently, the effort has expanded in order to include studies of problems that affect quality of life. For example studies have focused on environmental issues and dealt with concerns such as pollution, overcrowding, and noise. People have become more aware of how they are personally affected by what goes on around them and they are concerned with maintaining their own well-being and health. Problems like tinnitus that are not considered to be lifethreatening are nevertheless seen as threats to wellness and to a person's ability to function effectively both socially and in the workplace.

Studies of this sort are useful today because of their implications for health policy. Health costs are increasing. 
Direct costs of illness, while only a portion of the total costs of illnesses, are a concern for politicians who are being called upon to consider ways of relieving the financial impact on the individual. Indirect costs, particularly relating to the inability to work, are also important considerations for those allocating society's resources. Using legal decisions to establish valuations. One could in principle use court awards for injury damages to place relative values on non-fatal conditions, and this has been done in a number of instances. (For example Mooney refers to such an effort by Rosser \& Watts, 1971). He points out that awards for non-fatal conditions vary according to the judgement of loss and the level of compensation deemed necessary to compensate for that loss.

For tinnitus, however, information about court awards has not yet been accumulated. The court awards for tinnitus are new enough that the American Tinnitus Association is constantly being asked by lawyers to provide them with any relevant information, thus confirming that such information is not presently available. What little information there is indicates that awards seem to be made by pre-determined rules-of-thumb, such as the Veterans Administration disability percentages of $10 \%$ of military pay for hearing-loss and $10 \%$ for tinnitus, and these seem to be arbitrary. Or, they may be made similarly to other compensation claims; that is, an amount stipulated for lost 
income, another amount for general damages and an amount for punitive damages against the party responsible for the onset of the tinnitus. Court cases rely heavily on the patient's description of his tinnitus as well as upon medical and audiological reports relating to the tinnitus and other hearing difficulty. More objective measurements of distress are also sought in order to validate the patient's story. One approach, used by the Veterans Administration to elicit corroborating evidence of tinnitus before compensation can be awarded, is that the complaint of tinnitus must be supported by statements from family or significant others.

A framework for assessing the costs of tinnitus should include incidence figures as well as prevalence figures. Briefly, incidence figures relate to how many new cases of an affliction occur in a given year. Studies using the incidence approach focus on costs associated with a specific year. In the case of tinnitus the incidence is widely presumed to have increased as the environment has become more noisy and stressful. Tinnitus, however, is not a "medically reportable" condition (unlike scarlet fever or AIDS) and therefore figures pertaining to incidence are not specifically available.

Prevalence figures relate to enumerating the entire afflicted population regardless of how long each individual has been so afflicted (Hartunian,1981). Prevalence is the more useful approach when the policy issues to be decided 
have to do with controlling medical costs and absenteeism. A study of the prevalence of tinnitus may help decide whether it is important to institute programs for immediate treatment and medical research for new treatments. A prevalence study might provide a better estimate of costs by taking into account resources consumed by the condition over a longer timespan. It is relevant to compare these two approaches to look for economic benefits to be gained either by better treatment or by attempting to alter incidence.

\section{Prevalence of tinnitus}

It has been difficult to obtain accurate quantitative information about the prevalence of tinnitus. Studies are either outdated, or are focused on a particular area of interest, such as medical causes or treatments for tinnitus. According to accepted medical and audiological opinion, however, tinnitus is thought to affect a very large segment of the population. In addition physicians report that approximately 85 to 90 percent of their hearing-impaired patients also complain of tinnitus (Fowler, 1944).

Government agencies, research centers, clinical facilities, manufacturers of equipment and drugs used for tinnitus treatment, and others concerned with the problem all have a need to know the size of the population requiring their services. Therefore, the present study will examine the existing sources of prevalence information in an attempt 
to provide a more accurate estimate of the number of Americans with tinnitus who require professional help.

Sources of Information. Studies presenting quantitative information about the prevalence of tinnitus have been available since the 1960 's. The National Health survey Act was signed into law in July 1956. It provided for continuing surveys and special studies of sickness and disability in the United states, and for periodic reports of the results thereof. Thus for more than 30 years statistics on disease, injury, impairment disability and related topics have been collected and reported by the U.S. Government. Statistics on morbidity and infectious diseases had previously been the focus of concern and were reported as "Vital statistics". However, following the publication of the National Health Survey Act, the emphasis began shifting to the control of chronic diseases. New information was needed for those agencies concerned with personal care and rehabilitation. People were living longer and chronic illnesses were consuming a greater portion of the nation's resources. Table I lists large-scale studies in which tinnitus data may have been collected. The possible data sources listed in Table I have not in all instances actually provided information about tinnitus. In some of the studies, information about tinnitus was collected but never reported. It is important for future researchers to be aware that this information exists and may possibly be available someday. 
Those studies where tinnitus data has been published have been identified with codes (boldface and bracketed in Table I) for ease in discussing them in the rest of this paper. Table II reports the prevalence of tinnitus and hearing impairment in percentages for studies listed in Table I. 
TABLE I

POSSIBLE SOURCES OF DATA : PREVALENCE INFORMATION ABOUT TINNITUS AND HEARING IMPAIRMENT IN THE U.S.

\begin{tabular}{|c|c|c|c|c|c|c|c|}
\hline $\begin{array}{l}\text { NAME OF STUDY } \\
\text { (CODE) }\end{array}$ & $\begin{array}{c}\text { DATE } \\
\text { PUBLISHED }\end{array}$ & $\begin{array}{c}\text { NUMBER } \\
\text { SURVEYED } \\
\text { ALL AGES }\end{array}$ & $\begin{array}{l}\text { TINNITUS } \\
\text { ESTIMATE }\end{array}$ & $\begin{array}{l}\text { ADULT } \\
\text { TINNITUS } \\
\text { ESTIMATE }\end{array}$ & $\begin{array}{l}\text { HEARING } \\
\text { IMPAIRED } \\
\text { ALL AGES }\end{array}$ & $\begin{array}{l}\text { ADULT HEARING } \\
\text { IMPAIRED } \\
\text { ESTIMATE }\end{array}$ & $\begin{array}{l}\text { THE "TINNITUS } \\
\text { QUESTION" AS } \\
\text { PRESENTED }\end{array}$ \\
\hline $\begin{array}{l}\text { Current estimates from } \\
\text { the National Health } \\
\text { Interview Survey 1962-3 } \\
\text { Population } 179,323,000 \\
\text { Adult pop. } 111,100,000\end{array}$ & $1965:$ & $\begin{array}{c}\text { (usual } \\
41,000 \\
\text { households) }\end{array}$ & N.A. & N.A. & N.A. & N.A. & $\begin{array}{l}\text { "Besides your hearing trouble or } \\
\text { deafness, do you have any other } \\
\text { trouble with your ears? What kind } \\
\text { of trouble? Noises or ringing in } \\
\text { the head or ear? }\end{array}$ \\
\hline $\begin{array}{l}\text { Hearing Status } \\
\text { \& Ear Examination } \\
\text { Findings Among AduIts } \\
\text { U.S. } 1960-62 \text { (HSEE) } \\
\text { Population } 179,323,000 \\
\text { Adult pop. } 111,100,000\end{array}$ & 1968 & 6672 & N.A. & $36,000,000$ & N.A. & $16,300,000$ & $\begin{array}{l}\text { "At any time over the past few } \\
\text { years, have you ever noticed } \\
\text { ringing(tinnitus)in your ears or } \\
\text { have you been bothered by other } \\
\text { funny noises in your ears?" }\end{array}$ \\
\hline $\begin{array}{l}\text { National Health } \\
\text { Interview Survey, U. S. } \\
\text { Persons with impaired } \\
\text { hearing. }\end{array}$ & 1977 & $\begin{array}{l}\text { (usual } \\
41,000 \\
\text { households) }\end{array}$ & N.A. & N.A. & & & $\begin{array}{l}\text { "Does anyone in the family Now have } \\
\text { tinnitus or ringing in the ears?" }\end{array}$ \\
\hline $\begin{array}{l}\text { National Health and } \\
\text { Nutrition Examination } \\
\text { Survey } 1976-1980\end{array}$ & 1981 & $<10,000$ & N.A. & N.A. & & & $\begin{array}{l}\text { "During the past } 12 \text { mos. have you } \\
\text { EVER been bothered by ringing or } \\
\text { other funny noises in your ears?" }\end{array}$ \\
\hline $\begin{array}{l}\text { National Nursing Home } \\
\text { Survey } 1977^{\star \star}\end{array}$ & 1979 & 1.3 million & N.A. & N.A. & & 348,500 & $\begin{array}{l}\text { "Deafness, hearing trouble or any } \\
\text { eye condition?" }\end{array}$ \\
\hline $\begin{array}{l}\text { Current Estimates } \\
\text { from the National } \\
\text { Health Interview Survey, } \\
\text { U. S. } 1983 \text { (NHIS-1) } \\
\text { Population } 230,000,000 \\
\text { Adult pop. } 165,000,000\end{array}$ & 1985 & $\begin{array}{l}\text { (usual } \\
41,000 \\
\text { households) }\end{array}$ & $5,290,000$ & $5,255,000$ & $19,370,000$ & $0 \quad 18,270,740$ & $\begin{array}{l}\text { "Does anyone in the family Now } \\
\text { have tinnitus or ringing in } \\
\text { the ears?" }\end{array}$ \\
\hline $\begin{array}{l}\text { U. S. } 1984 \text { (NHIS-2) } \\
\text { Population } 231,606,000 \\
\text { Adult pop. } 169,013,000\end{array}$ & 1986 & $\begin{array}{l}\text { (usual } \\
41,000 \\
\text { households) }\end{array}$ & $5,708,500$ & $5,671,000$ & $21,319,195$ & $5 \quad 20,109,317$ & (Same as 1983, above) \\
\hline $\begin{array}{l}\text { U. S. } 1985 \text { (NHIS-3) } \\
\text { Population } 233,721,000 \\
\text { Adult pop. } 170,975,000\end{array}$ & 1986 & 91,531 & $6,228,000$ & $6,187,000$ & $21,198,000$ & $019,995,000$. & (Same as 1983, above) \\
\hline $\begin{array}{l}\text { U. S, } 1986 \text { (NHIS-4) } \\
\text { Population } 236,348,000 \\
\text { Adult pop. } 173,216,000 \\
\text { * Note: This study is par } \\
\star \star \text { Note: This study is pa }\end{array}$ & 1987 & 59,000 & $6,315,000$ & $\begin{array}{l}6,087,000 \\
\text { survey }\end{array}$ & $20,732,000$ & $019,462,000$ & (Same as 1983, above) \\
\hline
\end{tabular}


TABLE II

PREVALENCE OF HEARING IMPAIRMENT AND TINNITUS AS REPORTED IN VITAL AND HEALTH STATISTICS PUBLICATIONS

(Figures expressed as percents.)

\begin{tabular}{|c|c|c|c|c|c|c|c|c|}
\hline \multirow[b]{2}{*}{ Year 1960-62 HSEE } & \multirow[b]{2}{*}{ AII } & \multicolumn{3}{|c|}{ Under 45} & \multirow{2}{*}{$\frac{45-64}{45-64}$} & \multicolumn{3}{|c|}{65 and over } \\
\hline & & Tot & $\leq 18$ & $18-44$ & & Tot & $\underline{65-74}$ & $75+$ \\
\hline $\begin{array}{l}\text { Hearing Imprd } \\
\text { Tinnitus (Sev) } \\
\text { Tinnitus (Mild)' } \\
\text { Year } 1983 \text { NHIS-1 }\end{array}$ & $\begin{array}{r}14.7 \\
5.6 \\
26.8\end{array}$ & $\begin{array}{l}* \\
* \\
* \\
l^{*}\end{array}$ & $\begin{array}{l}* \\
* \\
* \\
\text { figu }\end{array}$ & $\begin{array}{l}8.1 \\
3.2 \\
25.0 \\
\text { ires not }\end{array}$ & $\begin{array}{c}20.0 \\
7.6 \\
27.4 \\
\text { eported) }\end{array}$ & $\begin{array}{l}* \\
* \\
*\end{array}$ & $\begin{array}{l}27.1 \\
11.5 \\
33.0\end{array}$ & $\begin{array}{l}35.3 \\
10.6 \\
30.6\end{array}$ \\
\hline $\begin{array}{l}\text { Hearing Imprd } \\
\text { Tinnitus }\end{array}$ & $\begin{array}{l}9.0 \\
2.4\end{array}$ & $\begin{array}{r}3.8 \\
.9\end{array}$ & $\begin{array}{r}1.9 \\
.1\end{array}$ & $\begin{array}{l}5.0 \\
1.4\end{array}$ & $\begin{array}{r}14.8 \\
4.4\end{array}$ & $\begin{array}{r}31.5 \\
8.0\end{array}$ & $\begin{array}{r}26.2 \\
8.2\end{array}$ & $\begin{array}{r}40.1 \\
7.6\end{array}$ \\
\hline $\begin{array}{l}\text { Year } 1984 \text { NHIS-2 } \\
\text { Hearing Imprd } \\
\text { Tinnitus }\end{array}$ & $\begin{array}{l}9.2 \\
2.4\end{array}$ & $\begin{array}{l}4.2 \\
1.0\end{array}$ & $\begin{array}{r}2.4 \\
.1\end{array}$ & $\begin{array}{l}5.3 \\
1.6\end{array}$ & $\begin{array}{r}13.9 \\
4.2\end{array}$ & $\begin{array}{r}31.1 \\
8.4\end{array}$ & $\begin{array}{r}25.8 \\
9.0\end{array}$ & $\begin{array}{r}39.6 \\
7.4\end{array}$ \\
\hline $\begin{array}{l}\text { Year } 1985 \text { NHIS }-3 \\
\text { Hearing Imprd } \\
\text { Tinnitus }\end{array}$ & $\begin{array}{l}9.1 \\
2.7\end{array}$ & $\begin{array}{r}3.8 \\
.9\end{array}$ & $\begin{array}{r}1.9 \\
.1\end{array}$ & $\begin{array}{l}5.0 \\
1.5\end{array}$ & $\begin{array}{r}15.9 \\
5.0\end{array}$ & $\begin{array}{r}29.4 \\
9.2\end{array}$ & $\begin{array}{l}26.2 \\
10.0\end{array}$ & $\begin{array}{r}34.7 \\
7.8\end{array}$ \\
\hline $\begin{array}{l}\text { Year } 1986 \text { NHIS }-4 \\
\text { Hearing Imprd } \\
\text { Tinnitus }\end{array}$ & $\begin{array}{l}8.8 \\
2.7\end{array}$ & $\begin{array}{l}4.0 \\
1.1\end{array}$ & $\begin{array}{r}2.0 \\
.4\end{array}$ & $\begin{array}{l}5.2 \\
1.5\end{array}$ & $\begin{array}{r}13.6 \\
4.9\end{array}$ & $\begin{array}{r}29.6 \\
8.5\end{array}$ & $\begin{array}{r}24.4 \\
8.3\end{array}$ & $\begin{array}{r}37.8 \\
8.8\end{array}$ \\
\hline
\end{tabular}


There is reason to believe that some studies have more accurately reported the prevalence of tinnitus and hearing impaired conditions than others. The studies vary in regard to at least the following: the questions that were asked; the interviewing techniques; whether or not an examination was part of the procedure; and of course, the numbers of people interviewed. The numbers of hearing problems reported are greater when otologic examinations take place (National Center for Health Statistics, Series 10, \#101, Vital \& Health statistics). It was found that an additional $1 \%$ were identified as being hearing impaired upon actual examination. Thus, surveys that do not include professional examination of hearing result in underestimates of hearing loss. This finding partially explains the apparently small increase in reported adult hearing impairment over the last 25 years because there have been no actual national examination studies of adult hearing during that time. The adult population increased about $49 \%$ since the HSEE study, but the reported number of hearing impaired people increased only about $18 \%$. What is not explained is the remarkable decrease in those reporting tinnitus, especially in view of the generally accepted assumption that tinnitus is increasing. The different estimates may possibly relate to the way the question was asked. This possibility will be discussed presently. It can be assumed that more people would be identified as having tinnitus when an actual examination 
takes place. The identification of tinnitus remains subjective but it would be more likely to be acknowledged during an ear examination where the examiner was discussing actual ear problems with the patient than during a household interview where the interviewer simply presents a list of conditions for the interviewee to specify, or where those conditions are identified by another family member.

The National Health Interview Survey. The initial National Health Survey grew out of previous investigations of diseases and mortality conducted by other agencies and private contractors. Studies of illness in Maryland, New York, California, Pennsylvania, and Michigan provided considerable data for that document. Prior to the enactment of the National Health Survey, a committee, The National Committee on Vital and Health statistics, was appointed to develop a new methodology for collecting information on illness and impairment. A number of the members of this committee had previously been involved in the state studies and their combined input provided the basis for the 1956 legislation.

The information about hearing problems and deafness that has been analysed and reported can be found in the following U. S. Government publications: 1) National Health Interview Survey, 2) National Health and Nutrition Examination Survey, and 3) Health Records Survey. Information from the National Health Interview Survey is obtained from randomly selected 
households. The interviews are conducted on a continuing basis with interviewing taking place each week in a selected sampling of the population. Questions are directed to the adult members of the household who are present at the time of interview. Answers for children and adults incapable of responding accurately are provided by a responsible adult member of the household. The questionnaires are continuously evolving, but the questions tend to remain the same over rather long periods of time.

Questions specifically relating to tinnitus have taken several forms in the National Health Survey program. In the first construct a person was asked "Besides your hearing trouble or deafness, do you have any other trouble with your ears?" If the answer was affirmative the next questions were "What kind of trouble?" "Noises or ringing in the head or ear?" (NCHS, Series 1, \#2, 1964, and NCHS Series 1, \#11, 1975, Health Interview Survey Procedure 1957-1974). The interview questions consisted of 6 lists of questions about various health conditions or problems. The question about tinnitus appeared on condition list \#2. Only one condition list was used for an interview, therefore each list was asked of $1 / 6$ of households interviewed. Condition list \#2 specified 26 health conditions or impairments that might be identified for each of the people in the interviewed household. Questions were asked of a responsible adult 
resident of the household who may or may not have been the individual suffering from the condition.

Collection of prevalence data for certain chronic conditions was done in 1971 and in 1977. The question about tinnitus from those surveys was "Does anyone in the family NOW have tinnitus or ringing in the ears?" "Now" was defined as during the past 2 weeks including last sunday night. If a person indicated that tinnitus was present, questions relating to physician visits, treatment, and limitation of activity were then asked (Section B of the NHIS surveys). This particular form of the tinnitus question appears to have persisted through 1986. Conversation with Elkins, (Note 8) indicated that much of the information obtained from the detailed condition questions relative to tinnitus in the 1971 and 1977 surveys is stored on tape in Washington, D.C. but has never been analyzed or reported. Some of the data about tinnitus from these two surveys was grouped with other data entitled "all levels of hearing trouble" for the written report and is therefore not available as a separately identified entity. (NCHS: Series 10, \#140, 1982).

The National Health Examination Survey. The National Health Examination Survey provided direct examination and testing in order to obtain more complete health data on a smaller sample of the population. The first of these examinations was completed in 1962 and it is from that study that most of the cited information about tinnitus in the U.S. 
has been derived. Information from the ear examination surveys (HSEE, NCHS Series 11, \#32, 1968) indicated that about 20 percent of adult Americans experience tinnitus at some time or another during their lives. About 4 percent of the population suffers from this condition so severely that their lives are disrupted. The tinnitus question asked in the National Health Examination Surveys was more detailed than the question in the National Health Interview Survey and is found in the Medical History part of the examination. For the First National Health Examination reported in study HSEE (see Table I), the question read "At any time over the past few years, have you ever noticed ringing (tinnitus) in your ears or have you been bothered by other funny noises in your ears?" If the answer was yes, then questions about the tinnitus were asked. These questions were: "How often?", "Every few days", or "Less often"; "Do they bother you?", "quite a bit", or "just a little".

The Medical History Questionnaire for ages 12-74 years contained in the National Health and Nutrition Examination Survey 1976-1980, (NCHS Series 1, \#15, 1981) read: "During the past 12 months, have you EVER been bothered by ringing or other funny noises in your ears?" "How often - every few days or less often?" "When it does occur, does it bother you quite a bit, just a little, or not at all?" The second health examination survey was designed to focus on children and therefore audiometry was performed only for the age group 4- 
19 years. The data collected from the Medical History about tinnitus was not published even though the medical histories were completed by age groups 25-74.

The Health Records Survey. The third source of information is from the Health Records Survey. This survey produces statistics on the characteristics of health services received and on the characteristics of those receiving them. There are five major projects included in the Health Records Survey: 1) The Master Facility List 2) The Complement survey 3) The Hospital Discharge Survey 4) Institution Population Survey and 5) Special ad hoc surveys. A by-product of this program is the National Nursing Home Survey which provides a way of gathering health information from those who reside in institutions. Residents of institutions are not surveyed in the National Health Interview Survey. The most recent National Nursing Home Survey, (NCHS Series 10,\#43, 1977), identified $1,303,100$ total residents with a median age of 81 years. Females comprised $60 \%$ of the total population of nursing home residents surveyed. Employees of the nursing homes were asked questions about residents under their care. The question pertaining to hearing problems was "Enter the words used by the respondent to describe the condition. Deafness, Hearing Trouble, or any Eye Condition." Although it can reasonably be expected that a large number of the hearing impaired people in nursing homes also have tinnitus, no specific information about tinnitus was collected in this 
survey. Deafness was reported for 90,400 residents from the above question. Additionaliy, conditions were identified from a series of condition cards: "Hearing aid" [use of], "Deafness or SERIOUS trouble hearing with one or both ears." The number reported having hearing impairment (partial, severe or total) was 348,500 or $27 \%$ of the residents. Contrast this figure with the estimate of $35 \%$ of noninstitutionalized people over 75 years of age being hearing impaired. (NCHS Series 10, \#140,1977) Hearing aid use was reported for 74,400 residents. Curiously, 30,500 of those wearing hearing aids were identified as not being hearing impaired. (NCHS, Series 13,\#43,1979)

other sources of tinnitus information. Other sources of information about health problems are the agencies with special interests in the problem in question. For tinnitus the only national agency that focuses exclusively on tinnitus is the American Tinnitus Association. On an informal level, the American Tinnitus Association, (hereafter abbreviated ATA) reports that it receives correspondence from tinnitus sufferers from all parts of the world. This broad based correspondence cannot provide actual prevalence estimates but it can testify to the wide occurence of tinnitus throughout the world. ATA also is frequently called upon to provide information to the health care community and to the legal profession, again providing indirect confirmation of the widespread nature of tinnitus. 
Information from abroad. Tinnitus is well known to be caused or exacerbated by noise and therefore would logically be expected to occur more frequently in the urbanized and industrialized areas of the world. Verschuure,(1986) reports that $20 \%$ of the population of developed countries suffer from tinnitus; (he cites census information from both the U.S. and the U.K.) according to his estimates about $2 \%$ of the population of developed countries suffer from severe tinnitus which in about $1 / 4$ of the cases, significantly disrupts their lives.

Applying these estimates to the present population of the United States (about 234,000,000) yields nearly 5 million people suffering severely and more than 1 million experiencing significant life disruptions. As will be shown below, there are reasons to think these are overly conservative estimates.

Studies that may be compared to the U.S. census surveys have been carried out in Great Britain by the Medical Research Council's Institute of Hearing Research, Nottingham, England. (Coles, 1981)

The pilot study for a multi-centre investigation of the clinical characteristics and epidemiology of hearing disorders in adults in England was carried out in 1979-80 and was based on 6804 questionnaires sent to a random sample of adults on the electoral rolls in four large cities. The response rate was $81 \%$. Tinnitus was reported by $17.6 \%$ (about 
6.5 million people) of those responding, and $5.25 \%$ reported either moderate or severe annoyance. (The total population of the U.K. at that time was estimated to be $38,300,000)$. The question used was "Do you get ringing or buzzing noises in your head or ears. The occasional whistling or ringing in the ears of less than 5 minutes duration should not be counted. Also do not count those times when this happens just after very loud sounds, e.g. discos, shooting or noise at work."

In 1983, Coles reported further information from the National study of Hearing conducted by the MRC Institute of Hearing Research. He summarized these findings saying that about $35 \%$ of adults have experienced some kind of tinnitus; $15 \%$ of adults reported having it last for more than five minutes; and at least $8 \%$ experience sleep problems as well as moderate to severe annoyance from tinnitus. He estimated then that about 4 million people in the U.K., and about 16 million in the U.S would be affected at the moderate to severe level. Information from this study indicates that $.5 \%$ suffer severely and report that tinnitus has a "severe effect on their ability to lead a normal life". If this percentage is compared with the estimates from study (HSEE) where $4 \%$ of the population reported severe tinnitus, it would seem to be rather low. However, if Coles figure of 8\%, who "experience tinnitus causing interference with their getting to sleep, and/or moderate or severe annoyance", is applied to the 
present estimate, (NHIS-3), in which $2.7 \%$ of the population are identified as having tinnitus, the U.K. percentages seem rather high. It becomes evident that a direct comparison of the U. S. reports and the U. K. reports cannot be made because of the difference in the way the questions were asked.

Another recent study of tinnitus prevalence was carried out in sweden in 1986. (Axelsson, Note 9) The study utilized a mailed questionnaire which was presented to a random, stratified sample of 3600 residents of Gothenberg. The useful return rate was $66 \%$, yielding a study population of 2,378 people. The results of the study indicate that $14.2 \%$ of this population always or often suffered from tinnitus. "Tinnitus plagues me all day" was selected by $2.4 \%$ of the population. This study also revealed a significant relationship between tinnitus severity and sleep problems. Perhaps the most interesting finding was from a scale rating the patient's perception of need for treatment. Understandably the desire for treatment was very high for those who perceived their tinnitus to be severe ( 888 wanted treatment), but those who said that tinnitus did not bother them much also indicated some desire for treatment (48\%).

\section{Problems obtaining data concerning the prevalence of}

tinnitus. As the preceding discussion has revealed, there is considerable confusion surrounding the prevalence of tinnitus. Part of the confusion stems from the heterogeneity 
of information gathering processes employed. Undoubtedly another factor complicating prevalence estimates of tinnitus is the fact that tinnitus is a condition that is often lumped with hearing problems and thus may not be reported as a separate entity.

Some points that must be contemplated when trying to derive accurate estimates of tinnitus and hearing impairment are these:

1. Certain factors influencing the prevalence of tinnitus are salutory and will cause a decrease in prevalence such as:

- Medical advances that have nearly eliminated some kinds of hearing loss in the last 25 years. - Ear protection in industry which now prevents some of the noise induced hearing problems that were common in the past. Ear protection was rarely used in the $1960^{\prime} \mathrm{s}$ and was not mandatory in industry until after 1970 . - Improvements in public health practices which have led to better health, nutrition, and hygiene, and thus to reduction of certain types of hearing damage.

2. Other factors may operate to cause an increase in the incidence of tinnitus, such as:

- The proliferation of amplified music, causing 
damage not only to the ears of the listener but also to the performer.

- The increased use of noisy items for leisure time enjoyment, of which some of the more noticable offenders are chain saws, snowmobiles, motorcycles, outboard motors, power lawn mowers and other power tools.

- Increased traffic noise in cities from cars, trucks and buses.

- Stress of modern life

3. Still other factors may cause an increased awareness of tinnitus, independent of any actual increases or decreases in the 'true' prevalence. Such factors include:

- Increased public knowledge about tinnnitus, through news media and other information sources including ATA.

- Increased medical concern about the medical problems presented by tinnitus.

- Increasing legal and societal concern about questions involving compensation, sick leave, divorce, and other outcomes of tinnitus.

4. Factors acting to decrease awareness or reporting of tinnitus include:

- About 5\% of the elderly are institutionalized and are therefore not sampled by the National Health Interview Survey; it is well known that 
tinnitus occurs more frequently in the older age groups. Additionally, because of the structure of the National Nursing Home Survey, where information about the institutionalized elderly is presented, tinnitus information has not been sought.

- Recent restructuring of the National Health Interview Survey to oversample the black population would tend to lower tinnitus estimates because fewer black people report hearing impairment and/or tinnitus than do whites.

- Military personnel are not sampled in the National Health Interview Survey. Tinnitus is known to be prevalent among people who have been exposed to the noise of gunfire, heavy equipment, and airplanes. The military population, if counted, would be expected to include many tinnitus sufferers.

How the question was asked. Comparison of the various census reports reveals that the most dramatic changes in prevalence appear to have occurred at times corresponding to revisions in the questionnaire wording, format, or administration. Clearly, the various forms of questions used to ask people about tinnitus may well influence the frequency with which tinnitus is reported. Even though tinnitus reporting remains a subjective phenomenon, subtle differences in questioning can influence the way a person responds. For 
example, if a person perceives himself to have normal hearing and the tinnitus question follows a question asking him to identify himself as having hearing problems, he may not respond. If the same person is asked directly about tinnitus he might indicate that he suffers greatly from it.

Looking first at the ear examination questionnaire of 1960-62, study HSEE, the tinnitus question was asked as follows: "At any time over the past few years, have you ever noticed ringing (tinnitus) in your ears or have you been bothered by other funny noises in your ears?" If the answer was yes, the question was followed with "How often?", "every few days", or "less often"? "Do they bother you"?, "quite a bit", or "just a little"? The reported tabulations based severity on two criteria, that of frequency of occurrence of tinnitus, and degree of annoyance. It was also found in this study that people were more likely to report severe tinnitus if they also had impaired hearing. It is important to note that the above question was part of a medical history which the patient completed while awaiting the ear examination conducted by the National Health Examination Survey physicians. The motivation for people to answer completely and fully during the health examination was likely to have been greater than it would have been during the standard health interview conducted at their home by a census interviewer. 
During the National Health Interview Survey for the years spanning 1960 to 1983 there was no specific question about tinnitus. Hearing information during the 1960s was derived from the question, "Does anyone in the family have deafness or SERIOUS trouble hearing with one or both ears". In the 1970s two questions were asked, "Does anyone in the family have deafness in one or both ears", and "Does anyone in the family have any other trouble hearing with one or both ears." A report issued in 1974, Vital \& Health Statistics series 10, \#101, noted a large increase in reported hearing problems probably because of the former emphasis on the word 'serious'.

From 1983 forward a question about tinnitus was added to follow the query about hearing. It was, "Does anyone in the family now have tinnitus or ringing in the ears?"

Because of the techniques established for obtaining information from the National Health Interview Surveys, questions regarding health were sometimes answered by someone other than the sufferer. Census interviewers are instructed to attempt to have all persons in a household present for the interview, but are also instructed that proxy answers are accepted if it is not practicable to interview all household members. Proxy answers are in fact stipulated for those under age 17 or those unable to answer for themselves for other reasons. 
It is possible that people with tinnitus don't discuss it much with others fearing lack of understanding and possible unpleasant repercussions, or, in the case of children with tinnitus, who don't realize that the head noises aren't heard by everyone. Many people are fearful of social sanctions or threats to their livelihood if they admit to a physical/psychological problem. Taking all of these factors into consideration it is expected that the numbers of people reported as having tinnitus in the present NHIS studies are more likely to be representative of severe tinnitus. Again, using percentages from the earlier study HSEE where it was found that $21.8 \%$ of the hearing impaired had severe tinnitus, and applying these to the 1985 estimate of $21,198,000$ hearing impaired persons, one should expect to find at least $4,621,164$ people with severe tinnitus among the hard of hearing alone, before even considering the rest of the population.

Not all people with tinnitus experience hearing impairment. A recent survey conducted by the American Tinnitus Association, about which more will be said later, revealed that $23.5 \%$ of those who had tinnitus denied any awareness of hearing loss.

There is an urgent need for more accurate estimates of tinnitus prevalence. Such figures would logically be derived from an updated and revised census study. There are no such plans for such a detailed study of the 1990 census at the 
present time according to John G. Keane, Director, Bureau of the Census. (Note 11)

Studies of the magnitude of the census reports are costly and must be left to government sponsored projects. It is possible, however, to obtain smaller population samples for the purpose of initiating research about how tinnitus affects its sufferers. Information derived from these limited samples may point to the need for more comprehensive, government-funded investigations in the future.

\section{Tinnitus in children}

Reports from U.S. census interviews indicate extremely low prevalence of tinnitus in children. There are at least two explanations for this. The first is that hearing levels for children are generally better than those of adults and thus there would be less reason to suspect hearing problems of any kind - including tinnitus. The other explanation comes from the way the census information is obtained. Census interviewers receive the information about the health of children from adult members of the household. Looking at the 1985 figures reported for hearing loss and tinnitus for persons under 18 years, (Table II), it can be observed that in this age group there were (1.9\%) described as suffering hearing loss and (.07\%) described as reporting tinnitus. Graham, 1980, reported that children seldom mention tinnitus or hearing losses unless they are associated with some painful experience. It is therefore quite likely that 
tinnitus as well as hearing loss might be unreported in the census interviews. Clinicians have observed that tinnitus occurs in children and there are an increasing number of cases of childhood tinnitus being reported. Graham, (1980), revealed that a significant number of children with hearing impairments also experience tinnitus, (about 49\%). A study of hearing impaired children in Oregon schools (Reich, Note 10) found that $37.5 \%$ also reported experiencing tinnitus. According to the census reports discussed above, the greatest rate of tinnitus that could be expected in the under 18 age group was . $1 \%$, a figure significantly smaller than what either Graham or Reich determined in their surveys.

Estimates of tinnitus in adults

Present estimates derived from the National Health Interview Survey, indicate that about $2.7 \%$ of Americans of all ages suffer from tinnitus. Since earlier studies reported figures for tinnitus in adults only, it is necessary to extract the figures for prevalence of tinnitus in adults in order to make a comparison. Presently the NHIS is reporting $3.5 \%$ of adults with tinnitus. Returning for a moment to the HSEE study which reported $5.6 \%$ severe tinnitus in adults, it becomes evident that there has been virtually no change in the actual number of cases reported, (both figures are about 6 million) and in fact, when one considers that the present figure is given to represent 'all' tinnitus, whereas the 1960-62 figure represented 'severe' tinnitus, a 
decrease, which may be spurious, appears to have occurred over the last 25 years.

Reports from National Health Interviews conducted in 1983, 1984, 1985, and 1986, (NHIS-1,NHIS-2,NHIS-3,NHIS-4) may possibly reflect changes that have occurred in the treatment and prevention of hearing disorders, changes that would have us expect fewer people with these disorders. (Tables I \& II) In spite of improvements in prevention, particularly that of ear protection in the workplace, and of improvements in treatment of conductive hearing problems, the noise of modern society is likely to cause an increase in the prevalence of tinnitus. Therefore the differences in the figures from the 1960 's HSEE and the surveys of the last four years (NHIS-1, NHIS-2, NHIS-3,NHIS-4) may represent sampling discrepencies, or a difference in the way the question was asked, or those differences may be unexplainable with presently obtainable information. The latter is a more likely explanation in light of the increasing prevalence shown in the data from studies NHIS-1, NHIS-2, NHIS-3, and NHIS-4. Looking at the figures for adults in Table I it can be calculated that in $1983,3.28$ of adults had tinnitus, in 1984, 3.4\%, in 1985, $3.6 \%$ and in $1986,3.5 \%$. If tinnitus had increased since the HSEE study at the same rate as shown in the last four years, then about 7\% of the 1985 adult population would be affected, between 11 and 12 million people, but, the present figure of $6,187,000$ is actually a little less than the reported number 
in HSEE of $6,221,600$. As a comparison the population of the United States has been increasing by about 11 percent per decade for the last 20 years. Applying the percentages from the HSEE study to the 1985 adult population would yield an expected prevalence of 9,574,600, a figure that agrees more closely with what might be expected in light of the reported $38 \%$ increase in prevalence of hearing impairment during the same time period. It should also be noted that National health interview statistics reported for 1983, 1984, 1985 and 1986 show that tinnitus prevalence increased during those years. Furthermore, HSEE figures, as will be seen, compare rather closely with tinnitus estimates coming from other countries.

Another method of obtaining a rough estimate of tinnitus prevalence is to take the latest NHIS survey estimate of adults with tinnitus, and add the estimate for the tinnitus cases that were not counted in the NHIS survey. Remembering that the NHIS survey counts only civilian, noninstitutionalized persons, in order to approximate the uncounted population an estimate needs to be derived from the military population, $2,138,000$, and from the institutionalized population, 2,492,000, both of which have a rather higher percentage of tinnitus cases than is found in the general population. These two populations are mostly adult, those in nursing homes have an estimated hearing impairment rate of nearly $30 \%$ (NCHS Series 13, \#43, 1977), 
higher than normal rates of hearing impairment are also expected in prison populations and in the military due to the high indicence of noise exposure. It is expected that about 85\% of the hearing impaired in nursing homes will have tinnitus. The estimated prevalence for prison and military might conservatively be set close to $20 \%$.

Another group which might not have been counted in the NHIS survey are those people who do not have a hearing problem. They might not have been asked the question about tinnitus as that question comes after a question about deafness, and is part of list of 27 chronic conditions. Many people, as has been discussed elsewhere in this study, are reluctant to admit any hearing problems, much less one that may be perceived as having psychological overtones. From 10 to 27 percent of people with tinnitus report having no hearing loss. The $10 \%$ figure comes from the oregon Health Sciences University Tinnitus Clinic and is derived from actual examination. The $27 \%$ figure comes from those people answering a mailed survey and is their own estimation of their hearing ability. Therefore it is necessary to increase the NHIS tinnitus prevalence figure in order to arrive at a reasonable, conservative estimate of those suffering from tinnitus. The number missed in the NHIS, that is, those with no hearing loss, is presumed to be around $10 \%$ of the survey population. 
Translating these percentages to numbers yields an additional 1,544,000 cases which, when added to the latest NHIS estimates yields a revised estimate (estimate \#1) of $7,731,700$ adult Americans with tinnitus in 1985, and more than 9 million today.

It has been necessary to detail all of the available sources of tinnitus prevalence information in order to present a complete picture. Admittedly, some of these sources are not accessible at present but the stored data may sometime be made available for public scrutiny. The present discussion has attempted to place the available data in proper context. Ideally, prevalence estimates should be based on all of the previously collected data. Since that is not possible, it seems that a reasonable substitute procedure would be to base tinnitus prevalence estimates on the largest available surveys as follows:

\section{Prevalence estimates for tinnitus in the United States 1985}

1. Reported from NHIS-3 1985 estimates, adult tinnitus, $3.6 \%$

2. Figure projected from HSEE study, severe adult tinnitus, $5.6 \%$

3. Figure projected from HSEE study, mild adult tinnitus, $26.8 \%$

4. Figure projected from U.K.study, moderate/severe tinnitus, $8 \%$

5. Clinical estimate based on (Fowler,1944), who reported that $85 \%$ of hearing loss cases have tinnitus, $(.85 \times 9.06 \%$ [hearing loss estimates NHIS-3]) $=7.7 \%$ )

6. Figure projected from Swedish study, tinnitus often/always, $14.2 \%$

7. Figure projected from Swedish study, tinnitus "plagues me all day", 2.4\% 
The percentages reported in items 1 through 7 may be regarded as the range of tinnitus prevalence. Based on the preliminary information that has been discussed a prevalence estimate has been derived by averaging the more conservative items (numbers $1,2,4,5,7$ ) of the above list to yield a prevalence percentage of $5.44 \%$. Applying that percentage population figures from the same census $(233,721,000)$ yields an estimate of more than 12 million Americans with moderate to severe tinnitus in 1985.

It is this author's opinion that people being interviewed or members of their family being interviewed, for the NHIS, are unlikely to specify that a person has tinnitus unless it is severe enough to have been complained of within the family, and/or to have sought treatment. Recall that the present surveys no longer ask people about mild or transitory tinnitus. An estimate of milder tinnitus can be derived using an average of items 3 and 6 which yields $20.5 \%$ experiencing mild or transitory tinnitus, nearly 50,000,000 Americans.

Following the rules set forth in the National Center for Health Statistics pubications standard error estimates may be calculated for the NHIS reported figures, using the equation: $S E(x)=\sqrt{\left(a x^{2}+b x\right)}$, where $a$ and $b$ are parameters for chronic conditions reported by NHIS, and $x$ is the estimated number of people for the chronic condition. $(a=.00013660$, and $\mathrm{b}=18,253.6)$ 
Applying these rules to the estimates derived in this chapter it is possible to state that the prevalence of severe tinnitus in adults in the U.S. in 1985 falls in a range from 5.8 to 6.5 million according to NHIS-3, or from 7.3 to 8.1 million according to estimate \#1, or from 12.2 million to 13.2 million according to estimate \#2.

It can be observed from Table II that there were many years during which data concerning tinnitus were not reported. In spite of having identified a problem affecting millions of Americans, nearly 20 years passed before a specific question relating to that problem was asked in the National Health Interviews. In the meantime, most professionals in the field of hearing agree that both tinnitus and hearing loss have become a greater problem, probably much greater than the reported figures of the last four years would indicate.

The yearly increase over the last four years in tinnitus prevalence for all age groups would suggest that even if the figures from the last four years are correct, and past experience would suggest that there is reason to doubt them, there is cause for concern and more than enough justification to call for a comprehensive survey of the problem.

Estimating incidence. Incidence is usually defined as the number of new cases of a disease or condition occurring during a given year. Physicians are asked to report all new 
cases from a given list of conditions. Incidence is often used as a measure of the impact on society of the problem in question. Estimates of annual expense can be derived from the numbers of acute conditions reported by estimating the average cost of the professional visit during which the condition was noted. The National Health Interview Survey reports incidence of acute ear infections and other ear conditions; (tinnitus by itself is not a reportable condition) these categories do not, therefore, provide useful information for trying to estimate tinnitus costs. Tinnitus often occurs many years after the event that is thought to have caused it. That lag time is demonstrated in the cases of tinnitus seen in veterans of World war II who experienced traumatic noise exposure while in the service. Sometimes their records indicate ear problems and tinnitus of relatively short duration. A lapse of 20 or more years in which they had no noticable ear problems is then followed by the identification of gradual-onset hearing loss and, often after an additional delay, gradually-increasing tinnitus. Incidence, then, is not only difficult to measure but seems to be less useful a measure than prevalence for trying to quantify the effects of tinnitus.

Prevalence estimates when combined with estimates of severity allow analysis of the problem at a societal level. For the purposes of this study an assumption has been made that those people contacted fall into the estimated 
population of tinnitus patients who require professional help. The respondents have self-selected themselves into that population by virtue of their contacting the American Tinnitus Association. An attempt to investigate the effect of tinnitus on the individual leads to studies relating various illnesses to social cost. 
CHAPTER III

FACTORS THAT INFLUENCE INDIVIDUAL COSTS

\section{Severity}

In order to better understand tinnitus it is necessary to be able to differentiate among patients with respect to the amount of distress it causes. Reports of tinnitus are often confusing because there has been no standard measurement. One might hear from one patient "I have tinnitus so loud that it is driving me crazy." From another patient one might hear "My tinnitus never stops. I can't stand it." Or another might say "MY tinnitus is such a high screeching noise that I can't hear anything else." Yet another might say "MY tinnitus makes me so nervous that I can't concentrate on anything." Four different measurements have just been noted to describe how the person reacted to tinnitus; 1) intensity, 2) regularity, 3) quality, and 4) annoyance level. Clearly a standard for describing the perceived severity of tinnitus is needed.

One of the early classification systems for the severity of tinnitus was proposed by Reed (1960), who provided a three dimensional index as follows: Mild Tinnitus--not always present; noticed only in quiet places or at bedtime; patients easily can be distracted from thinking 
about tinnitus. Moderate tinnitus--constantly present; more intense in quiet surroundings; bothersome when patients attempt to concentrate and/or get to sleep. Severe tinnitus-- very debilitating; patients complain bitterly; they cannot concentrate; they can think of little other than tinnitus. This system measured regularity, loudness, and annoyance level, but not in such a way that an ordinal scale could be created.

Data about tinnitus severity reported from the first 1806 tinnitus patients to attend the Oregon Health Sciences Center Tinnitus clinic was obtained using a tinnitus severity scale ranging from 1 to 10. A horizontal line was marked with numbers from 1 to 10 , the endpoints were labelled mild and severe, and patients were asked to tick the line at a place corresponding to the severity of their tinnitus. The measure was easily converted into an ordinal scale, but concerns about the validity of this kind of measurement led to subsequent revisions of the questionnaire which provided a more complete verbal description of severity as seen in the two following questions. Similar questions were used in the questionnaire for the present study.

'How would you rate the severity of your tinnitus'? (Check more than one level if needed.)

1 _ Tinnitus is there if attended to but it is not very irritating and can usually be ignored 
2- Tinnitus is often irritating but can be ignored much of the time

3 - Tinnitus difficult to ignore even with effort

4 _ Tinnitus is always present at an irritating

level--often causes considerable distress.

5 - Tinnitus is more than irritating, causes an

overwhelming problem much or all of the time.

'How would you rate the degree to which tinnitus interferes

with your life'? (Check more than one level if needed)

1_ Tinnitus causes little or no interference with

work or social activities

2_ Tinnitus causes some interference, but I can

live with it

3 - Because of tinnitus, it takes considerable

effort to maintain normal work or social activities

4_ Tinnitus is serious interference with normal

lifestyle--can do only simple tasks

5 _ Tinnitus renders me unable to perform any work

or social activities

Two four level items for rating tinnitus severity were used in the epidemiological studies carried out over the past seven years in Great Britain. (Coles, 1984) The most recent versions of the two questions as reported in the above study are: 'Indicate how annoying you find the noises in your hear or ears when they are at their loudest.'

a. not annoying at all 
b. slightly annoying

c. moderately annoying

d. severely annoying

'Indicate to what extent the noises in your head or ears affect the quality of your life as a whole.'

a. not at all

b. to a slight degree

c. to a moderate degree

d. to a severe degree

Parisier (1984) used a similar scale in his study of patients with chronic mastoiditis and cholesteatoma.

Patients in that study responded to a question asking the extent to which tinnitus interfered in their daily lives on a descending scale of 'severelY', 'moderately', 'slightly', and 'not at all'.

Hulshof (1984) used a 6-point scale for grading the degree of tinnitus impediment as follows:

o- no tinnitus

1- only audible in silence

2- hardly audible

3- audible but not obstructive

4- obstructive

5- very obstructive

In a study of the effects of Tocainide on tinnitus patients Emmett (1984) used a 4-point scale to measure tinnitus severity. 
tinnitus present and I would be unable to

function normally

tinnitus present but I would be able to

function partially

tinnitus present but I would be able to

function normally

tinnitus absent

Lechtenberg and Shulman (1984) used an activity impairment scale to measure tinnitus severity in a study of the effects of Benzodiazepine for the relief of tinnitus. This is a 6-point scale as follows:

0- no activity impairment

1- interferes with concentration less than once a week

2- interferes with concentration once a week to daily

3- interferes with concentration much of every day

4- interferes with ability to participate in gainful employment

5- interferes with employment and personal relationships

Sweetow (1986) used a weighted severity scale in assessing the perception of tinnitus by patients. In a 14item questionnaire six questions were weighted (1), five were weighted (2), and the remaining three were weighted (3). The questions with the highest weights represented responses from 
the patient indicating significant disruptions of living, and the lowest weights were attached to responses to concerning the more common characteristics of tinnitus, such as "I am always aware of my tinnitus."

Glorig (Note 12), reported the use of a severity scale for measuring industrially caused tinnitus. This scale consists of 5 levels as follows: 1) slight, 2) mild, 3) mild to moderate, 4) moderate, 5) severe. The scale contains additional items relating to the character of tinnitus such as intermittency, sleep prevention, worse in quiet, sounds like, botherșomeness. (Glorig's work dealt only with tinnitus when there was an accompanying compensable level of hearing loss; he made no provision for tinnitus cases with measurably normal hearing.) In the introduction to the present work it was pointed out that there is no true objective measure of tinnitus. Glorig again refers to this problem when he states that a difficulty inherent in previous tinnitus studies is the possibility that what is being measured are only the terms used by patients to describe tinnitus and not the tinnitus itself.

Turning to more objectively-measurable correlates of tinnitus, the loudness and pitch of tinnitus can be objectively measured using electroacoustic techniques. This task was facilitated by the recent development of a Tinnitus Synthesizer which is used to present tones and combinations of noise in order for the patient to identify sounds that 
match his tinnitus. The ability of the tinnitus to be "masked" or covered up by external sounds is also relevant. The Minimum Masking Levels can be determined (intensity level which just covers the tinnitus sound). Another test measures the Loudness Discomfort Levels for tinnitus sufferers, that is, the intensity levels at which various external sounds become intolerably loud. This test can be used to determine a person's tolerance for sounds that are similar in pitch to that individual's tinnitus. It is anticipated that this particular test will provide objective audiological information relating to severity (Vernon, 1987). Tinnitus sensations, remain, however, highly complex and individual phenomena. The multidimensional nature of tinnitus makes it difficult to make comparisons between individuals, and it is not yet known how the various objective measures relate to the severity dimension.

Penner (1983), attempted to relate the annoyance of tinnitus to individual differences in regard to sound adaptation but she did not find a significant correlation. She further commented that the internal "noise" of tinnitus does not appear to exhibit the fatigue characteristics of an external noise, where neural activity levels off and then decreases after noise exposure, which could mean that the auditory system "adapts" to the noise, allowing the tinnitus to rise above the external noise that previously covered it, or that the neural activity increases. 
In general the use of external loudness matches as a basis for comparing individuals in regard to severity have not been successful. Regardless of the dramatic differences between patients in regards to the perceived severity of the tinnitus, they all tend to match their tinnitus to external sounds only slightly above threshold. (Johnson, Note 13) This paradoxical finding has yet to be explained. It has been known since the $1940^{\prime}$ 's and has been repeatedly confirmed.

There is an element of psychological distress present in all illness but it appears to exact a greater toll from those who suffer from chronic conditions. clinical observations and patients' own accounts allude to the widespread incidence of anxiety and distress associated with tinnitus. Tyler and Baker (1983), reported difficulties that were experienced by tinnitus suffers in a study of 72 members of a tinnitus self-help group in Nottingham, England. In this group, tinnitus affected the lifestyle of $93 \%$ of the sample and caused emotional problems for $70 \%$. The symptom of tinnitus was associated with hearing difficulty for $53 \%$ and was thought to have an effect on general health for $56 \%$. Clinical observations of tinnitus patients, Vernon, Schleuning, Odell, and Hughes, (1977) indicate that patients experience significant distress along with their tinnitus and that the perceived severity of the distress does not seem to 
correlate with the audiometrically determined perceived loudness of the tinnitus. Personal and demographic factors

Age is expected to be a predicting factor for the perception of severity of tinnitus. Informal interviews by the author with older tinnitus patients have revealed a more accepting attitude toward tinnitus than is found with younger patients. An older patient in the course of an interview commented that he could not have dealt with tinnitus if it had happened to him when he was younger. Previous work of this author has shown that younger patients are more likely to be psychologically troubled by their tinnitus. (Reich \& Johnson, 1984)

Other demographic factors which may have a relationship with perception of tinnitus severity are sex, income, geographic location of residence, and whether or not a person is employed. 
CHAPTER IV

CONCEPTUAL FRAMEWORK, RESEARCH QUESTIONS, \& HYPOTHESES

Conceptual Framework for Tinnitus

Keeping in mind the complexity of tinnitus, both its medical significance and its implications for psychological and social effects, it is necessary to take account of a variety of variables in seeking to understand the importance of tinnitus for our society. In this chapter a conceptual framework is presented depicting relationships among variables related to tinnitus which have been identified in the literature and additional tinnitus variables observed in professional settings. A discussion of the components of the conceptual framework follows Figure 1. 


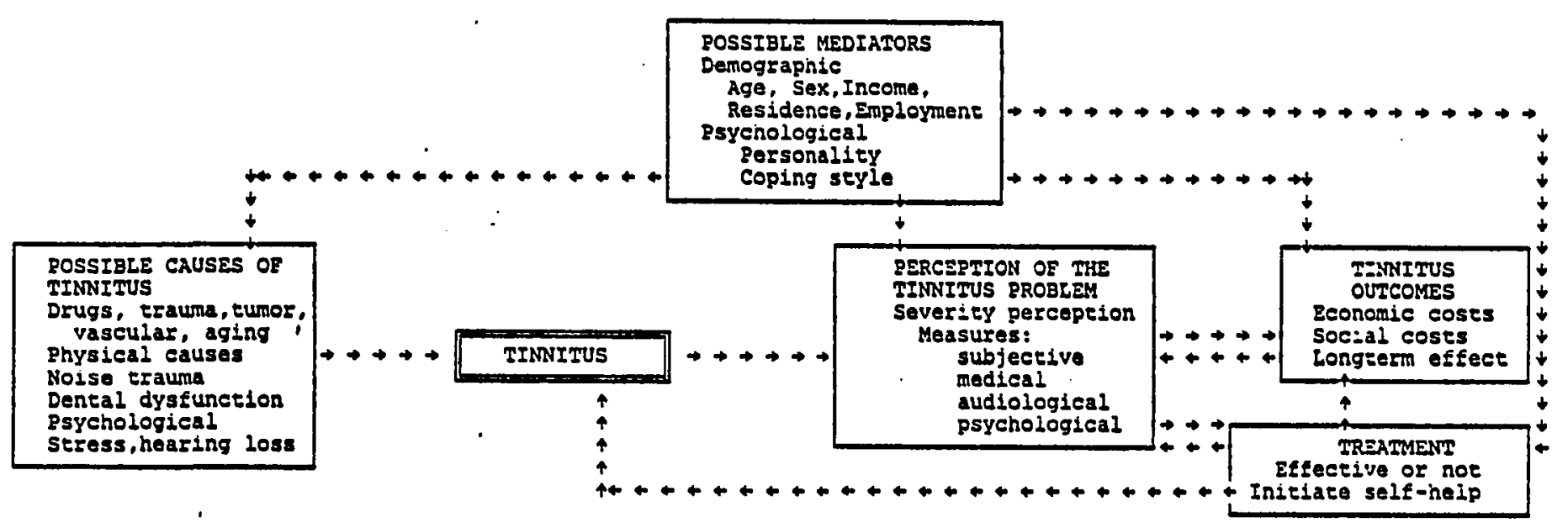

FIGURE 1. Concepeual Eramework for Tinnieus 
Possible causes of tinnitus. The conceptual framework presents tinnitus as a complex problem without a clear path from cause to effect. The possible causes presented for tinnitus illustrate one of the problems that face both sufferer and professional. There is no truly objective measure of tinnitus and no tests which can point to a single cause. In fact, the causes are likely to influence the entire problem, how it is perceived, coped with, or treated. Tinnitus is not like a broken arm. It matters little whether a person breaks an arm while skiing or from falling out of bed, the standard treatment is to reduce the fracture and keep it immobile until the break has healed. Tinnitus caused by exposure to loud noise may be quite different from tinnitus caused by a dental anomaly. While the tinnitus caused by noise may be treatment resistant, the tinnitus caused by dental irregularity may respond quite well to treatment of the underlying dental cause.

The person suffering from tinnitus may also perceive the problem in a variety of ways. It is generally acknowledged that if one has damaged ears from noise exposure, the damage is permanent. Patients who have damaged their ears because of choosing to be in noise, such as rock musicians, sometimes have feelings of anxiety and guilt that are an important part of their tinnitus problem. Patients who are able to associate their tinnitus with conventional medical problems may have an easier time ignoring it, partly because they 
perceive it as an externally caused problem rather than an internal one.

Head trauma is sometimes implicated in tinnitus. The exact mechanisms are not fully understood but may be related to possible damage of the temporal bone structure housing the inner ear. Infections are implicated in tinnitus when they have caused a very high fever resulting in damage to the hair cells in the cochlea.

Presbycusis, the hearing loss associated with old age, often has tinnitus as an accompaniment; such tinnitus usually has a gradual onset. A gradual onset of tinnitus appears to be less distressing to patients than when the onset is rapid. This difference may account for the fact that tinnitus tends to be accepted with more serenity by older patients.

In summary the possible causes for tinnitus are many and complex and the causes themselves may be acted upon by other variables.

Possible mediators or agents of change. Possible mediators of tinnitus perception have interested many clinicians and researchers. If it were possible simply to tell someone how to cope with tinnitus a large part of the problem would be solved. Or, if it was known that only a certain group of people were at risk for tinnitus, an effort could be made to protect them. The modulating influence of demographic variables is suspected but not well researched with respect to tinnitus. 
Mediating variables acting upon the causes of tinnitus may exert an influence by causing a person to have a prolonged exposure to a suspected cause, as in the case of a noisy employment situation. A person's personality or coping style is another mediating influence that would be reflected in a different response to the stress.

Mediators can also exert a powerful influence on a person's perception of the severity of the problem. In this study only subjective measures are being considered in severity perception, therefore psychological mediators are especially important. Additional information needs to be developed about the relationship of other mediating variables to the perception of severity of tinnitus and to the costs of tinnitus.

A further influence of mediators is seen in tinnitus outcomes. A person's income might be expected to influence the costs of tinnitus. One's coping style might influence whether treatment was effective or not, since patient participation in treatment is essential for a positive result, or whether methods of self-help were initiated. It can be seen that in this framework mediators can influence tinnitus anywhere along its course.

Perception of the tinnitus problem. Past experience has pointed to the perception of severity as an important influence on how tinnitus affects the individual in addition to its influence on treatment and outcome. If a person sees 
himself as having a "severe" problem it is expected that he will be more likely to initiate treatment and or self-help, and have both monetary and social costs associated with his problem.

The person's perception of tinnitus is in turn likely to be influenced by all of the other components in the framework. A person who had to quit working because of tinnitus would likely perceive it as a greater problem than someone who was able to continue with their daily routine. If a person had received treatment for tinnitus this fact would also make tinnitus seem like more of a problem than someone who had received no treatment. It could even be argued that the suspected cause of tinnitus would have an influence on perception of severity. (Would one's perception be different if it were known that the tinnitus was caused by a brain tumor as opposed to having tinnitus from taking too much aspirin?)

Tinnitus outcomes. For the purposes of the present investigation, the outcomes of tinnitus are the costs incurred. Economic costs are incurred when people spend money for consultation, treatments, hospitalization, drugs and devices. Some tinnitus patients spend large amounts of money looking for and engaging in treatments for tinnitus. Others do not, regarding the problem as insoluble either because they have been told that no help is available or 
because their own attitude toward the problem is one of acceptance.

Social costs are incurred when a person withdraws from social activities, quits work, has problems with living what is considered a normal life. Social withdrawal is also often reported in letters from patients. Anxiety and fear about tinnitus and its possible effects are other common complaints. Feelings of hostility may arise if the afflicted person believes that tinnitus came about because of something someone else did to cause it. Sometimes people become so upset that they can no longer perform effectively at their jobs, or in social situations. They may curtail their activities, and change or quit their jobs. Reports of family tension, divorce, alcoholism and drug dependence are often found in patient correspondence. Suicide because of tinnitus, while rare, is in a number of instances well documented.

Longterm effects of tinnitus are beyond the scope of this study but include the study of the effects over time of reports of stress and psychological problems. Often patients with tinnitus claim that their difficulty hearing is caused by the interfering noise of tinnitus. This incessant noise leads to the most commonly cited problems, stress and inability to concentrate. Depression also is common in tinnitus patients. (House, 1981) Many tinnitus patients find sleep difficult. sleep problems may manifest themselves as 
insomnia, wakefulness, or sleep can be an actual trigger for tinnitus. Some patients report that if they are having a period free from tinnitus they will experience its return as soon as they have slept.

Treatments. It is desirable to treat the cause of a problem but in the case of tinnitus where causal events are often unknown, treatment to alter the patient's perception of the problem is another choice. Popular interventions for tinnitus are hearing aids and maskers which allow the person to focus on other sounds than their own internal noise. Electrical suppression for tinnitus has been tried a number of times during the last century. There is presently a resurgence of interest in this area of treatment as evidenced by a number of papers on the topic presented at recent seminars (III International Tinnitus Seminar, 1987). Drugs have been used for tinnitus for as long as there are written records, but their success in reducing tinnitus is far from clear cut. Cathcart (1982) reported that after one drug study 2 patients were still experiencing beneficial results with no side effects---from the placebo! The drug lidocaine, administered intravenously, has been demonstrated to affect tinnitus for a large percentage of patients. An attempt was made to produce an oral analog for lidocaine (tocainide) which was then tested at several university clinics and found to be ineffective, (Emmett, 1984). Vitamins have been 
recommended for tinnitus control since the 1930's. Their effectiveness has not been clearly established.

over the years certain surgical procedures for other ear disorders have appeared to help tinnitus as well. Sometimes, however, those same surgeries will alleviate the other ear disorder and leave tinnitus unchanged or worse. Presently, there is, in general practice, no surgery specifically for tinnitus relief.

Dentistry, particularly procedures to remedy TMJ, has been effective for many tinnitus sufferers. Other techniques occasionally have been reported to be beneficial including chiropractic manipulation, myotherapy, and acupressure.

Tinnitus often produces stress. Procedures designed to relieve stress such as hypnosis, relaxation therapy, and acupuncture can be helpful in coping with stress. Biofeedback helps a person to understand his own body and respond positively to its signals. Some patients report positive benefits from exercise, others say it makes their tinnitus worse. Diet management has some advocates. Certainly, if an individual is in excellent health they will have more energy with which to cope with any problem, including tinnitus. Some professionals believe that counselling produces as much relief as any of the other interventions. It may be that most people should be given 
understanding and reassurance about their tinnitus before trying anything else.

OnIy recently have health providers begun to realize the importance of referring patients to other specialties when control of the problem has not been achieved through their own discipline. Patients, therefore, have often been led to believe that nothing can be done to help them when in fact that may be untrue.

In the present study the major concern is the number of different treatments people have used for tinnitus, not an evaluation of the success or failure of that treatment. Similarly the present study is not concerned with whether or not a person had initiated self-help methods for their tinnitus, except that self-help can sometimes be considered a form of treatment. The members of the self-help groups, by their membership have made a first step towards self-help and their comments have indicated that membership in a self-help group is beneficial (Reich, 1987). Similarly, those who have sought information from ATA have initiated a degree of selfhelp for their tinnitus problem.

\section{Research questions}

Research questions appropriate to this study include how the costs of tinnitus relate to other descriptive characteristics of tinnitus suffers.

1. Can a monetary value be placed on the costs associated with treatment and upon indirect costs to the sufferer? 
Information about the nature of tinnitus and about treatment specifically for tinnitus is difficult to acquire because the condition is often associated with some other complaint and there is no standard sequence of cause, treatment and outcome for tinnitus. People who have tinnitus will be asked to provide information specifically about tinnitus to the best of their ability.

2. How many people have tinnitus that is severe enough to require treatment?

In order to relate these costs to society for the purpose of allocation of resources for prevention, treatment, and research relating to tinnitus, information must be developed about how many people have tinnitus and how many are bothered by it to the extent that treatment is necessary. 3. Can the perception of severity of tinnitus be reliably measured?

Factors affecting the person's perception of tinnitus and his utilization of treatments are crucial in the attempt to quantify the costs of tinnitus. Perceived severity appears to be an important variable and measures of severity are needed in order to help predict the numbers of people who are likely to require or seek professional treatment for the condition. Severity of tinnitus has been assessed by clinicians in a variety of ways. The literature was searched for these various measures and earlier work done by this 
author was built upon in an attempt to develop a scale for assessing severity.

\section{Summary of the Problem}

The present work seeks to provide information about the day-to-day effects for individuals who have tinnitus through an investigation of a group of people who are thus afflicted. The study focuses on the specific costs incurred by patients over the course of having tinnitus and also seeks to provide information about the indirect costs through questions relating to psycho-social behaviors.

In this paper estimates of mild and severe tinnitus prevalence have been derived from available information. The studies utilized were the United States census publications, reports in the literature of clinical studies and observations, and prevalence studies from abroad. These estimates of tinnitus prevalence will be used wherever called for in the following chapters.

The measurement of severity is addressed through the development of a scale for perception of severity which will be discussed more fully in the sections to follow.

The review of the literature has suggested a number of more specific questions elaborating this general objective and thus provides a focus for the rest of this work.

\section{The hypotheses for study}

The research questions suggest two testable hypotheses: 
1. The direct and indirect costs attributable to a given individual's tinnitus are directly proportional to the severity of that individual's tinnitus, as measured by the severity rating scales developed in this study. Direct costs can be estimated from survey data relating to reported amounts spent by patients in an attempt to relieve their tinnitus. Indirect costs can be estimated from reports of sleep problems, psychological problems, and social activity curtailment.

2. Tinnitus costs are expected to be related to the variables of age, sex, length of time afflicted, perception of general health, income, whether presently working, perception of the severity of the problem, and number of treatments employed. 


\section{CHAPTER V}

METHODS

\section{The survey method}

It is generally acknowledged that meaningful information about health problems may be elicited from those people who suffer from them, therefore, in this study a survey questionnaire (Appendix A), was conceived and employed to obtain personal subjective reports about the effects of tinnitus. The use of a survey allows exploration beyond verifiable behavior. These areas include descriptions of personal characteristics and recollections of events that have affected their lives or things that they have done. Questions may also be asked about psychological states or attitudes even though these are not accessible to an external observer.

Response biases are likely to be encountered in survey research having to do with memory recall and failure to understand the question. This problem was ameliorated to some extent by asking for information in a number of different ways in order to help people remember and to clarify what was being asked. If people wished to conceal information or were ignorant of the knowledge required then it was not possible to collect the data required. 
Sample selection

It was desirable for the data set for this study to be national in character and to include those people who had tinnitus to a degree sufficient to have sought some advice or professional help in how to deal with it. A convenient group of people with these attributes existed and were members of American Tinnitus Association self-help groups. More than 100 self-help groups for tinnitus have been formed by ATA. These groups provide help and support for people with tinnitus. People are attracted to the self-help groups when they first notice their tinnitus, or when they have been unable to achieve relief through treatments currently in use, or when they have been successfully treated but still are looking for more knowledge about their problem. Some of these people are seeking information, some are seeking treatment, and some are seeking fulfillment. This author inaugurated the self-help movement for tinnitus within the American Tinnitus Association with which she has been associated for the last 12 years.

ATA's experience has been that the proportion of people inquiring about tinnitus geographically follows the general population. A sampling, therefore, from the ATA groups and from new inquiries is expected to reflect the general population. Figure 2 shows the present number of people on the American Tinnitus Association mailing list. In spite of the possible problems inherent in a mailed survey such as 
consulting with others before answering a question, the questionnare was thought to be the cheapest method that would provide the required information. 


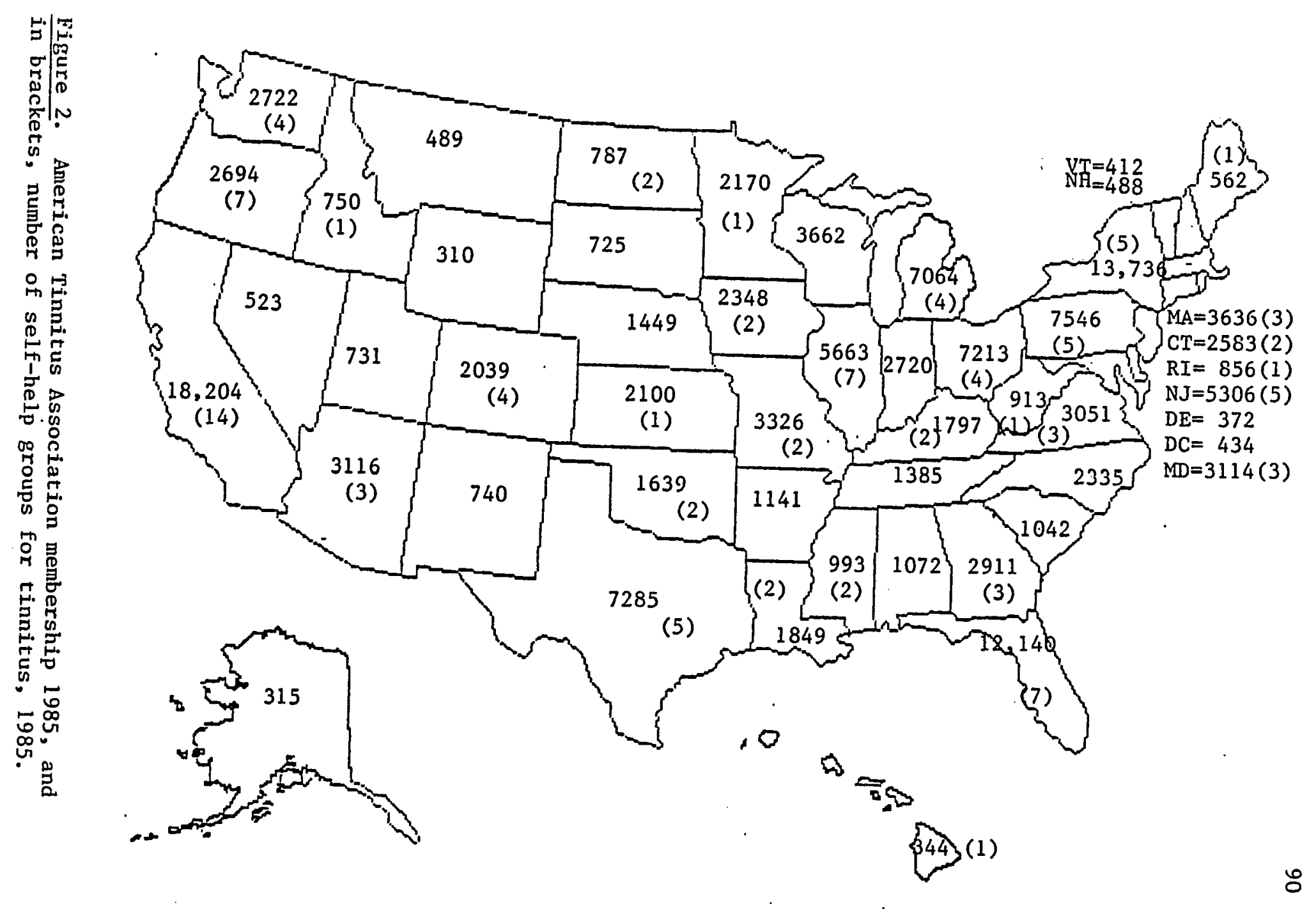


This study employed two samples, which will be referred to as Group I and Group II. The sample for Group I of this study was drawn from members of tinnitus self-help groups in various parts of the United states. An attempt was made to draw a representative sample from four different regions of the United States, as identified in the U. S. Census. Information was collected from groups in the Northeast which included New England, and part of the Eastern Seaboard, (all U. S. zipcodes from 0 through 21999), the southeast and the South, (zipcodes greater than 22000 and less than 39999 plus zipcodes 70000 through 79999), the Mid Continent, (encompassing zipcodes 40000 through 69999, plus 80000 through 81999), and Farwest areas, (zipcodes 82000 through 99999). These areas correspond roughly to the areas delineated in the National Health Interview Survey. In order to achieve as broad a sample as possible while ensuring satisfactory participation specific self-help groups were selected that met at least one of the following criteria: (a) that the group was large, greater than 50 people, and active, (b) that we had personal access to the group to explain the goals and nature of the project, (c) that the group regardless of size had a leader who had a history of interacting constructively with ATA. Some groups satisfied all of the criteria. These included groups in California, Maryland, New Jersey, and New York. Groups satisfying items (a) and (c) included those in Arizona, 
District of Columbia, Louisiana, Minnesota, Washington, Texas, and Virginia. Groups satisfying (b) and (c) included oregon and Colorado. Some smaller groups satisfied only (c) including groups in Massachusetts, West Virginia, Mississippi, Michigan, and Kentucky • Criteria for a subject's inclusion in Group I was that the individual was part of a tinnitus self-help group, perceived himself as having tinnitus, and completed and returned the survey. Subjects in Group II were new inquirers to ATA. These people were thought to be less well informed about tinnitus than members of self-help groups and possibly to have acquired tinnitus more recently and have different patterns of treatment seeking than the self-help group members. At the first contact, when the person asked for information about their tinnitus, the questionnaire (see Appendix A) was sent along with the information that the person had requested, and a cover letter was included which solicited their participation in the survey. A stamped return envelope was included for easy return of the completed survey.

Subjects in Group II were not selected on a strict geographical criterion. Informally, however, an attempt was made to provide a balanced sampling of all regions of the U.S. by selecting people from each region to participate in the mail survey. These names were selected weekly over a several month period by taking an equal number of names from each of the four geographical regions in the order that new 
inquiries were received in the ATA office. The total number selected each week varied with the number of new inquiries received.

The issue of confidentiality and/or consent forms for Group I and II has been presented to the Graduate studies and Research office of Portland State University where the appropriate forms are filed. Neither of these groups had constraints placed upon them regarding their participation in the survey. They stood neither to gain nor to lose by virtue of participating. Questioning, however, is a social process that gives a person the chance to express his feelings and experiences to a sympathetic and non-judgmental listener, thereby producing the feeling that they are being helpful.

Sample size consideration. The size of the sample required for a prospective study is difficult to determine when there is no prior information available concerning the variables. In this study, the sample size was determined by the funds available, the self-help groups accessible, and the time required for data collection. The final sample size of 255 cases, (Group $I=171$, Group $I I=84$ ), while small, is a start towards a much larger study. The numbers of responses received were adequate to provide data for the statistical procedures that were used for analysis.

Sampling Bias Considerations. Members of tinnitus self-help groups tend to live in urban and suburban areas, a grouping which also reflects the incidence of tinnitus and 
the location of self-help groups generally. Poorer or disadvantaged people are less likely to seek either the social support of a self-help group, or medical treatment that might not be covered by insurance or government programs. It is known, for example, that the Tinnitus clinic of the Oregon Health Sciences University has seen no black people. Reports from other tinnitus clinics indicate that they see very few blacks. On the other hand, audiologists working in Veterans Hospitals in the deep South report that there are many blacks with hearing problems and tinnitus among their patients. Health statistics in general indicate that the poor are not using medical services. The poor may lack both the means and the social skills necessary for participation in a self-help group. They may also fear that admitting that they have a problem such as tinnitus will further prevent them from obtaining and keeping employment. In sum, all of the people reached in this study are those who have been treated or are likely to be treated for tinnitus. The vast majority of those with tinnitus and who never seek help for it were not included.

There is, in addition, an identifiable response bias which arises because those subjects recruited from self-help groups were made up of persons who had already gone to some effort to seek help for their tinnitus and who are perhaps more willing to provide significant data for researchers. As an attempt to control for that bias, an additional collection 
of data was made from people making their first inquiry about tinnitus with the American Tinnitus Association. Based on their written or telephoned comments, that population appeared to be more newly involved with the problem of tinnitus and thus less likely to have had contact with others who have the problem and less likely to have read or heard much about it. Those people had, however, gone to the trouble to seek help by responding to a media contact (there are Public Service Announcements on Radio and TV, there are frequent syndicated articles and columns, and there are often local human interest stories about tinnitus).

\section{Variables used in the study}

As will be seen, many of the test items refer to variables listed in the conceptual framework. Not all of the variables included in the conceptual framework were measured in the survey and those that were measured are too numerous to be analysed in a single study. Further, to facilitate comparisons, questions that had appeared in previous studies about tinnitus were included along with general demographic data. What follows is a list and short explanation of each of the variables used in this study. The complete list of variables from the questionnaire will be found in appendix $B$. The variables are numbered in the order in which they appeared in the questionnaire and were entered into the computer. Variables in this section will be grouped 
according to category or in some instances according to the way they were used in the analysis.

\section{Demographic and personal variables:}

Variable 75, AGE, measured the person's age in years.

Variable 76, SEX, $1=$ male, 2 = female, $0=$ no response

Variable 77, SCHOOLEVL, educational training completed. High

= more schooling.

Variable 78, MARRIEDOR, was a nominal scale regarding marital status.

Variable 82, HEALTHRATE, person's rating of their general health, high $=$ poor health

Information about a person's employment status and income was obtained. Some of these variables were not able to be utilized for analysis as explained elsewhere in this study.

Variable 127, INCOME, represents the dollar value from variable 99, FAMINCOME, which measured income either as a specified range, or in actual dollars. Those cases reporting actual dollars were used to calculate mean scores within each income range. These figures in dollars then replaced the range choice.

Variable 126, WORKING, is a composite of items 85 and 86 reporting either full or partime employment.

Measures of severity:

Variable 68, SEVERITY, measured perceived severity 
(annoyance) of tinnitus. Five level scale -- high = more severe.

Variable 69, INTRFRLIFE, measured the amount of interference with life caused by tinnitus. Five level scale -- high = more interference.

Variable 131, SEVSCALE, is a composite of items $64,68, \& 69$. It measures severity on a scale of 1 to 4 , the scores possible on this scale from the composite items range from 1 to 15 .

Variable 128, SEVHIGH, is a composite of levels 3 and 4 of item 131 .

Variable 129, SEVLow, is a composite of levels 1 and 2 of item 131 .

Measures of psychological and social cost: Measurement was made of indirect costs of tinnitus through changes in lifestyle or social habits. The items in this section also relate to the perception of severity and were used in developing a severity scale. Variable 64, SLEEPROB, sleep problems because of tinnitus, 0 = no, 1 = Yes.

Variable 66, PSYCHELP, professional psychological help for tinnitus. $0=$ no, 1 = yes. Variable 67, CURTAILSOC, measured social activity curtailment due to tinnitus. Five level scale -- high = more curtailment. 
Measures of economic cost: Data were sought pertaining to direct expenditures of dollars in seeking relief for tinnitus. Cost data collected from the survey were adjusted to conform with Consumer Price Index information (Standard \& Poors Statistical Service, 1986; and the Social Security Bulletin, 1986), which set out Medical care commodities, Medical care services, and Hospital services in yearly adjusted dollar amounts. In this way, the dollar amounts reported from different years were able to be converted to comparable values. These comparisons were made in an attempt to determine whether or not tinnitus patients spend more money on health care than does a typical citizen. Variable 8, WHATYEAR, the year that help was most actively sought. The year was used for adjusting (by CPI) the costs reported in most active year to 1985 dollars.

Variables 11 through 14 called for monetary estimates for professional visits to any of 15 named progessionals or 'others'. In cases where respondents reported professional visits but did not reveal the monetary costs an estimate was made by taking an average of the costs that were reported by others in the sample for the same indicated year. Variable 11, PASTYEAR7, measured in dollars the amount spent for professional visits during the past year, which was 1985 . Variable 12, ACTVYEAR7, measured in dollars the amount spent for professional visits during the most active year, converted to 1985 dollars. 
Variable 13, AVGYEAR7, measured in dollars the average amount spent during each year since tinnitus began. This measure as well as Variable 14, and other measures of total or average costs were not used in the analysis because it was not possible, due to averaging or totalling over a number of years, to accurately adjust the amounts to 1985 dollars. Variable 14, TOTCOST7, measured in dollars the amount spent for professional visits over the course of having tinnitus. Variable 125, PYcosT, Past year costs, is a composite of items $11,45,49,132,133$.

Variable 124, CPICOST, was the CPI adjusted cost of reported expenditures for the most active year in which a person sought help for tinnitus. Again, this variable was not used except as a comparison variable between Group I and Group II because of the inherent difficulties in trying to compare costs for an average year with income and perception of severity information from the current year.

Costs of possible hospitalization for tinnitus were also sought for comparison to U.S. census information. These were used along with other reported medical costs to establish whether or not tinnitus patients spent more than the average citizen on health care.

Variable 44, HOSPITAL, hospitalization for tinnitus, $0=$ no, $1=$ yes.

Variables 45, HOSCOSPY, measured in dollars the cost of the past-year's hospitalization for tinnitus. 
Variable 46, HOSCOSACT, measured in dollars the cost of mostactive-year's hospitalization for tinnitus.

Variable 48 , HOSCOSTOT, measured in dollars the total costs of hospitalization for tinnitus since onset. (see comment for Variable 124)

Variables 49, TRAVELPY, measured in dollars the cost of travel during the past year to get tinnitus treatment. Variable 53, OTHRMEDPY, measured in dollars last year's medical costs that were not associated with tinnitus. Variable 101 and 106 report the percentage of income lost from changing jobs or quitting work. Variable 108, COSTOFHELP, the dollar amount reported by housewives who had to hire someone to do their housework because they were incapacitated by tinnitus.

Another possible way of looking a costs involves counting the number of physician visits and the number of different treatments used. The next group of variables measured the number of different professionals contacted, and how many professional visits were made. Variable 130, PYTXS, a composite variable, created from the score derived from the number of professionals seen during the past year and number of different kinds of treatments for the same time period. To calculate the different number of treatments utilized each person's tally of different devices and drugs was summed with the number of different professionals contacted. Each different professional was 
presumed to initiate one kind of treatment, to that figure was added a score created from items 17 through 43 calling for monetary estimates of the amount spent for drugs and devices relating to tinnitus relief. For the purpose of calculating variable 130 each of these variables was given a score of one if a person had indicated spending money for hearing-aids, maskers, tinnitus instruments, prescribed medicines, non-prescription drugs, vitamins, ear-plugs, bedside maskers, special telephone bells, books for selfhelp, recordings for self-help, massage/vibrator devices, electrical stimulation devices, or other similar devices. For example; a person might have mentioned going to a dentist for their tinnitus, and having spent money on earplugs and vitamins. These answers would have produced a score of 3 for PYTXS.

Variable 5, HOWMANYPRO, measured the number of different professionals consulted. A list of 15 possible types of consultants was presented along with an 'other' type so that people could check as many as applied to them. Score = sum of checkmarks.

Variables $6,7, \& 10$ comprised a multiple part question calling for the number of visits made to health professionals in several time periods and totally since their tinnitus began.

Variable 6, PASTYR6, the number of professionals seen during the past year 
Variable 7, ACTVYEAR6, most-active-year visits, was used to calculate an average number of professional visits for that year.

Variable 10, TOTVISIT6, measured the total number of professional visits since acquiring tinnitus. The number of visits was used to compare the tinnitus population with the U.S. Census population.

Insurance coverage information was obtained from items $59,61, \& 62$.

Variable 59, INSURCOVT, tinnitus costs for the past year covered by medical insurance, $0=$ no, $1=$ yes. Variable 61, PERCNTCOV, measured the percentage covered in percent. This percentage was used to estimate actual out-ofpocket expense to the individual. Variable 62, INSACTYR, tinnitus costs covered by insurance during the year that help was most actively sought, $0=$ no, 1 = yes.

The insurance coverage information obtained was incomplete. People didn't seem to be able to recall information about their insurance if there was a time lag of a few years or more. Face to face interviews would be recommended for obtaining data of this type. Other variables relevant to tinnitus: Information relating to perception of the tinnitus and its relationship to hearing loss was collected in order to make comparisons with available data on hearing impairment. 
Often tinnitus is closely related to hearing loss and is often confounded with hearing impairment particularly when seeking information about both economic and social effects. Variable 1, HOWLONG, measured in years how long a person had been aware of having tinnitus. Variable 2, LONGPROB, measured in years how long tinnitus had been a problem.

Variable 3, HEARLOSS, measured dicotomously ( $0=$ no, 1=yes) whether or not the person perceived himself to have a hearing-loss.

Variable 4, PROBHLORT, identified which was the greater problem, hearing-loss or tinnitus. ( $1=\mathrm{HL}, 2=\mathrm{T}, 3=\mathrm{Both}$ equally bothersome)

\section{Data analysis}

With the help of a microcomputer, descriptive statistics have been derived for each of the survey variables using the Statpak software from Northwest Analytical Co. The data were stored in the computer using the database program dBase III Plus. Further analysis of the data was accomplished as necessary using the above mentioned software. Additional analysis was accomplished using SPSS-X 2.1A on the Harris computer at Oregon Health Sciences University.

Data entry for Groups I and II was accomplished by the author. Data checking was accomplished by random selection of questionnaires for item-by-item inspection. Additionally, the data were printed and visually scanned for column 
alignment, missing values, or out of range values. Missing values were coded with the symbol -999999 so as to be recognized by the computer.

In the results section it will be shown that the sample chosen is similar, with minor exceptions, to other samples from which previous data have been derived. The social, psychological, and economic costs of tinnitus will be described and differences will be analysed and models will be developed for the prediction of tinnitus costs. The results of hypotheses testing will be described. 
CHAPTER VI

RESULTS

Characteristics of the sample

Differences between the two samples and their subsequent combination. Comparisons of the two groups [Group I ( $N=171$, self-help group members) and Group II ( $N=84$, new inquirers)] were made by graphing the mean scores for selected demographic and tinnitus severity variables and comparing them visually. Visual inspection showed the variables to be remarkably similar and the decision was made to pool data from the various groups. The graph is shown in Figure 3. 


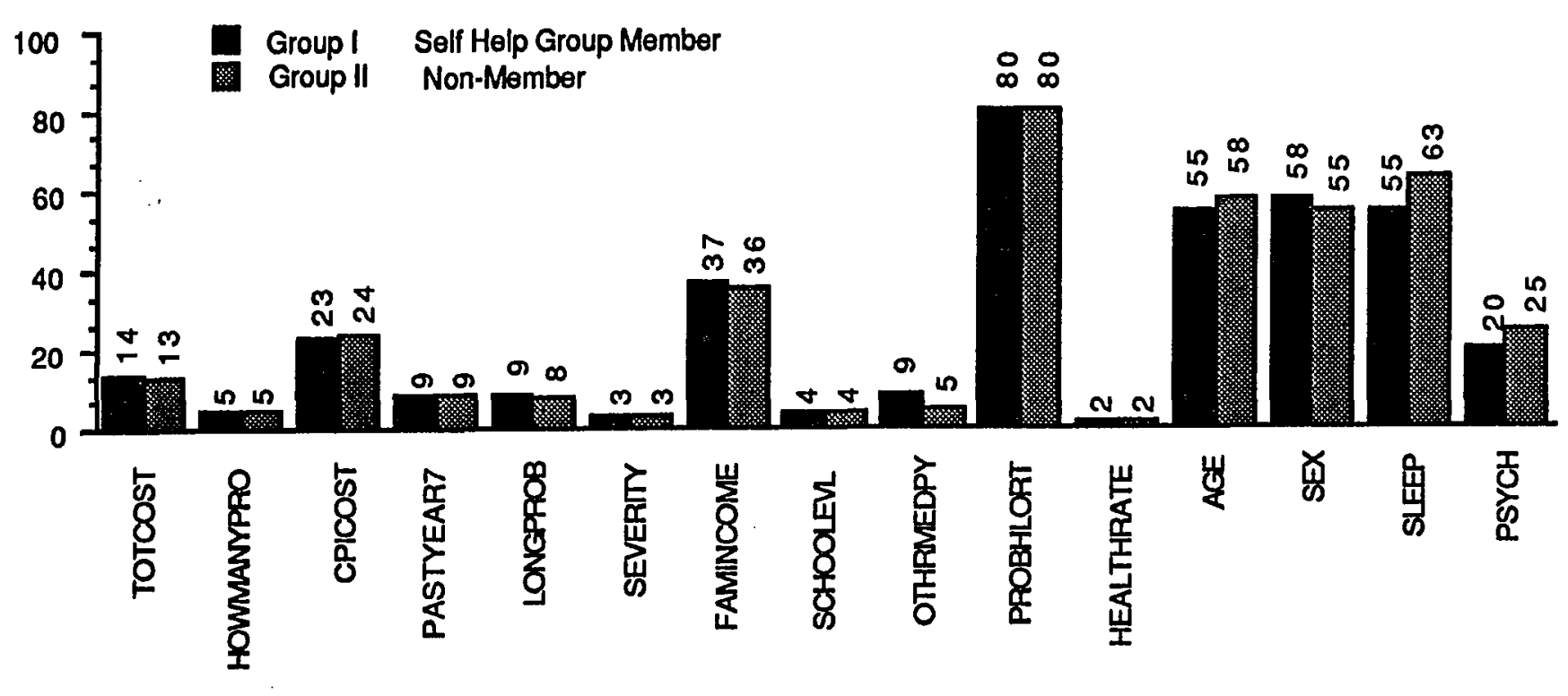

Figure 3. Tinnitus survey data comparing means of 15 variables.

TOTCOST $=$ hundreds of dollars HOWMANYPRO=number seen CPICOST=hundreds of dollars PASTYEAR7 =hundreds of dollars LONGPROB=how many years
SEVERITY=choice of 5 levels( $3=$ difficult) HEALTHRATE=choice of 5 levels $(2=$ good) FAMINCOME=thousands of dollars $\quad A G E=y e a r s$ SCHOOLEVL=choice of 6 levels(4=college) SEX=dichotomous(\%male)

OTHRMEDPY=hundreds of dollars SLEEP=dichotomous(\%troubled)

PROBHLORT=dichotomous(\%tinnitus) $\quad$ PSYCH=dichotomous(\%who consulted) 
Pooling of the data facilitated further analyses by providing a larger number of responses for each of the individual items on the questionnaire.

\section{Demographic features}

Results reported in this work are based on the combined sample of 255 responses. Respondents ranged in age from 20 to 87 with a mean age of 56 . The age distribution is shown in Figure 4. The age pattern is consistent with the ages of patients reported at the Oregon Health Sciences Center Tinnitus Clinic and in other studies (Meikle \& Walsh, 1984); (NHIS-4, 1987). There were 107 women and 143 men in the sample; for one respondent the sex was not identified. Differences in response by sex will be discussed later in this chapter. In the survey population, 718 were married, and $76 \%$ had children. Most of the group reported having 2 children (58\%), but only $27 \%$ of the group still had children living at home.

The group as a whole reported above-average educational levels; 98\% had completed high school and 58\% reported college or advanced degrees. A comparison of the educational levels reported by the respondents to Bureau of Census data follows in Figure 5. The socio-economic status of the group studied is consistent with tinnitus clinic patients (Meikle \& Walsh, 1984) and with members of self-help groups for other health problems as reported by the National Self-Help Clearing House in their Newsletter, 1985. 


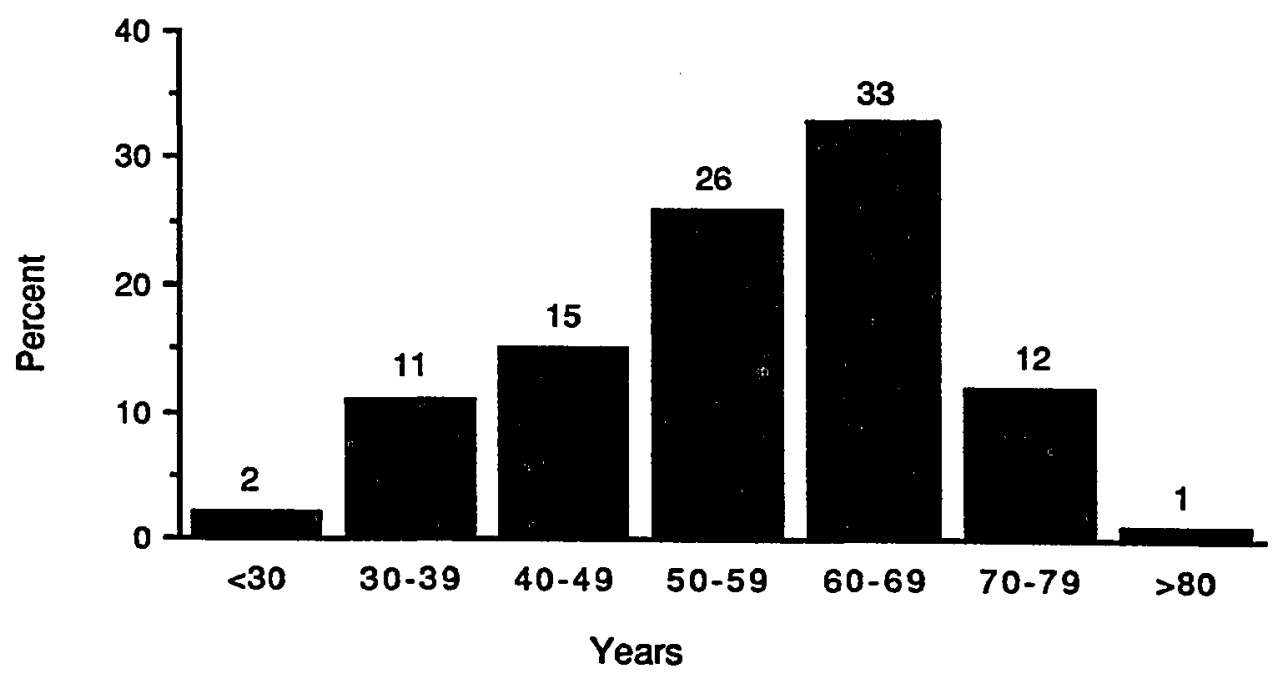

Figure 4. Age distribution of tinnitus survey population. 


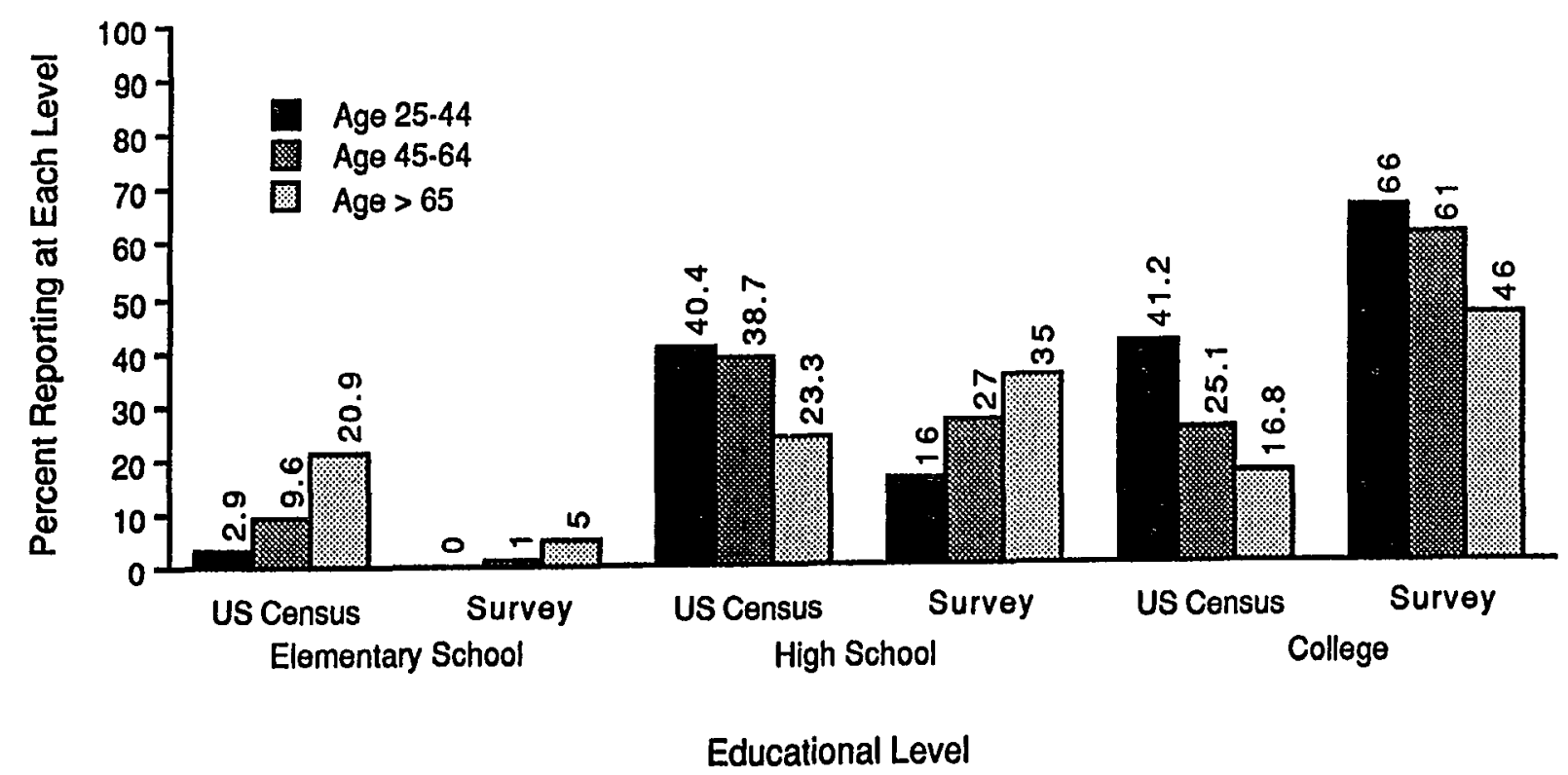

Figure 5. Highest educational levels acheived by adults in survey.

Census figures from 1980 census 
The group was made up almost equally of wage-earners and retirees, with 37 and 33 percent respectively in these categories. The rest of the sample was made up of housewives (13\%), part-time workers (15\%), and a small number of students. Of the 238 people who gave income information, $78 \%$ fell into the 3 highest income levels, that is, an annual income of greater than $\$ 15,000$. The survey population turned out to have, as was expected, higher than average family incomes. Table III indicates income levels from the National Health Interview Survey (NCHS,Series 10, \#160, 1985) compared to those for the present work. Figure 6 shows the actual income distribution for the tinnitus survey.

TABLE III

ANNUAL FAMILY INCOME

Percent of people reporting at the level indicated AMOUNT NHIS 1985 PRESENT SURVEY

less than $\$ 10,000$ $17 \%$ $12 \%$ $\$ 10,000$ to $\$ 24,999$ $34 \%$ $29 \%$

more than $\$ 25,000$ $49 \%$ $59 \%$ 


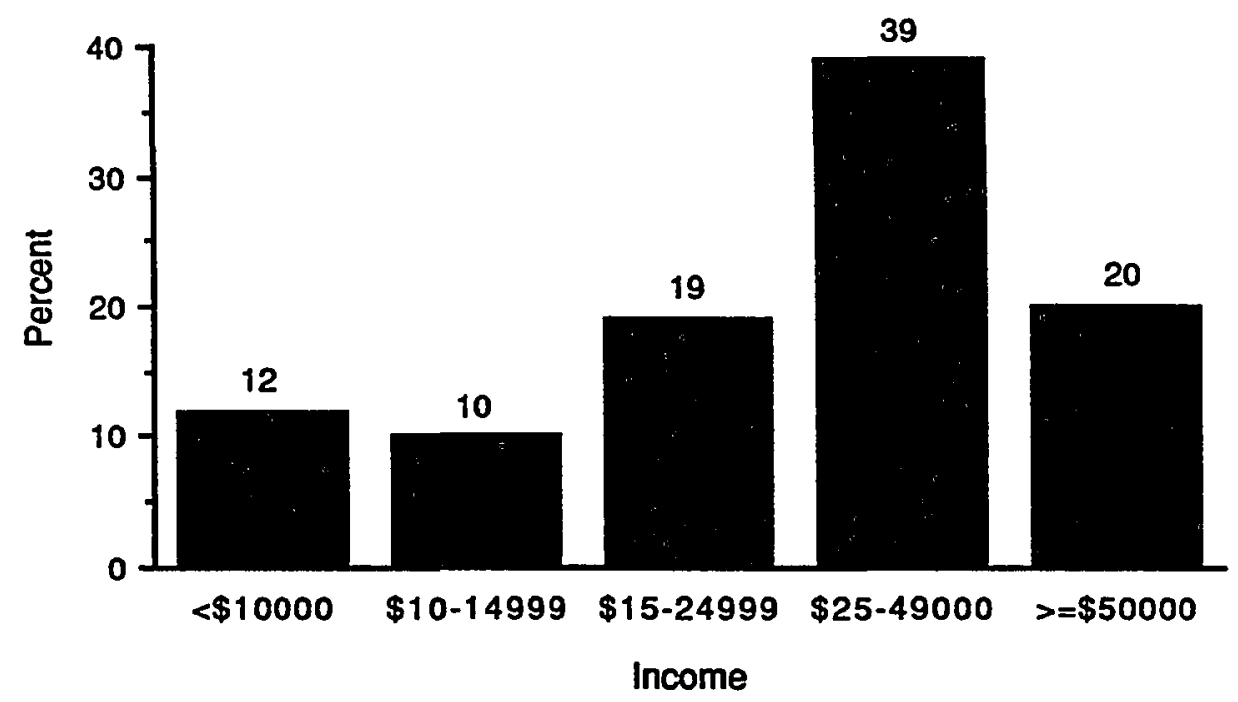

Figure 6. Income distribution for tinnitus survey. 
Data obtained from the present survey of tinnitus sufferers while similar to other self-help groups and tinnitus clinic patients, contrast sharply with the information from the National Health Interview Survey, (NCHS, Series $10 \# 160,1985)$, where most of the tinnitus is reported to occur when family income is less than $\$ 10,000$. The sampling bias predicted due to self-help group members having higher than average income is borne out. It would be expected that a bias toward higher income would cause an overestimation of tinnitus costs but, as it will be seen later in this chapter, in the present sample those with incomes over $\$ 15,000$ actually spent last year less than $75 \%$ of that spent last year by those with incomes under $\$ 15,000$. of those in the present survey who reported that they had lost income because of tinnitus, $14 \%$ had changed jobs with a $75 \%$ loss of income, and 148 had to quit work losing an average of $70 \%$ of their income. Thirty people, (12\%), responding said that someone else had had to change jobs or quit work to provide care for them because of the tinnitus. Characteristics relating to tinnitus and hearing loss. Hearing difficulties were noted by $74 \%$ of the survey respondents but $79 \%$ indicated that tinnitus was the primary problem. Additionally, $26 \%$ of those in this survey suffered from tinnitus with no noticable hearing loss. On the average, people had been aware of their tinnitus for 11 years. Over half had been aware of their tinnitus for 
fewer than 10 years, with $62 \%$ of the group aware of it for 4 years or less. There was only weak correlation between length of time of having tinnitus and its perceived severity. $(r=.1255, p=.04)$ Figures are shown comparing the respondent's awareness of tinnitus with the length of time they have considered it to be a problem in Figure 7 which follows Table IV.

\section{TABLE IV}

AWARENESS OF TINNITUS

\begin{tabular}{|l|c|c|c|c|c|c|}
\hline Length of time in years & $<1$ & $1-2$ & $2-5$ & $5-10$ & $10-20$ & $>20$ \\
\hline Expressed as percents & $10 \%$ & $9 \%$ & $23 \%$ & $22 \%$ & $19 \%$ & $17 \%$ \\
\hline
\end{tabular}

(How long have you been aware of your tinnitus?) ( $N=251$ ) 


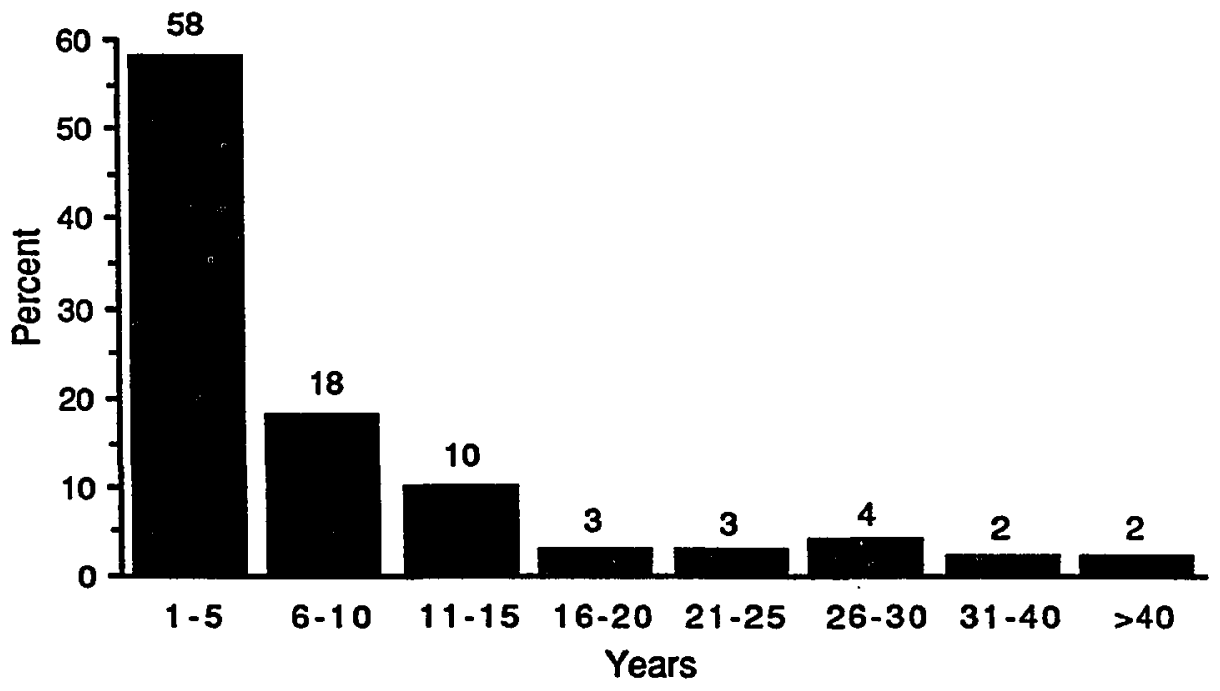

Figure 7. How long tinnitus has been a problem. 
Social and psychological costs of tinnitus

Development of a severity measurement scale. The conceptual framework for tinnitus has presented severity as an important factor. Theoretically severity of tinnitus may be measured medically, audiologically, and perceptually. Medical measurements of tinnitus are concerned with the underlying medical problem having tinnitus as a symptom. Audiologically, tinnitus may be evaluated in terms of hearing function. The present study is concerned with measurement of the patient's perception of severity.

No one has yet designed an instrument that measures either severity or a person's perception of severity to everyone's satisfaction. In fact, it appears that a number of different areas need to be evaluated when working with this problem.

In the U. K. severity was measured by how often tinnitus occured taken together with the length of time it usually lasted (Slater and Terry, 1987). Slater and Terry also state that "the more the noises (tinnitus) bothered the individual the more he or she was likely to have consulted a doctor about them."

A severity measurement item was brought into the tinnitus questionnaire used at the OHSU Tinnitus clinic several years ago and was subsequently divided into two items, severity and interference with life, which more nearly approximated the verbal reports of patients. Several items 
were included in the present questionnaire with the expectation that they would be related to severity perception, (Variables $64,66,67,68,69)$. It was not the intent of this study to construct a test to measure severity because such a test would necessarily include medical and audiological examinations. However, to the extent that human attributes may be measured by self-report items, at least a part of a severity test can be derived from questionnaire items. One of the requirements for measurement of a criterion is that the items used in the scale have content validity. The items relating to severity should be representative, highly correlated, and circumstantially be able to be shown to be measuring the same thing. Nunnally (1978) says that content validity rests mainly on the appeal to reason regarding the adequacy with which content has been measured. The section which follows provides indication that the severity measures are valid.

Descriptive data for severity. Figures 8 and 9 indicate the distribution of responses to two different but closely related items about the severity of tinnitus, 'severity', (Variable 68) and 'interference with life' (Variable 69). Data from two sources are presented (1) Tinnitus data from 1068 patients of the Tinnitus Clinic, Oregon Health Sciences University, (Meikle \& Walsh, 1984), and (2) the present work. 


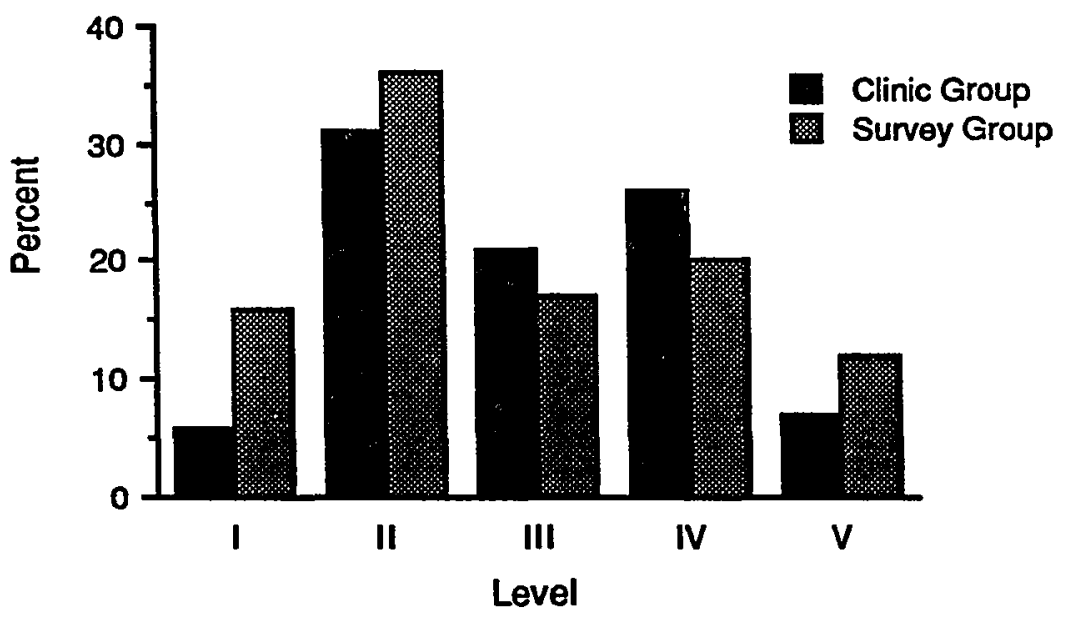

Fiqure 8. Percent choosing indicated severity item level: comparison of two groups 


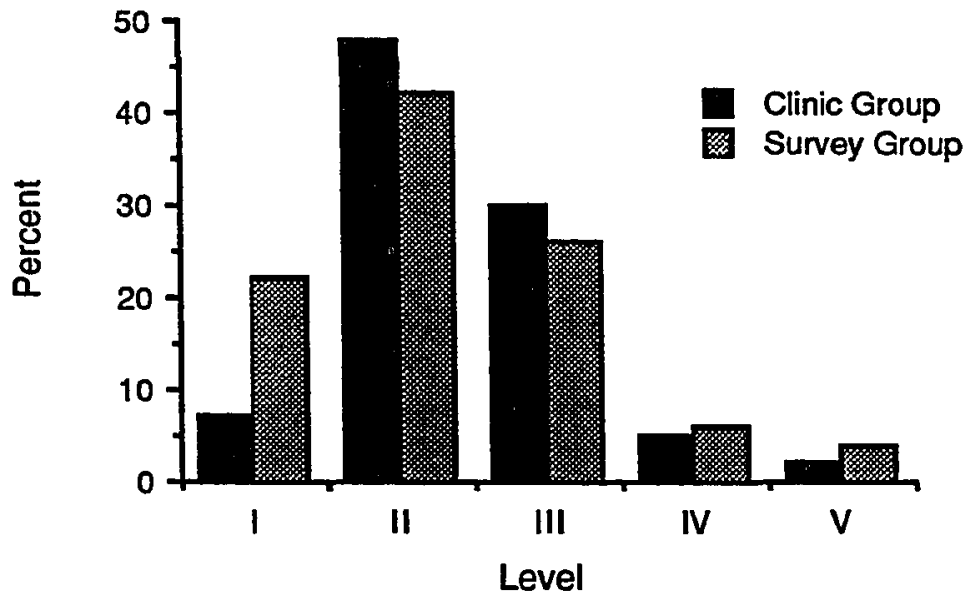

Figure 9. Percent choosing interference-with-life item level: comparison of two groups.

(Appendix A, Questionnaire item 25) 
It can be noted that the choice of severity and interference-with-life levels are similar for the two populations. Somewhat fewer clinic patients identify themselves at the lower levels. This is not unexpected from a group that has chosen to initiate treatment at a clinic dedicated to the evaluation and treatment of tinnitus patients.

Severity item level data from the present study, Variable 68, were further analyzed by dividing the responses into five groups based upon the perceived severity rating with Group I being least severe and Group $\mathrm{V}$ being most severe. A comparison of the frequency tallies of the severity scores and the life interference scores variable 69, revealed a positive correlation $(R=.71)$ between the two items.

Correlates of severity. In comparing the two groups from which data was obtained for this study, Group I and Group II, one notes that the severity and interference with life levels for the groups are strikingly similar. The differences noted between the study sample and the tinnitus clinic population are likely due somewhat to interviewing procedures and the fact that the clinic population is made up of people who are making a concerted effort to relieve their tinnitus. The study sample, recall, was made up of people in self-help groups and new inquirers of ATA. Recognizing these differences, the two populations show very similar tendencies 
on their choices of perceived severity and on interferencewith-life levels.

It was proposed in designing this study that severity would be related to annoyance, interference with life, psychological problems, sleep disorders, and social curtailment. In order to create a severity scale, scores on the items SEVERITY, INTRFRLIFE, SLEEPROB, PSYCHELP, and CURTAILSOC were summed.

People who have sleep problems associated with their tinnitus almost always report them as totally disabling. In order to reflect the seriousness of sleep problems this item was recoded to reflect either a minimal problem, 1, or a severe problem, 5. The variable PSYCHELP was also recoded to 1 and 5 values in order to reflect the fact that people with mild or moderate tinnitus very rarely seek psychological consultation. The other three items were measured on 5-point scales.

The reliability analysis is discussed here because the severity scale has been used in further analyses. Estimating the reliability of the severity scale. The reliability of this new scale used to measure severity was assessed using the SPSS-X software program "Reliability". Reliability analysis provides an alpha coefficient which may be used for making decisions about the level of reliability of the scale being evaluated. Theoretical discussions about levels of reliability are more directed toward tests which 
measure attributes or abilities of individuals than tests measuring a person's perception of a medical condition. According to Nunnally (1978) reliability coefficients of .70 are sufficient for working in the early stages of research on predictor tests or hypothesized measures of a construct. Much higher coefficients $(.90$ to .95$)$ are necessary when tests are used in applied settings where important decisions about people are made based on the tests involved. Not all of the expected items were useful in predicting severity, the five items were reduced to three when the largest alpha (.67) was obtained with only sleep, severity level, and life interference level. Even though the psychological items appear to be related to severity it actually lowered the value of the reliability coefficient and was deleted from the severity scale. Social curtailment had little relationship as evidenced by the small correlations. It may be, however, that the people in the survey by virtue of being members of self-help groups or seeking help from an organization may be less likely to curtail activities than people from a general population sample. The results of the reliability analysis are presented in Table $\mathrm{v}$. 
TABLE V

RELIABILITY ANALYSIS FOR SEVERITY SCALE

CORRELATION MATRIX

SLEEP PSYCH SEVERE INTERF SOCIAL

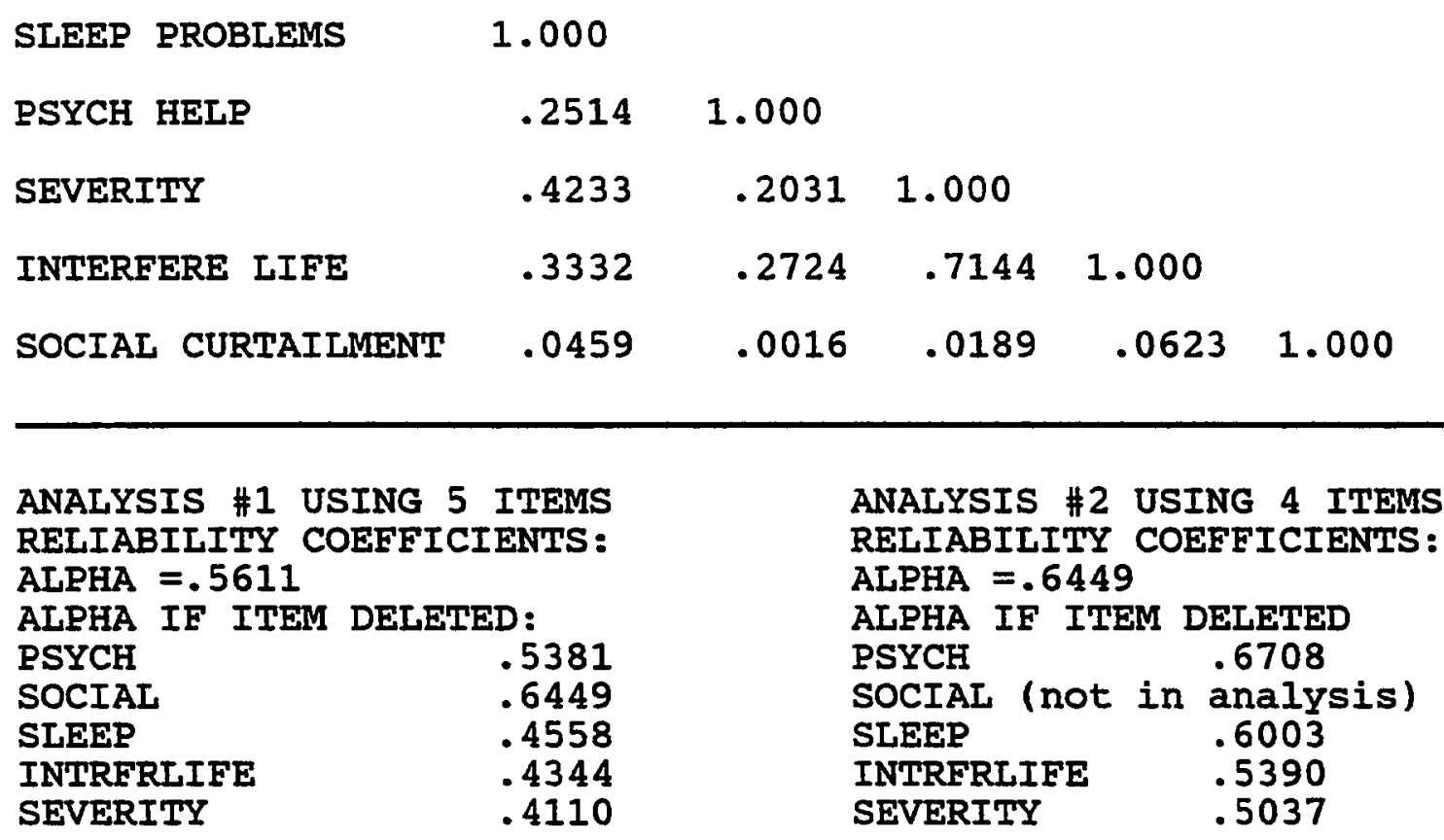


An estimate of perceived severity is possible with the scales presently being used as long as the rating from those scales is combined with clinical observation and evaluation. Other clinical indicators that might also serve to establish a severity level include observations relating to the patient's hearing function, their coping style, and their general medical status. When used as a part of the total assessment of an individual's tinnitus the reliability coefficients for the severity scale need not be as high as would be necessary if the scale were to be used as the sole predictor of severity. The severity scale will be found in Appendix C.

Gender differences. It was expected that a severity grouping by age would show more females in the severe categories. There are indeed more females in the more severe categories using the 5 point severity item, information which corresponds to the clinical report from a similar severity item utilized by Meikle \& Walsh (1984), but the differences are not particularly remarkable as can be seen from Figure 10. Figure 11 shows the percent reporting at each level of the new severity scale, spread to a 5 point scale to correspond with the severity item scale. Notice that the new severity scale identifies more people at the high ratings, and particularly that more males have moved into the higher severity range using the new scale. It appears that the 
additional items in the scale provide a more sensitive measure of severity than the one item found in the survey questionnaire. This finding provides empirical evidence to support the reliability analysis discussed previously. 


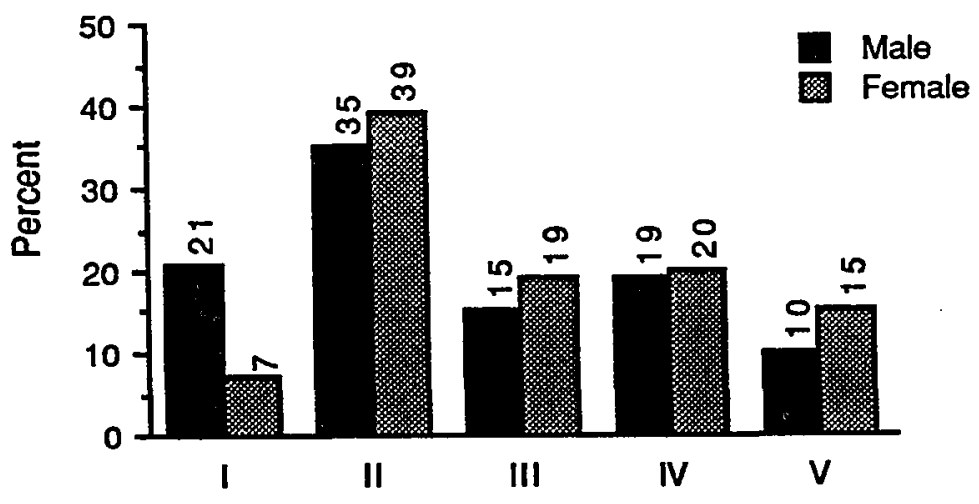

Eigure 10. Percent reporting at each severity item level by sex. (Appendix A, Questionnaire item 24) 


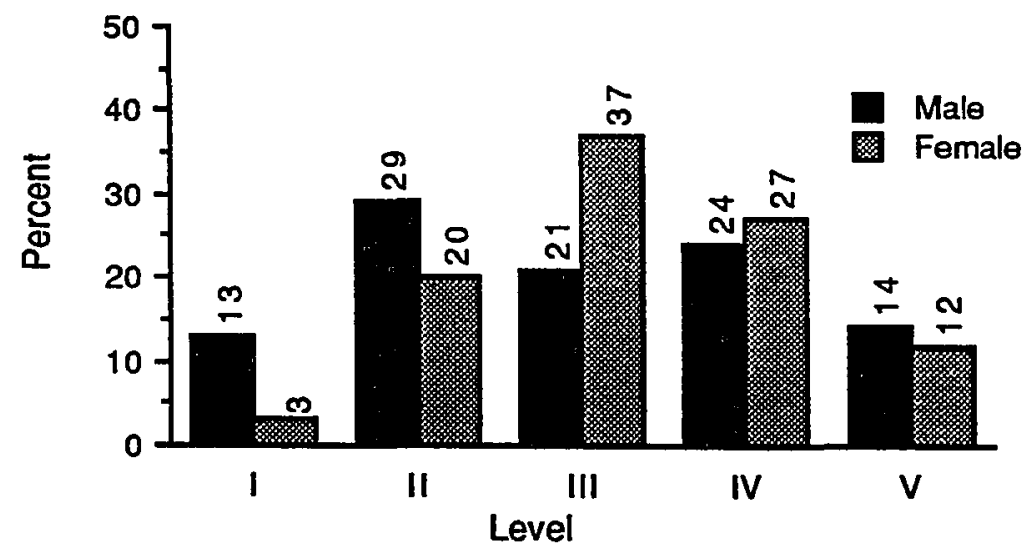

Figure 11. Percent reporting at each severity scale level by sex. (Appendix C) 
Age and socioeconomic differences. Utilizing the severity scale developed in the previous section comparisons were made by age, income, and education. The summed scale scores were arranged equally into 5 levels, sums of 3 or less equalled level 1, sums of 4,5 , and 6 equalled level 2 , sums of 7,8 , and 9 equalled level 3 and so on through level 5, to facilitate comparison with the 5-point severity item measures on the questionnaire. No significant differences were revealed that would lead one to believe that social economic status is a factor in whether or not a person has tinnitus. Tables VI, VII, and VIII show the percent reporting at each of the severity levels (1 through 5) for the variables age, income, and education level.

Table VI indicates a greater percentage at low severity for those under 25 years of age. It must be noted that there were only 3 subjects in this age group, too small a number for meaningful analysis. Similarly, with only 8 subjects, Table VI shows a greater percentage of people over 75 years old at higher severities. For the purpose of Chi-Square testing the age cells were collapsed into three columns by combining the $<25$ and 25-44 ages, and by combining the 65-74 with the 75 and over ages, in order to provide sufficient numbers for analysis. In Table VII it was necessary to collapse the two lowest severity levels in order to provide adequate cell frequencies. In Table VIII the education levels were collapsed into three columns by combining grade 
school, high school, and vocational school into one level. The college and graduate school levels were maintained and the 'other' column was eliminated because the responses were unable to be forced into any of the existing categories. 
TABLE VI

NUMBER REPORTING AT EACH SEVERITY SCALE LEVEL BY AGE

\begin{tabular}{|c|c|c|c|c|c|c|c|c|c|c|}
\hline $\begin{array}{c}\text { SEVERITY } \\
\text { SCALE LEVEL }\end{array}$ & $-N_{-}^{-}$ & & 2 & $\begin{aligned}-44 \\
-24\end{aligned}$ & 45 & & $\begin{array}{c}65- \\
-N-\end{array}$ & $\begin{array}{l}4 \\
\%\end{array}$ & $>7$ & \\
\hline 1 & 2 & 66 & 2 & 4 & 11 & 8 & 6 & 10 & 0 & 0 \\
\hline 2 & 0 & 0 & 8 & 16 & 41 & 31 & 15 & 25 & 0 & 0 \\
\hline 3 & 1 & 33 & 15 & 29 & 36 & 27 & 15 & 25 & 6 & 75 \\
\hline 4 & 0 & 0 & 17 & 33 & 28 & 21 & 17 & 28 & 1 & 12 \\
\hline 5 & 0 & 0 & 9 & 18 & 15 & 12 & 7 & 12 & 1 & 12 \\
\hline
\end{tabular}

Chi-square $=7.3$

$p=.5$ for 8 df $(5-1)$ rows $\times(3-1)$ columns [collapsed] 
TABLE VII

NUMBER REPORTING AT EACH SEVERITY SCALE LEVEL BY INCOME

\begin{tabular}{|c|c|c|c|c|c|c|c|c|c|c|}
\hline $\begin{array}{l}\text { SEVERITY } \\
\text { SCALE LEVEL }\end{array}$ & \multicolumn{2}{|c|}{\begin{tabular}{l}
\multicolumn{2}{c}{$<10 k$} \\
$N \quad$ q
\end{tabular}} & \multicolumn{2}{|c|}{$\underset{N}{10 k-14.9 k}$} & \multicolumn{2}{|c|}{$\begin{array}{c}15 k-24.9 k \\
N\end{array}$} & \multicolumn{2}{|c|}{$\begin{array}{c}25 \mathrm{k}-49.9 \mathrm{k} \\
\mathrm{N}\end{array}$} & \multicolumn{2}{|c|}{$N^{>50 k}$} \\
\hline 1 & 4 & 9 & 5 & 22 & 6 & 12 & 4 & 4 & 6 & 13 \\
\hline 2 & 10 & 23 & 7 & 30 & 9 & 19 & 27 & 29 & 13 & 28 \\
\hline 3 & 9 & 21 & 8 & 35 & 16 & 33 & 31 & 33 & 10 & 21 \\
\hline 4 & 13 & 30 & 3 & 13 & 11 & 23 & 20 & 22 & 13 & 28 \\
\hline 5 & 7 & 16 & 0 & 0 & 6 & 12 & 11 & 12 & 5 & 10 \\
\hline
\end{tabular}

Note: $\mathbf{k}=$ thousand dollars

Chi-Square $=11.6$

$p=.5$ for 12 df $(4-1)$ rows [collapsed] $\times(5-1)$ columns 
TABLE VIII

NUMBER REPORTING AT EACH SEVERITY SCALE LEVEL BY EDUCATION EDUCATION LEVEL

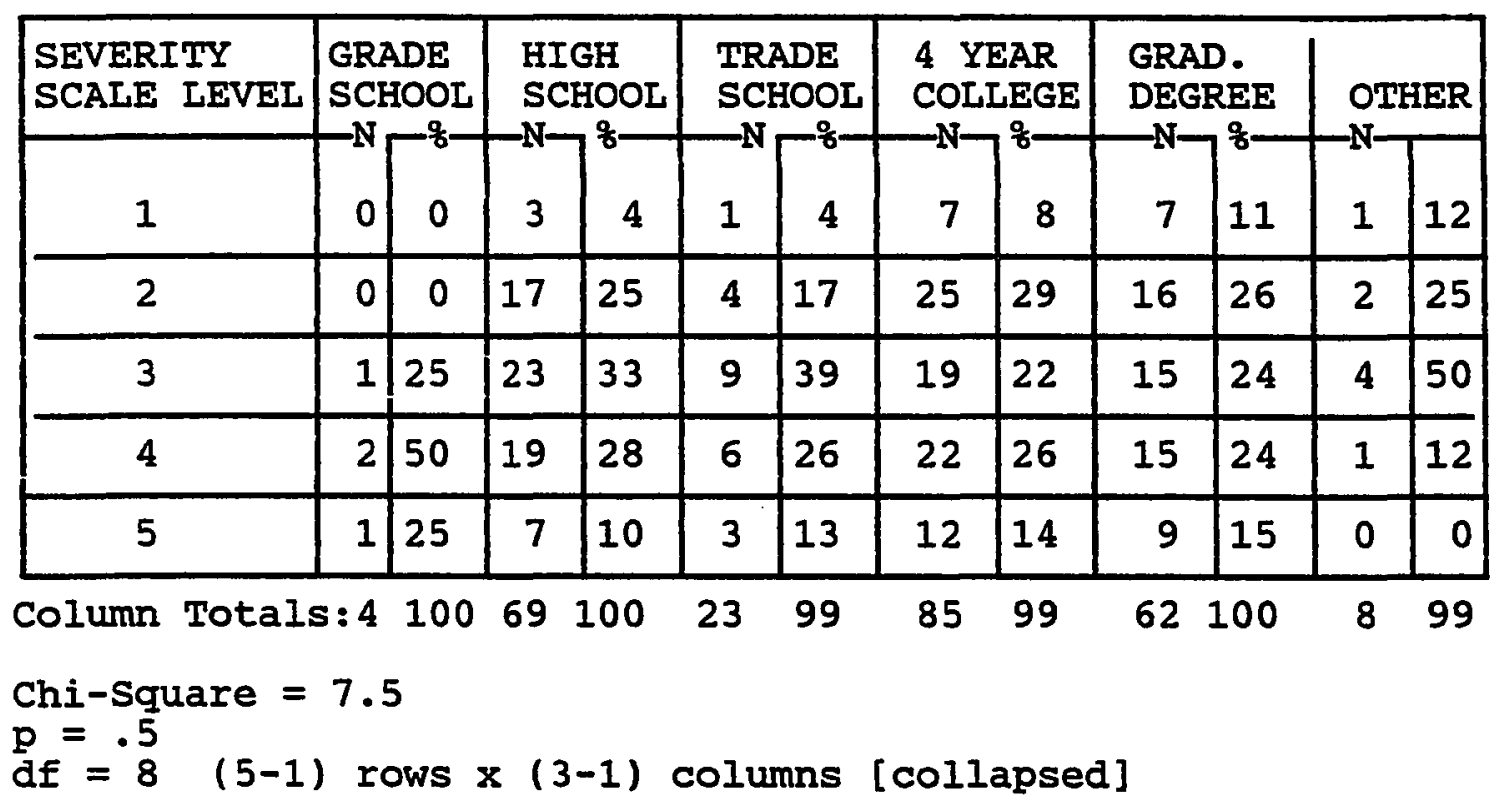


Economic costs of tinnitus

Accounting model for tinnitus. The first hypothesis, that direct and indirect tinnitus costs are directly proportional to perceived severity, was tested utilizing cost data from the first section of the questionnaire. In that section people were asked how much they had spent on professional consultation and treatment. In order to arrive at a per-capita cost figure for tinnitus the dollar data were summarized and averaged for three time periods: 1) an average year expenditure, 2) the greatest year expenditure, 3) the past year's expenditure. The past year expenditure figure is reported in the results.

Most studies of particular illnesses count medical care and lost wages to create a cost of illness index. An attempt to provide a similar index for tinnitus was made through the development of an additive model whereby the average amounts spent on various direct and indirect expenses can be portrayed. In the following model the average amounts are reported for various survey items, in order to yield a cost to society. If one were looking for the typical cost to an individual seeking each kind of care the figures would need to be calculated only on those people reporting costs.

Costs associated with lost income are not shown in this model although an ideal accounting model would contain this information. Income and employment information from the present survey was not sufficient to calculate amounts 
representing average lost income. A figure for lost income was calculated for 28 male respondents whose questionnaires indicated that they were the sole wage earner of their family and that they had had to quit or change jobs because of tinnitus. Lost income for females was not calculated due to insufficient information but it was interesting to note that $25 \%$ of the women in the survey reported having to hire household help because of their tinnitus.

The costs reported for various survey items were averaged to yield the figures in Table IX. 
TABLE IX

ACCOUNTING MODEL FOR TINNITUS COSTS

(all figures for past year costs)

\begin{tabular}{|c|c|c|c|}
\hline & $\begin{array}{l}\text { Averaged for } \\
\text { entire group } \\
\qquad N=255\end{array}$ & \multicolumn{2}{|c|}{$\begin{array}{l}\text { Averaged for } \\
\text { those report- } \\
\text { ing costs }\end{array}$} \\
\hline $\begin{array}{l}\text { Dollars Spent - Professional } \\
\text { Care last year variable } 11\end{array}$ & $\begin{array}{c}416 \\
(1216.8)\end{array}$ & $\$ \begin{array}{c}862 \\
(1641.7)\end{array}$ & $\mathrm{N}=123$ \\
\hline $\begin{array}{l}\text { Dollars Spent - Hospital } \\
\text { Care last year Variable } 45\end{array}$ & $\begin{array}{r}\$ 109 \\
(749.4)\end{array}$ & $\$ \begin{array}{l}1,733 \\
(2550.9)\end{array}$ & $N=16$ \\
\hline $\begin{array}{l}\text { Travel costs - to obtain care } \\
\text { for tinnitus, variable } 49\end{array}$ & $\begin{array}{l}\$ 28 \\
(105.4)\end{array}$ & $\$ \begin{array}{c}98 \\
(179.7)\end{array}$ & $N=73$ \\
\hline $\begin{array}{l}\text { Average amount spent last year } \\
\text { on drugs variable } 133\end{array}$ & $\$ \begin{array}{c}114 \\
(314.0)\end{array}$ & $\begin{array}{c}307 \\
(454.6)\end{array}$ & $N=95$ \\
\hline on devices Variables 132 & $\$ \begin{array}{c}167 \\
(410.7)\end{array}$ & $\$ \quad \begin{array}{c}454 \\
(573.9)\end{array}$ & $N=94$ \\
\hline $\begin{array}{l}\text { Amount spent last year for } \\
\text { other medical, Variable } 53\end{array}$ & $\$(304)$ & & \\
\hline $\begin{array}{l}\text { Estimated lost income last year } \\
\text { Variables } 127,101,106\end{array}$ & [male] & $\$ 17,128$ & $N=28$ \\
\hline Housewives costs last year, Var & iable 108 & $\$ \quad \begin{array}{l}741 \\
(607.7)\end{array}$ & $N=27$ \\
\hline
\end{tabular}

(Values in parentheses, standard deviations) 
Using the above model, it is estimated that during the past year in seeking help for tinnitus, people in the survey spent an average of $\$ 834$ for professional care, hospital care, drugs, devices, related travel costs, and had additional costs for lost income or household help. (It must be remembered that some patients continue to pursue relief year after year, and some never pursue relief at all). In the surveyed group $82 \%$ had made expenditures to professionals for their tinnitus during the course of their tinnitus, $56 \%$ had done so last year, and only $11 \%$ had ever been hospitalized for tinnitus. A few patients had been hospitalized for evaluative testing or for ear surgery, or for psychological problems consequent to tinnitus so that hospital expenditures were reported by 168 of the respondents during the course of their tinnitus.

Reports from 73 people (29\%), indicated significant medical transportation costs in the course of seeking relief for tinnitus last year. The average amount spent by this subgroup, was $\$ 98$ per person.

Insurance coverage for tinnitus averaged $25 \%$ and thus the most conservative estimate of the past year's out-ofpocket professional and hospital costs for tinnitus for the entire study group was $\$ 500$ (75\% of items $1-4$ in the accounting model). The costs of devices are not included in this estimate because they are not usually covered by insurance except in the case of veterans administration 
medical centers. There were only two people receiving tinnitus services from the VA in this study and those respondents did not answer the items in question.

Costs by age and sex. Averaging costs for the entire study group by age and sex revealed that women spent more than men and that young adults spent more than either people in mid-life or older or the very young. Table $\mathrm{x}$ shows the breakdown of these costs by age and gender for the total costs of treatment, including professional visits, hospitalization, drugs and devices. Costs in the sections to follow should be taken to mean costs for the categories just discussed. 
TABLE X

PAST YEAR TINNITUS COSTS BY AGE AND SEX NUMBER-MALE/COSTS NUMBER-FEMALE/COSTS

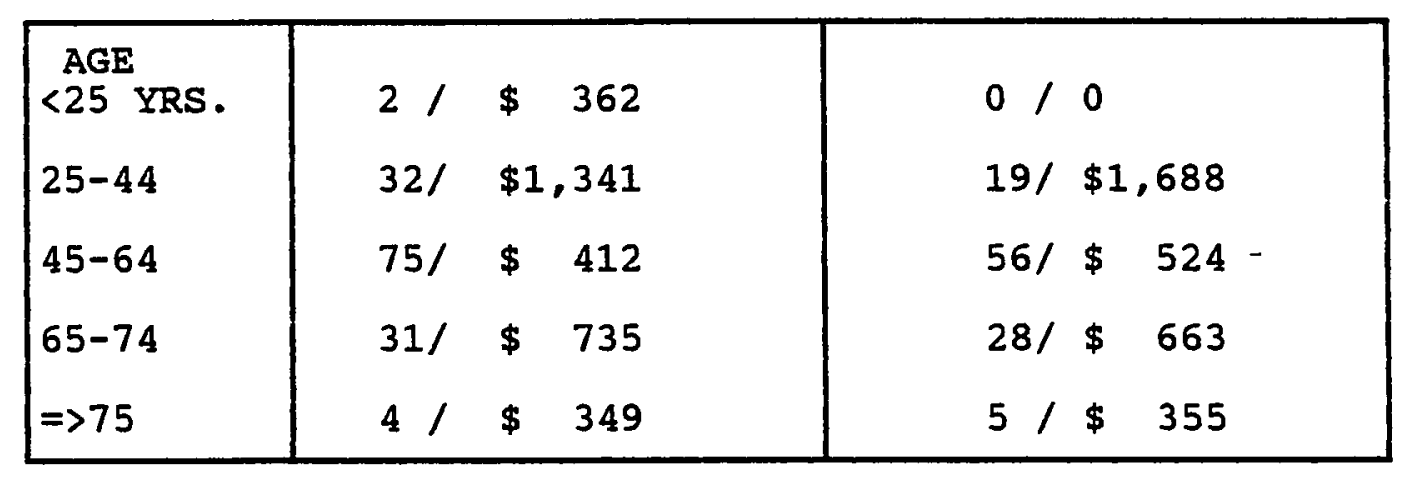

The same percentage (14\%) of women as men reported having to change jobs because of tinnitus but the cost of that change was not able to be reported because individual components of family income were not reported. One-quarter of the women in the survey had to hire someone to assume household chores that they were unable to perform because of their tinnitus. This household help cost an average of $\$ 741$ for those using it.

Three husbands reported that their wives had to go to work to provide additional income because of the husband's tinnitus, and 14 husbands reported that their wives had to quit jobs to provide additional home care for them. one wife reported that her husband had to go to work to provide additional income because of wife's tinnitus, and 8 wives reported that their husbands quit work to provide additional home care for them. 
Costs by income and socio-economic status. Averaging costs for the entire study group by income and educational level revealed differences in expenditures shown in Table XI. Costs include professional visits, hospital costs, drugs, and therapeutic devices.

TABLE XI

PAST YEAR TINNITUS COSTS BY INCOME AND EDUCATIONAL IEVEL

\begin{tabular}{||l|c||c||c|c||}
\hline INCOME LEVEL & PAST YR COST & EDUCATION LEVEL PAST YR COST \\
\hline \hline$<10,000$ & $\$ 1,792$ & 1 & (Elem.) & $\$ 1,206$ \\
2 & 1,581 & (High) & 774 \\
$310,000-14,999$ & 704 & (Trade) & 76 \\
$\$ 15,000-24,999$ & 638 & (Coll.) & 1,159 \\
$\$ 25,000-49,999$ & 1,110 & & (Grad.) & 865 \\
\hline$\$ 50,000$ & & & \\
\hline
\end{tabular}

* Note: Income levels and education levels are not meant to correspond. (For example: an education level of 2, meaning High school does not imply income of $\$ 10,000-14,999$ )

Costs by severity level. In order to try to establish a pattern for tinnitus costs, the average past year costs for professional and hospital care, related travel, drugs, and devices were tabulated by severity level as shown in Table XII. The table shows that these costs increased as the severity level increased. 
TABLE XII

PAST YEAR TINNITUS COSTS BY SEVERITY SCALE LEVEL

\begin{tabular}{c|c|cc}
\multicolumn{2}{l|}{$\begin{array}{l}\text { SEVERITY } \\
\text { SCALE LEVEL }\end{array}$} & $\begin{array}{l}\text { NUMBER } \\
\text { REPORTING }\end{array}$ & \multicolumn{2}{l}{ DIRECT COSTS } \\
\hline 1 & 21 & $\$$ & 474 \\
2 & 64 & $\$$ & 387 \\
3 & 73 & $\$$ & 547 \\
4 & 65 & $\$$ & 861 \\
5 & 32 & $\$ 2,562$
\end{tabular}

Costs by severity and income. Table XIII depicts comparative costs by severity scale and income. To construct this table the levels of the new severity scale were compressed to represent low and high severity. Scale scores below the median were considered low severity and those above the median were considered high severity. It is evident from these two tables that those with the most severe tinnitus had greater costs than those with a milder type. This analysis further revealed that those with high incomes spent less when their tinnitus was severe than did those with lower incomes. The low income group however spent less than those with higher income when the tinnitus was perceived as being of low severity. 
TABLE XIII

PAST YEAR TINNITUS COSTS BY SEVERITY AND INCOME LEVELS

\begin{tabular}{|l|l|l|}
\hline \multirow{2}{*}{$\begin{array}{l}\text { SEVERITY } \\
\text { SCALE }\end{array}$} & HIGH & INCOME \\
\hline HIGH & $\$ 992$ & LOW \\
\hline LOW & $\$ 249$ & $\$ 1263$ \\
\hline
\end{tabular}

\section{Predictors of tinnitus costs}

The second hypothesis to be tested stated that the costs of tinnitus are expected to be related to the variables of age, sex, length of time afflicted, perception of general health, whether presently working, perception of severity, and number of treatments employed. This chapter's analysis of these relationships provided evidence indicating that these relationships exist but that they are not particularly strong except for severity and the number of treatments employed.

\section{Explanatory analysis of causal relationships. In} theory, there are a number of variables influencing the amount of money a person afflicted with tinnitus will spend seeking help. Information discussed previously in the accounting model revealed direct costs to be associated with income and job status. Whether or not a person is working and the amount of their income may be related to the amounts people spend seeking help for tinnitus. 
In order to test hypothesis number two, regression analysis was employed in order to examine a set of variables from the survey and to identify those which appear to contribute to the direct costs of tinnitus. It was expected that patterns among the variables would also be identified. The variables age, sex, length of time afflicted, perception of general health, income, employment status, perception of severity of tinnitus, and the number of treatments employed, were used to construct a saturated model of tinnitus costs from which information about the specific relationships between the variables was derived using the technique of path analysis.

Path analysis was selected in order to be able to interpret the effects of intervening variables on the total amount spent for tinnitus relief. (Nie, Hull, Jenkins, Steinbrenner \& Bent, 1975)

The data set used for path analysis consisted of the nine variables conceptualized in the path model shown in Figure 12. The variables included in the path model were assumed to have a weak linear causal ordering and to meet the minimum assumptions for regression analysis. The standardized betas of regression analysis were used to estimate path coefficients, after the method of Goldberger (1970), because the variables in the analysis were measured on different scales and consequently have quite different variances. The causal relationships represented by the paths 
were considered to be significant if the ' $t$ ' statistic associated with the regression met the alpha level which had been set at p<.05 (1.97 for approximately 20.0 degrees of freedom.)

Path coefficients for the model were obtained from the regressions of each endogenous variable with all causally prior variables. The regression equation took the form: $\mathrm{Y}=\mathrm{B}_{\mathrm{O}}+\mathrm{B}_{1} \mathrm{X}_{1}+\mathrm{B}_{2} \mathrm{X}_{2}+\ldots+\mathrm{B}_{\mathrm{J}} \mathrm{X}_{\mathrm{J}}+\ldots+\mathrm{B}_{\mathrm{P}} \mathrm{X}_{\mathrm{K}}$ Where $Y$ is the dependent variable, $x_{1}, x_{2}, x_{J} \cdot . \cdot x_{K}$ are the independent variables, $B_{O}$ is the regression constant, and $B$ is the regression coefficient.

The standardized structural model for path analysis takes the form:

$$
P_{y z}=\sum_{i} P_{y x} P_{x_{i}}
$$

Where $\mathrm{P}_{\mathrm{YX}}$ is the causal parameter from variable $\mathrm{x}$ to $\mathrm{Y}, \mathrm{Pxz}$ is the correlation between $x$ and $z$ and the set of $x$ variables are all the causes of the variable $Y$. The actual values for the paths were derived from an empirical approach developed according to the work of Goldberger (1970) where the Beta or standardized regression coefficient is used as the estimated path coefficient for paths leading from the particular set of independent variables to the dependent variable under consideration. Taking one variable at a time as the dependent variable and all the variables with higher causal order as the independent variables, the direct and indirect path estimates were delineated and combined to yield the 
total effect. This total effect was compared with the original correlation between the variables in question to indicate how much of the effect was unaccounted for or noncausal.

In this model the variable representing the total past year's dollar costs (PYCOST) of tinnitus is presumed to have direct paths from the following variables: perception of severity (SEVERITY), income, whether working or not (WORKING), and variety of treatments used (PYRTXS), how long affected (LONGPROB), general health (HEALTHRATE), age, and sex. In addition to the direct paths, there are also indirect paths between and among these variables as shown in the path model diagrams, Figures 14 and 15.

Variables specified in the path model were chosen to reflect as accurately as possible their present relationships. For example, in comparing a person's age to the variety of treatments used it was necessary to select the measure for variety of treatments that corresponds to the age the person was when those treatments were used. The variety of treatments, therefore, is a combination of treatments reported for the past year, the year that the survey was completed, rather than the combination of all treatments that a person has reported over the course of their tinnitus. Similarly, the figures used for total cost for this particular analysis were based on the total costs reported just for the past year. 
In the path model the direction of causal ordering proceeds from the most distal independent variable towards the dependent variable, past year's cost (PYCOST). One is interested in the relative amount of variance in (PYCOST) accounted for by the various intervening independent variables. Because these variables have been measured on different scales the appropriate path coefficient estimates are taken from the standardized Betas of regression. Following are the functional equations implied by the saturated path model depicted in Figure 12. LONGPROB $f$ AGE, SEX HEALTH $f$ AGE, SEX, LONGPROB WORKING $f$ AGE, SEX, LONGPROB, HEALTH SEVERITY $f$ AGE, SEX, LONGPROB, HEALTH, WORKING INCOME $f$ AGE, SEX, LONGPROB, HEALTH, WORKING PYRTXS $f$ AGE, SEX, LONGPROB, HEALTH, WORKING, INCOME, SEVERITY PYCOST $f$ AGE, SEX, LONGPROB, HEALTH, WORKING, INCOME , SEVERITY , PYRTXS 


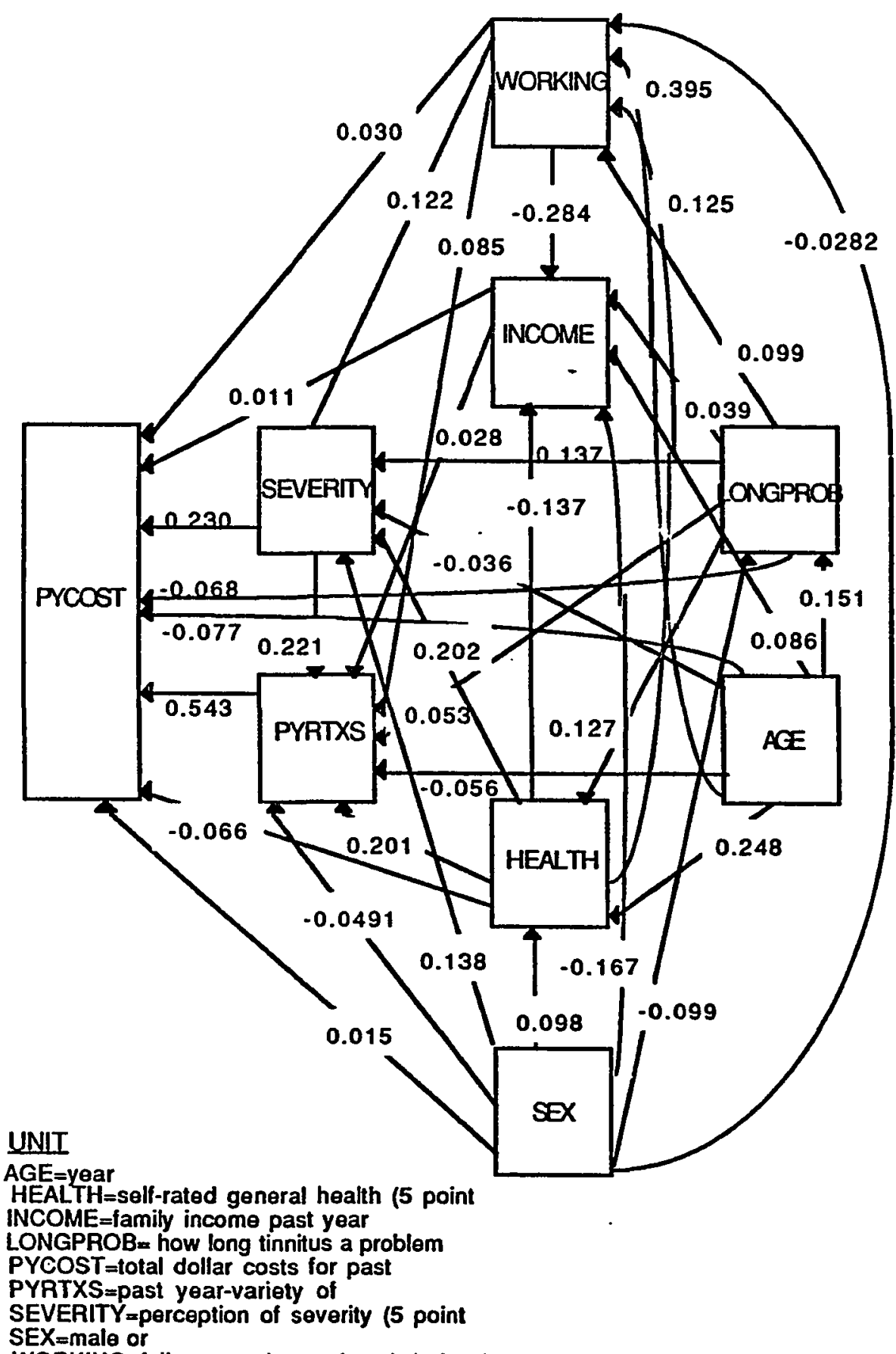

WORKING=fully or partly employed during last year

Eioure 12. Saturated path model for tinnitus costs 
In order to analyse both the direct and indirect effects of the variables on the total amount spent it is necessary to break down or decompose the correlations. For example, if one wishes to look at the composition of the effect of severity on total costs it is evident from the model that this effect is composed of a direct effect and an indirect effect through the variable 'PYRTXS', (the variety of treatments reported for the past year). Not all of the paths in a given saturated model are likely to be significant. This means that the effects through that particular path are mainly indirect. The variable in question, however, may still exert an effect on the total costs through other variables. Observations regarding the paths with little direct effect on total costs led to the conclusion that the saturated model could be trimmed. The trimmed path model is shown in Figure 13.

The functional equations implied by the trimmed model as depicted in Figure 13.

LONGPROB $f$ AGE

HEALTH $f$ AGE, LONGPROB

SEVERITY $f$ AGE, HEALTH, SEX

WORKING $f$ AGE, HEALTH

INCOME $f$ HEALTH, SEX, WORKING

PYSTXS $f$ AGE, HEALTH, SEVERITY

PYCOST $f$ SEVERITY, PYRTXS 
The decision to trim the model was based on the significance of the given ' $\underline{t}$ ' statistic for a path coefficient (Beta). An alpha level of $p<.05$ was chosen. Table XI delineates these relationships. The correlation matrix for the path variables is reported in Table XVI. 
UNIIS

AGE=years

HEALTH=self-rated general health (5 point scale)

INCOME=family income past year (\$)

LONGPROB=how long tinnitus a problem (yrs)

PYCOST= total dollar costs for past year (\$)

PYRTXS=past year-variety of treatments (\#)

SEVERITY=perception of severity (5 point scale)

SEX =male or female

WORKING=fully or partly employed during past year (Y/N)

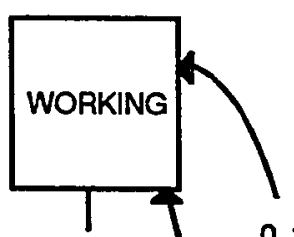

0.1479
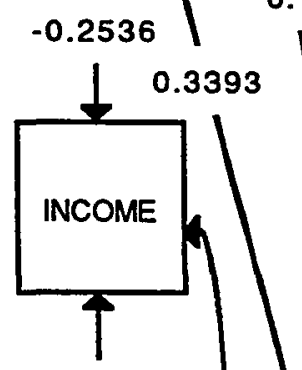

$-0.1207$

$-0.0711$

1
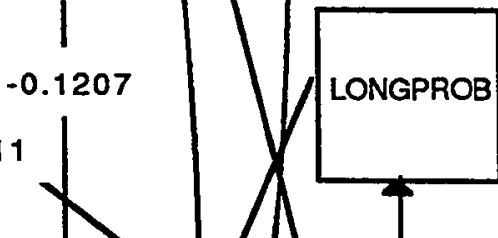

0.2569

0.2047
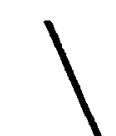

$-0.1849$

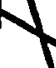

0.1617

HEALTH

0.2490

0.1175
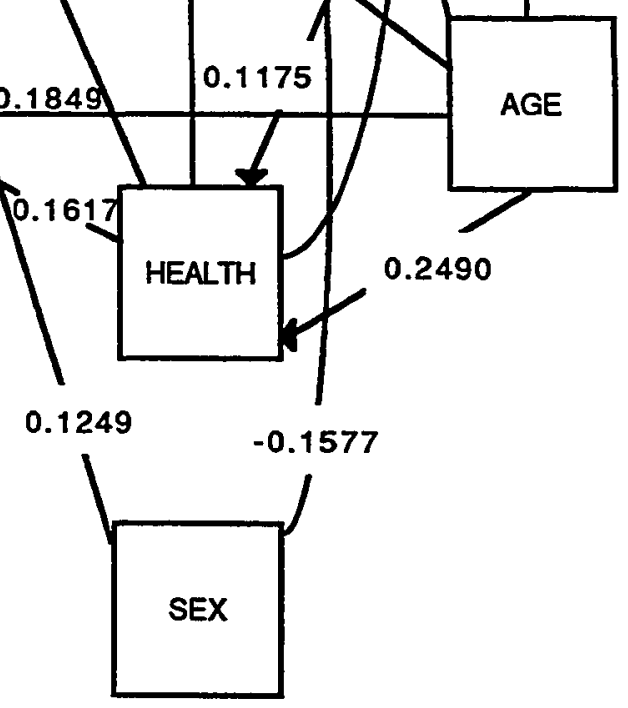

0.1249

0.1328

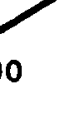


TABL: XIV

PATH MODEL FOE TTVNTTUS COSTS

DECOMPOSITION OF EEEECTS - SATTURATED MODEL

$(*=$ significant at

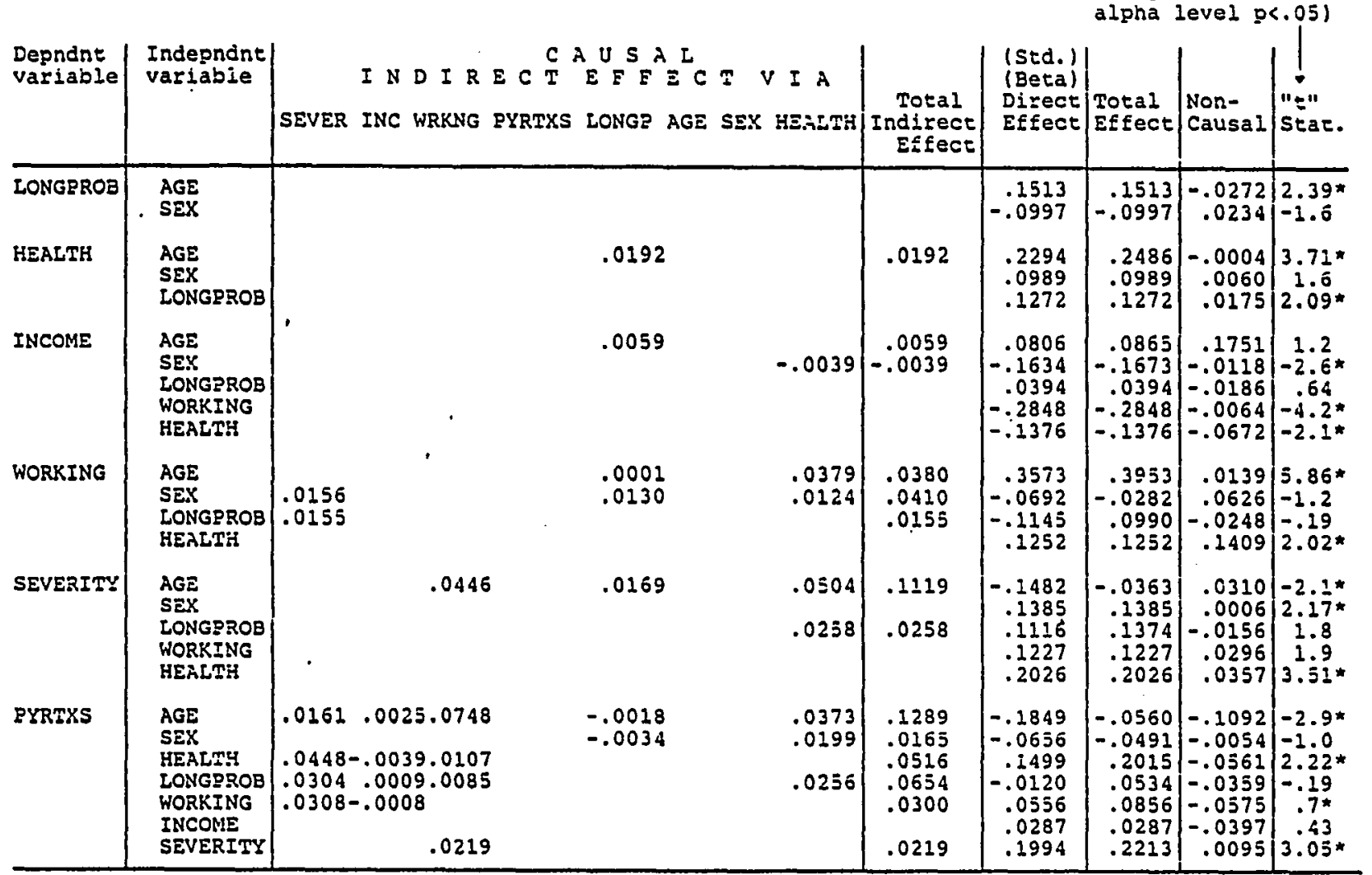

Functional equartons for pach analysis for the sacurated model

LONGPROB $f$ AGE, SEX

W AGE, SEX, LONGPROD, HEALTH

SEERTY AGE, SEX, LONGPROB, HEALTH, WORKING

PYRTYS I AGE, SEX, LONGPROB, HEALTH, WORKING, INCOME, SEVERITY

PYCOST I AGE, SEX, LONGRROB, HEALTH, WORKING, INCOME, SEVERITY, PYRTXS 
TABLE XV

PATH MODEL EOR TINNITUS COSTS

DECOHPOSITION OF EFEECTS - TRIMMED MODEL

\begin{tabular}{|c|c|c|c|c|c|c|c|c|c|c|}
\hline \multirow[t]{2}{*}{$\begin{array}{l}\text { Dependen: } \\
\text { variabie }\end{array}$} & \multirow[t]{2}{*}{$\begin{array}{c}\text { Independen } \\
\text { variable }\end{array}$} & \multicolumn{5}{|c|}{ 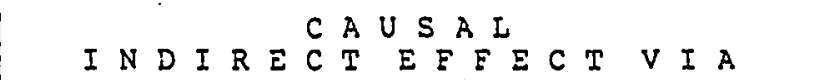 } & \multirow{2}{*}{$\begin{array}{c}\text { Total } \\
\text { Indirect| } \\
\text { Effect }\end{array}$} & \multirow{2}{*}{$\begin{array}{l}\mid \begin{array}{l}\text { (Std) } \\
\text { (Seta) } \\
\text { Direct }\end{array} \\
\text { Ėfect }\end{array}$} & \multirow{2}{*}{$\begin{array}{l}\text { Total } \\
\text { Effectl }\end{array}$} & \multirow{2}{*}{$\begin{array}{l}\text { Non- } \\
\text { Causal }\end{array}$} \\
\hline & & $\begin{array}{l}\text { SEV- } \\
\text { ERITY }\end{array}$ & $\begin{array}{l}\text { IN- } \\
\text { COME }\end{array}$ & $\begin{array}{l}\text { WORK PRYTXS } \\
\text {-ING }\end{array}$ & $\begin{array}{l}\text { LONG- AGE SEX } \\
\text { PROD }\end{array}$ & HEALTH| & & & & \\
\hline LONGPROB & AGE & & & & & & & .1328 & .1328 & -.0087 \\
\hline HEALTH & $\begin{array}{l}\text { AGE } \\
\text { LONGPROB }\end{array}$ & & & & .0156 & & .0156 & $\begin{array}{l}.2490 \\
.1175\end{array}$ & $\begin{array}{l}.2646 \\
.1175\end{array}$ & $\begin{array}{r}-.0164 \\
.0272\end{array}$ \\
\hline INCOME & $\begin{array}{l}\text { SEX } \\
\text { HEALTH } \\
\text { WORKING }\end{array}$ & & & -.0375 & & & -.0375 & $\begin{array}{r}-.1577 \\
-.1207 \\
-.2536\end{array}$ & $\begin{array}{l}-.1577 \\
-.1582 \\
-.2536\end{array}$ & $\begin{array}{l}-.0214 \\
-.0466 \\
-.0376\end{array}$ \\
\hline SEVERITY & $\begin{array}{l}\text { AGE } \\
\text { HEALTH } \\
\text { SEX }\end{array}$ & ' & & & & .0680 & .0680 & $\begin{array}{r}-.0711 \\
.2569 \\
.1249\end{array}$ & $\begin{array}{r}-.0031 \\
.2569 \\
.1249\end{array}$ & $\begin{array}{r}-.0022 \\
-.0186 \\
.0142\end{array}$ \\
\hline
\end{tabular}

Functional equations for path analysis for the trimmed model

LONGPROB $f$ AGE

HEALTH $f$ AGE, LONGPROB

WORKING $f$ AGE, HEALTH

INCOME $f$ SEX, HEALTH, WORKING

SEVERITY $f$ AGE, HEALTH, SEX

SEVERITY $f$ AGE, HEALTH, SEX
PYRTXS $f$ AGE, HEALTH, SEVERITY

DYCOST I SEVERITY, PYRTXS 
gesie XVI

COREEZITION MATRIX

VARIABLES USED IN T:EE IFTE MODEL IOR TINNIMUS COSTS

\begin{tabular}{|c|c|c|c|c|c|c|c|c|c|}
\hline VARIFSIE & PYCost & SEVERITY & INCOME & EVRAXS & LONEPROB & AcE & EIAITH & WORKING & $\mathrm{SEX}$ \\
\hline Pycost & 1.000 & 0.3371 & -.0133 & 0.5983 & -.0486 &.$-: 793$ & 0.0457 & 0.0236 & 0.0043 \\
\hline$S \Xi V \Xi R I T Y$ & 0.3373 & 1.000 & -.1151 & 0.2308 & 0.1218 & 0.0053 & 0.2383 & 0.1523 & 0.1391 \\
\hline INCOME & -.0133 & -.1151 & 1.000 & -.0110 & 0.0208 & -.0386 & 0.2048 & -.2912 & -.1791 \\
\hline PVREXs & $0 . \equiv 983$ & 0.2308 & -.0110 & $\therefore .000$ & 0.0175 &.$-: 552$ & 0.1454 & 0.0281 & -.0545 \\
\hline ZONGPROB & -.0486 & 0.1218 & 0.0208 & $0.0: 75$ & 1.000 & $0 .: 241$ & 0.1447 & 0.0742 & -.0763 \\
\hline$\therefore \Delta E$ & -.1793 & 0.0053 & -.0886 & -.1652 & 0.1241 & 1.000 & 0.2482 & 0.4092 & 0.1427 \\
\hline$\because \Xi A D$ มี & 0.0457 & 0.2383 & 0.2048 & 0.2454 & 0.1447 & $0.2\{82$ & $1: 000$ & 0.2661 & 0.1049 \\
\hline WORKING & 0.0236 & 0.1523 & -.2912 & 0.0281 & 0.0742 & 0.4092 & 0.2501 & 1.000 & 0.0344 \\
\hline$s \equiv x$ & 0.0043 & 0.1391 & -.1791 & -.0545 & -.0763 & $0 .: 427$ & 0.1049 & 0.0344 & 1.000 \\
\hline
\end{tabular}


The trimmed path model was consistant with the expected relationships. Starting from the distal end of the model, (please refer to Table XV), the variables, age and sex, exert no direct effect on costs except by their indirect effect on the intervening variables. Age exerts a positive effect on how long a person had tinnitus, and on how long it has been a problem, on general health, and on whether or not a person is employed. Age exerts an inverse effect on the variety of treatments utilized, and on the perception of severity. The inverse relationship suggests that as age increases the perception of severity decreases and fewer treatments are used. Sex affects income inversely, that is, women have lower incomes, and it affects perception of severity positively meaning that more women report tinnitus at the higher severity levels, (also refer to Figure 10). How long tinnitus has been a problem, has a direct effect on general health. Whether or not a person is working and their state of health affects their income but whether working or not and income do not contribute directly to costs incurred. one's general health affects both the variety of treatments employed and a person's perception of tinnitus severity and through those variables exerts an indirect effect on costs. These relationships are depicted in Figures 12 and 13 and described in Tables XIV and XV. Path analysis allowed the visualization of the direct and indirect effects of a number of variables on the total amount spent for tinnitus during 
the past year. While only about $42 \%$ of the variablity of costs was accounted for by the trimmed model, it was possible to trace effects from variables that exert their effect indirectly through other variables. For example, it was postulated that a person's perception of severity of their tinnitus was related to the amount spent seeking relief. Tabulations of the mean of total direct costs for each level of perceived severity showed clearly that those costs increased as the severity level increased. 
CHAPTER VII

DISCUSSION

\section{Introduction}

This chapter presents a discussion of the results as they relate to the research questions, the hypotheses, and the existing literature on tinnitus. Tinnitus is not a visible condition, nor is it measurable in a strictly objective sense. Those who suffer from tinnitus do report profound effects on their lives. In this study an effort was made to quantify the effect on the individual and to relate the patient's perception of the condition to measures of cost.

The attempt to set monetary values for tinnitus costs The first research question asked whether or not a monetary value can be placed on costs associated with tinnitus treatment and on indirect costs for the sufferer. In the accounting model for tinnitus direct costs were shown for amounts spent last year. It can be noted that people in the survey reported spending slightly more last year for tinnitus costs $(\$ 834)$ than they did for all of their other medical costs $(\$ 804)$. These figures may be contrasted with figures reported in Health, 1983, showing personal per capita health care expenditures of $\$ 745$ for the year 1978 . 
Although monetary values for indirect costs were not established in the present study, the information that was gathered indicates that there are indirect costs to society because of behavior changes caused by tinnitus. There were reports of sleep deprivation by $59 \%$ of the respondents, $58 \%$ reported curtailment of social activities, and $14 \%$ either had to change jobs or quit working because of tinnitus. The most frequent comment that people wrote on the back of the questionnaire was that they suffered from stress because of their tinnitus. These changes all signify a handicap for the afflicted person and perhaps even a disability.

In order to try to establish monetary values for these indirect costs the present survey included a section about willingness-to-pay. People were asked to imagine the existence of a safe and effective treatment for tinnitus and then to tell how much they would be willing to pay, per month, to achieve varying levels of relief. Unfortunately, people either did not understand the question, leaving it unanswered, or they guessed so wildly, sometimes indicating amounts in excess of 1 million dollars per month, that the data was not suitable for strict analysis. It appeared that people would spend modestly increasing sums for equivalent levels of relief, the exception being that for the hope of nearly complete relief they were willing to spend extremely large amounts.

Relating individual costs to society 
Having shown that individuals do bear costs as a result of having tinnitus the larger question is of how those costs relate to society as a whole. Projections of individual costs to the numbers estimated to have severe tinnitus would yield very large sums. A more conservative approach would use an estimate of those who would be expected to seek treatment. The sample for the present study was admittedly biased toward those seeking help through self-help groups and inquiries of the ATA. The sample also was shown to approximate patients seeking medical treatment from the comparisons drawn with the Tinnitus Clinic on measures relating to severity. There are no U.S. figures estimating the number of people with tinnitus who seek treatment for it. From the above two sample populations, we know that people seeking tinnitus treatment are more likely to have moderate to severe tinnitus but that sometimes treatment is sought by those people having low levels of severity.

Prevalence of tinnitus. Prevalence estimates for tinnitus have been shown to be imprecise and they are often controversial. One thing that is generally accepted is that there are large numbers of people with the problem. Even the most conservative of the estimates, that from the National Health Interview Survey, showed more than 6 million adults with tinnitus in 1985. It can be argued that these represent moderate to severe tinnitus because people tend not to report having mild or transitory tinnitus. From the various sources 
of available data referenced in this study another estimate of severe tinnitus prevalence was suggested. This estimate, $5.3 \%$ or 12 million, was used in order to relate the information from this study to the general population. Adopting a very conservative approach and supposing that only $10 \%$ of the people who have severe tinnitus are motivated to do something about it, we arrive at a (probably low) figure of more than 1 million individuals who would be willing to seek and pay for medical treatment. Slater and Terry (1987), using information gathered by Coles (1981), estimate that 250,000 people in England need specialized help beyond that provided by their family doctor. Certainly then, applying their ratio of $1 / 200$ of the $U . K$. population $=$ 'true tinnitus sufferer', there are more than 1,000,000 adults in the U.S. who require specialized help for tinnitus. This figure approximates the conservative estimate of about $10 \%$ of those with severe tinnitus actually seeking specialized professional help. This figure is also approximated if about 208 of those estimated in the NHIS-3 study were to seek specialized treatment for tinnitus.

Tinnitus severity. It is apparent that severe cases of tinnitus are of primary interest when making estimates of cost and decisions about allocation of resources. In testing hypothesis number 1 it was found that direct costs rose as expected along with increased perception of severity. A variety of approaches to severity measurement were reviewed 
and from the available survey data a scale was developed that appears to be more sensitive in identifying how tinnitus is perceived than are single measures of severity. By adding the dimension of sleep deprivation to measures of annoyance and life interference a larger group of people are identified at the more severe levels of tinnitus. This information helps to clarify the larger dimension of severity and identifies people who perceive their tinnitus as severe but may have been missed in assessments involving only single item measures.

The effects of other variables on tinnitus

The relationships expected in hypothesis 2 , that tinnitus costs would be related to age, sex, length of time afflicted, general health, income, working, severity, and number of treatments employed, were evident but not as strong as expected.

Path analysis allowed the visualization of the direct and indirect effects of a number of variables on the total amount spent for tinnitus during the past year. While only about $42 \%$ of the variance of costs was accounted for by the trimmed model, it was possible to trace effects from variables that exert their effect indirectly through other variables.

The results reported in Table VI showed that age was not a determining factor for the reporting of perception of severity. Regression analysis, however, indicated an inverse 
relationship between the amounts people pay and their age. This finding is consistent with the fact that older people generally are less anxious about their tinnitus than younger people, and also may have lower income in retirement. Gender affects income inversely, that is, women have lower incomes, and it affects the perception of severity positively meaning that more women report tinnitus at the higher severity levels, (also refer to Figure 10). In Table X it was shown that younger women spent slightly more than men on their tinnitus but in the over 65 age group men spent a little more than women. This finding may relate more to whether or not a person is working than to age. Although women reported more often than men at the four higher levels on the questionnaire items, they reported higher only on levels 3 and 4 of the new severity scale. From this it would appear that gender does not play such an important part in predicting tinnitus costs.

In cases where tinnitus worsens over time, or has an effect on a person's general health, one might expect the length of time afflicted to be a predictor of costs. However, as discussed previously, tinnitus does not have a predictable course for most patients, and most of the patients in the present study reported themselves to be in good health. The trimmed path model for tinnitus costs indicated a weak relationship between how long tinnitus had been a problem and a person's health, the greater influence 
on health coming from a person's age. It must be concluded therefore that the length of time afflicted is of minor value in predicting tinnitus costs.

Most people in the study rated their health in general as either excellent or good. They were not asked to exclude tinnitus from this rating although it is more usual for a person not to include tinnitus in the answer to this question. General health affects both the variety of treatments employed and a person's perception of tinnitus severity and through those variables exerts an indirect effect on costs. These relationships were depicted in Figures 14 and 15 and described in Tables XI and XII. Inasmuch as health affects whether or not a person is working and consequently their income, amounts spent for tinnitus (even for severe cases) may be lower if available resources had already been used up on a life-threatening condition. It appears from the present results that costs incurred for tinnitus are not directly related to income level or whether or not a person is working. Remember, however, that the mean income for this study sample was $\$ 36,000$, and many people were retired. The availability of funds for treatment, when the condition is perceived as being relatively milder or less annoying, would naturally be greater with a higher income group and that group did in fact spend more for mild tinnitus. It was interesting, however to observe that the lower income patients actually spent more 
than high-income patients when the tinnitus was severe. One explanation may be that people whose employment furnishes their only subsistence, and who have tinnitus severe enough to affect how they perform their work, are probably willing to incur substantial costs to alleviate the problem. Perhaps those with higher income are able to arrange their lives to accommodate the tinnitus more easily.

Another possible explanation for the non-relationship of income to costs might be that most of the costs are covered by third party payments. This study did not reveal that to be true. Very few of the people surveyed reported having received disability compensation for tinnitus but a good many reported having medical insurance which covered at least part of the costs of their treatment. People reported various levels of coverage for tinnitus ranging from no coverage at all to the full coverage accorded to veterans. The average coverage of $25 \%$ may reflect the fact that most insurers cover professional medical visits and treatment but not assistive devices such as hearing aids or maskers. Only two of the respondents were veterans or currently in the military service with treatment costs fully covered. Furthermore, the general public attitude in this country is that medical treatment is universally available. People may not weigh their decision to seek medical treatment for conditions they perceive as severe on the basis of their income. 
Results from path analysis also suggested that the main reasons for costs to increase was because the person had a number of different treatments for tinnitus. This finding serves to point out the need for safe and effective treatment for tinnitus so that people are not forced to "try everything" while seeking relief. Implications for policymaking and further research

When future decisions are made regarding the allocation of resources for tinnitus research and development of tinnitus treatment, the measures put forth in this study can help to determine the numbers of patients requiring such help. It has been shown that the number of people with severe tinnitus is large. Clearly, larger studies on a broad based sample are required to produce the necessary information for economic analysis.

Future information gathering efforts should be made with respect to gathering data specifically about tinnitus without confounding the issue by its inclusion with other hearing problems.

There is an additional confounding issue, that of psychological distress. Use of personality inventories in previous studies (House, 1978, Reich 1984) has revealed a category of patients whose primary problem is not tinnitus, but an inability to cope. Future research efforts need to be made in the area of trying to identify those patients for whom psychological treatment might be more appropriate. To 
the extent that the present study is likely to have included some respondents who would fit the designation of non-copers, the cost estimates for the group reporting the most severe tinnitus may be inflated with costs of psychological care or of seeking inappropriate medical care. However, it is the author's opinion, based on personal contact with thousands of people who have tinnitus, that the number of cases falling into this category is small.

Information from this study may be utilized by clinicians treating tinnitus to help assess the amount of distress caused by tinnitus. The severity scale that was developed did not have sufficient reliability to be used as a single decisionmaking instrument, but used in conjunction with other tests can be helpful in developing information to help plan for his or her needs for treatment. Furthermore, the new scale appears to be helpful in recognizing males who are reticent to admit to suffering from moderate to severe tinnitus. It is possible that men feel more comfortable identifying their distress as a sleep problem than as an annoyance problem.

Predictive information that was derived from the path analysis is also not meant to be used as a sole criterion of the amount someone will spend on tinnitus. It is important that future research take all of the presently identified predictor variables into account, as well as others that may be identified later, when evaluating tinnitus patients, and 
to try to evaluate the indirect costs of tinnitus. Clearly, the use of a strictly medical assessment, or a strictly psychological assessment, or any evaluation that is not cross-disciplinary and comprehensive in nature will fail to provide sufficient information for informed decisionmaking. 


\section{SELECTED BIBLIOGRAPHY}

Ambrosino, S. V., Neuropsychiatric aspects of tinnitus.

in A. Shulman (Ed.). Tinnitus: Proceedings of the first international tinnitus seminar (New York 8-9 June 1979). Jrl Laryn Oto, Suppl. 4, 1981.

Asher, H.B., Causal Modeling. Beverly Hills: Sage Publications, 1976.

Baum, J. A review of the psychological aspects of rheumatic diseases. Sem. in Arthritis and Rheumatism, 11, No.3, 352-361, Feb. 1982 .

Bird, H.A., Taylor, D.G., Inman, W. Measurement of other outcomes. Br J. Rheumatol, 1983, Aug 22 (3 suppl):90-4.

Brantman, M. The status and outlook for commercial health insurance coverage of speech and hearing services, ASHA Jrl, 15 (4): 183-187, 1973.

Brody, W. H. Economic value of a housewife, DHEW Pub. No. (SSA) 75-11701, 1975.

Brown, V. A. From sickness to health: an altered focus for health-care research. Soc.Sci.Med., 15A, 195-201, 1981.

Carmen, R. Positive solutions to hearing loss. New Jersey, Prentice-Hall, Inc. 1983

Cathcart, J. Assessment of the value of tocainide hydrochloride in the treatment of tinnitus. Jrl Laryn.\& Oto., 96 (9),981-984, 1982 .

Cheung, S.N.S. The myth of social cost. Hobart paper 82 , The Institute of Economic Affairs, 1978.

Coase, R. H. The problem of social cost. JrI Law \& Econ, 3,1960 .

Coles, R. R. A. Epidemiology of tinnitus. in Evered, D. (Ed.) Tinnitus, Ciba Foundation Symposium 85. Pitman, London, 1981 . 
Coles, R. R. A. Epidemiology of tinnitus: (1) Prevalence, in A. Shulman \& J. Ballantyne, (Eds.) Proceedings of the II International Tinnitus Seminar New York, 10 and 11 June 1983. Supp.9, Jrl Laryn \& Oto, 1984.

Cooper, B.S., Rice, D.P. The economic cost of illness revisited. Soc Sec Bull, 39(2), 21-36, 1976.

Cooper, C. Economic evaluation and the environment. Hodder \& Stroughton, London, 1981.

Culyer, A.J., Health indicators. Martin Robinson, Oxford, 1983.

Dean, K. Self-Care responses to illness: a selected review, Soc. Sci. Med., 15, 673-687, 1981.

Dillman, D. A. Mail and telephone surveys: the total design method. New York, Wiley, 1978 .

Discursive dictionary of health care. U. S. Government Printing Office, 1976.

Downs, A., Uncompensated non-construction costs which urban highways and urban renewal impose upon residential households. in The analysis of public output. $J$. Margolis (ed.). New York:NBER, 69-106, 1970.

Ehrlich, G.E. Social, economic, psychologic \& sexual outcomes in rheumatoid arthritis. Am Jrl Med, 1983 Dec $30 ; 75(6 A): 27-34$.

Emmett, J. R., \& Shea, J.J. Medical treatment of tinnitus. in A. Shulman \& J. Ballantyne (Eds.). Proceedings of the II international tinnitus seminar. Jrl Laryn \& Oto, Supplement No.9., 1984.

Erickson, P., Henke, K-D., Brittain, R. D. A health statistics framework: Us data systems as a model for european health information? in A. J. Culyer (ed.), Health indicators. Oxford, Martin Robertson, 1.983.

Fein, R. Economics of mental illness. Joint commission on mental illness and health. New York: Basic Books, Monograph series No.2, 1958.

Flanagan, J. C.. Measurement of quality of life: current state of the art. Arch Phys Med Rehabil, 63, 56-59, Feb 1982 . 
Fowler, E. P. Head noises in normal and disordered ears: Significance, measurement, differentiation and treatment. Arch. Oto., (39) 498-503, 1944.

Fowler, E. P. Nonvibratory tinnitus, Arch.Oto, (47) 2936,1948 .

Frankenhaeuser, M. \& Patkai, P. Catecholamine excretion \& performance under stress. Perceptual and Motor Skills, $19,13-14,1964$.

Fried, M. Grieving for a lost home:psychological costs of relocation, in Urban renewal: the record and controversy. J. Q. Wilson, (ed.), Cambridge, Massachusetts: MIT Press, 359-79, 1967.

Gerber, R. E., Nehemkis, A. M., Charter, R. A., \& Jones, H. C. Is tinnitus a psychological disorder?

Int1.Jrl.Psych.Med, 15(1) 81-87, 1985-86.

Goldberger, A. S. On Boudon's method of linear causal analysis. Amer. Soc. Rev., 25, 97-101, 1970.

Goodwin R. E., \& Johnson, R. M. The loudness of tinnitus. Acta Otolaryng, 90: 353-359, 1980 .

Grahom, J. Tinnitus in children with hearing loss, in D. Evered \& G. Lawrenson (Eds.) Tinnitus, Ciba foundation symposium 85. London: Pitman, 1981.

Hallam, R. S., \& Jakes S. C., A comparison of different methods for assessisng the intensity of tinnitus, Acta Orolaryngol, 99, 501-508, 1985.

Hartunian, N. S., Smart, C. N., Thompson, M. S. The incidence and economic costs of major health impairments. Lexington, MA: D.C. Heath \& CompanY, 1981.

Hazell, J. W. P. Tinnitus masking therapy, in Hazell, J. W. P. ed. Tinnitus, Churchill Livingstone, London, 96-117, 1987 .

Heffler, A. Cost effective hearing conservation for industry. Occup Health SAF, May-June 48(4):40-4, 1979.

Honig-Parnassus, T. Lay concepts of the sick-role: an examination of the professionalist bias in Parsons' model, Soc.Sci.Med. 15Ä,615-623, 1981.

Hoover, S. Tinnitus and allergy, ATA Newsletter, 12, 3, 1987. 
House, J. W. Treatment of severe tinnitus with biofeedback training. Laryngoscope (88), 406-412, 1978.

House, P. R. Personality of the tinnitus patient. In D. Evered \& G. Lawrenson (Eds.) Tinnitus, Ciba foundation symposium 85. London: Pitman, 1981.

Hulshof, J. H., \& Verney, P. The effect of several doses of oral Tocainide $\mathrm{HCl}$ on tinnitus:a dose finding study. in A. Shulman \& J. Ballantyne (eds.). Proceedings of the II international tinnitus seminar, Jrl Laryn Oto suppl.9, 1984 .

Hunt, S., Mckenna, S. P., McEwen, J., Williams, J. \& Papp, E. The Nottingham health profile: subjective health status \& medical consultations. Soc.Sci.Med.15A, 221-229, 1981.

Jakes, S. C., Complaints about tinnitus;implications for the treatment of tinnitus distress. Audiology in practice. III/2, 1986.

Jakes, S. C., Hallam, R. S., Chambers, C. \& Hinchcliffe, R. A factor analytical study of tinnitus complaint behavior., Audiology, 24 (3),195-206 May-June 1985.

Kenny, D. A., Correlation and causality, New York: John Wiley \& Sons, 1979.

Kerlinger, F. N., \& Pedhazur, E. J., Multiple Regression in Behavioral Research, New York: Holt, Rinehart \& Winston, Inc., 1973 .

Ianyon, R. I. A handbook of MMPI group profiles. Minneapolis: Univ. of Minnesota Press, 1968.

Lechtenberg, R., \& Shulman, A. Benzodiazepines in the treatment of tinnitus. in A. Shulman \& J. Ballantyne (Eds.). Proceedings of the II international tinnitus seminar, Supp.9, Jrl Laryn Oto, 1984.

Leske, M. C. Prevalence estimates of communicative disorders in the U.S., Lang.Hrg \& Vest.Dis., ASHA, 23 (3):229237,1981 .

Levin, H. M. Cost effectiveness, Beverly Hills: Sage Publications, 1983 .

Liang, M. H., Larson, M., Thompson, M. , Eaton, H. , McNamara, E., Katz, R., \& Taylor, J. Costs \& outcomes in rheumatoid arthritis and osteoarthritis. Arth. Rheum., 555-9, 1984 . 
Lindberg, P., Lyttkens, I. Melin, L., \& Scott, B. Tinnitus-incidence and handicap. Scandinavian Audiology, 13 (4), 287-291, 1984 .

Lipscomb, D. M. Environmental noise is growing - is it damaging our hearing? Clin.Ped. 11 (7):374-375, 1972.

Longridge, N. S., A tinnitus clinic, Jrl Oto, 8, (5), 390-5, 1979 .

Maltbie, A. A., Cavenar, J. O., Hammett, E. B., \& Sullivan, J. L. A diagnostic approach to pain. Psychosomatics, $19,361-366$.

Meenan, R. F., Yehlin, E. H., Henke, W., Curtis, D. L., Epstein, W. V. The Costs of rheumatoid arthritis: A patient-oriented study of chronic disease costs. Arth. Rheum., Sept-Oct 21(7):827-33, 1978 .

Meikle, M. B. \& Walsh, E. T. Characteristics of tinnitus and related observations in over 1800 tinnitus clinic patients, in A. Shulman \& J. Ballantyne (Eds.). Proceedings of the II international tinnitus seminar. Jrl Laryn \& Oto, Supplement No.9., 1984.

Meikle, M. B., Vernon, J., \& Johnson, R. M. The perceived severity of tinnitus, Amer.Acad.Oto.Head \& Neck Surg., Annual Meeting Presentation, 1983.

Melding, P. S. Goodey, R. J. \& Thorne, P. R. The use of intravenous lignocaine in the diagnosis and treatment of tinnitus, Jrl Laryn \& Oto, $92,115,1978$.

Mikesell, R. F. The rate of discount for evaluating public projects. Washington: American Enterprise Institute for Public Policy Research, 1977.

Mishan, E. J., Evaluation of life and limb: A theoretical approach. Jrl of Pol.Econ. 687-705, July/August 1971.

Mishan, E. J., Economics for social decisions, New York: Praeger Publishers, 1973.

Mishan, E. J., Cost-Benefit analysis, New York: Praeger Publishers, 1976.

Mooney, G. H. The valuation of human life. London: MacMillan, 1977.

Mooney, G. H. Human life and suffering, in D. W. Pearce, (ed.) The valuation of social cost, London: George, Allen \& Unwin, 1978. 
Mueller, A. D.,\& Lefkowitz, M. Personality, structure, and dynamics of patients with rheumatoid arthritis. Jrl.Clin.Psy. 12 143-147, 1956.

Myklebust, H. R. The psychology of deafness, New York: Grune and stratton, 1960.

Nash, C. A. The theory of social cost measurement, in Pearce, D. W. The valuation of social cost. London: George, Allen \& Unwin, 1978.

National Center for Health Statistics: Health, United States, 1983, DHHS Pub. No. (PHS)84-1232. Public Health Service, Washington. U. S. Gov't Printing Office, Dec. 1983.

National Center for Health Statistics:

Vital and Health statistics, Series 1;

Number 1, Origin, Program, and Operation of the

U.S. National Health Survey. 1963

Number 2, Health Survey Procedure:Concepts,

Questionnaire Development, and Definitions in the Health Interview Survey. 1964

Number 7, Design and Methodology for a National

Survey of Nursing Homes, 1968 .

Number 11, Health Interview Survey Procedure 1957-

74. 1975.

Number 15, Plan and Operation of the Second

National Health and Nutrition Examination Survey

1976-80. 1981 .

Number 16, Data Systems of the National Center for Health Statistics, 1981 . Number 18, The National Health Interview Survey

Design, 1973-84, and Procedures, 1975-83. 1985.

Vital and Health Statistics, Series 10;

Number 101, Persons with Impaired Hearing. 1975

Number 140, Hearing Ability of Persons by

Sociodemographic and health characteristics: United

States. 1977.

Number 142, Health Status Assessment. 1978.

Number 155, Prevalence of selected chronic

conditions: U.S. 1979-1981.

Number $154,156,160,164$ Current estimates from the

national health interview survey: U. S. 1983, 1984,

$1985,1986$.

Vital and Health Statistics, Series 11;

Number 32, Hearing status and ear examination

findings among adults: U. S. 1960-62, 1968.

Number 215, Basic data on hearing levels of adults 25-74 years, U.S. 1971-75, 1980. 
Vital and Health Statistics, Series 13;

Number 43, The National Nursing Home Survey:1977

Summary for the United States, 1979.

National Self-Help clearing House, Self-Help Reporter,

City University of New York, Newsletter, Spring 1985.

Nie, N. H., Hull, C. H., Jenkins, J. G., Steinbrenner, K. \& Bent, D. H. SPSS:Statistical package for the social sciences, New York, McGraw Hill, 1975.

Nunnally, J.C. Psychometric Theory, New York: Mc Graw Hill, 1978.

Pareto, V. Manual of Political Economy, New York: Kelley, 1971. (translation of 1909 work from the original French)

Parisier, S. C., Chure, P. M., Kramer, S., \& Gold, S. Tinnitus in patients with chronic mastoiditis and cholesteatoma, in A. Shulman \& J. Ballantyne (Eds.). Proceedings of the II international tinnitus seminar. Jrl Laryn \& Oto, Supplement No.9., 1984.

Pearce, D. W., Nash, C. A. The social appraisal of projects. New York: John Wiley \& Sons, 1981.

David $W$. Pearce, (ed.) The valuation of social cost. London: George, Allen \& Unwin, 1978.

Penner, M. J. The annoyance of tinnitus and the noise required to mask it. Jrl Sp \& Hrg Res, 26, 73-76, 1983.

Pigou, A. C., The economics of welfare, (4th ed.), London: Macmillan, 1932.

Pullar, T., Capell, H.A., Millar, A., Brooks, R.G. Alternative medicine: Cost and subjective benefits in rheumatoid arthritis. Br Med Jrnl [Clin Res] 1982 Dec 4; $285(6355)$ : $1629-31$.

Ramsde11, D. A., The psychology of the hard-of-hearing and the deafened adult. In $H$. Davis \& $S$. R. Silverman Hearing and Deafness, New York: Holt, Rinehart and Winston, 1960.

Ray, A. Cost-Benefit analysis, Baltimore, MD:World Bank, Johns Hopkins University Press, 1984.

Reed, G. F. An audiometric study of two hundred cases of subjective tinnitus. Arch. Oto., 71, 94-104, 1960. 
Reich, G. \& Johnson, R. Personality characteristics of tinnitus patients, in shulman, A. (Ed.)

Proceedings of II international tinnitus seminar, Jrl.Laryn.Oto., Suppl.9, 1984.

Reich, G., Evaluating tinnitus self-help groups, in $\mathrm{H}$. Feldmann (Ed.) proceedings III international tinnitus seminar Muenster 1987, Harsch Hverlag, Karlsruhe, 1987.

Rice, D.P. Estimating the costs of illness. (PHS Health Economic Series \#6). Washington, D.C.: US Govt Printing office, 1966.

Rifkin, S. B., The role of the public in the planning management and evaluation of health activities and programmes, including self-care, Soc.Sci.Med. 15A, $377-386,1981$.

Rogers, M. P., Liang, M. H., \& Partridge, A. J., Psychological care of adults with rheumatoid arthritis. Annls Int Med, 96, 344-348, 1982 .

Royston, L.H., Thomas, W.G., Royston, J.D., Lilley, D. Potential Hearing Compensation Costs by Race and Sex. JOM, Dec: $20(12): 801-6,1978$.

Sassone, P. G., Schaffer, W. A. Cost-Benefit analysis, New York: Academic Press, 1978.

Schelling, T. C. Choice and consequence, Cambridge, MA: Harvard University Press, 1984 .

Schwartz, I. H., Marcus, R. \& Condon, R. Multidiscplinary group therapy for rheumatoid arthritis, Psychosomatics, 19, 289-293, 1978 .

Selye, H., Stress without distress, Philadelphia: J. B. Lippincott, 1974.

Shulman, A., \& Goldstein, B. Neurotologic classification and tinnitus, in A. Shulman \& J. Ballantyne (Eds.). Proceedings of the II international tinnitus seminar, JrI Laryn Oto, supp.9, 1984 .

- Shulman, A., Medical audiological evaluation of the tinnitus patient, in Sweetow, R. ed. Seminars in hearing, New York: Thieme Medical Publishers, 1987.

Shuval, J. T. The contribution of psychological and social phenomena to an understanding of the aetiology of disease and illness. Soc.Sci.Med., 15A, 337-342, 1981. 
Sinden, J. A., \& Worrell, A. C., Unpriced Values: Decisions without market prices, New York: Wiley \& Sons, 1979.

Slater, R., \& Terry, M. Tinnitus: a guide for sufferers and professionals, New York: Sheridan House, 1987.

Social Security Bulletin, Consumer price index for urban wage and clerical workers, 1977-86. U.S. Department of Health and Human Services Social Security Administration, Table M-38 (66), June 1986.

Social Security Bulletin, Medical care component of the consumer price index for urban wage and clerical workers, 1977-86. U.S. Dept. Of Health and Human Services Social Security Administration, Table M-38 (66), June 1986.

Spergel, P., Ehrlich, G. E., \& Glass, D., The rheumatoid arthritic personality: a psychodiagnostic myth. Psychosomatics, 19, 79-83, 1978.

Standard \& Poors Statistical Service, cost of Isiving Index, Standard \& Poors Corporation, Current Statistics 52, 12, June, 1986.

Stanley, J., \& Rattray, A. Social severance. in D. W. Pearce (ed.) The valuation of social cost. London: George Allen \& Unwin, 1978.

Stephens, S. D. G. The treatment of tinnitus: A historical perspective. Jrl Laryn \& Oto, 98,963-72, 1984.

Stephens, S. D. G. Historical origins of the treatment of tinnitus, ATA Newsletter, 10,1, 1985.

Stephens, S. D. G. Historical aspects of tinnitus, in Hazell, J. W. P. ed., Tinnitus, Churchill Livingstone, London, $1-19,1987$.

Strauss, A.L. Chronic illness and the quality of life. St Louis: C.V. Mosby, 1975.

Sullivan, D. F. A single index of mortality and morbidity, HMSHA Health Reports, 347-55, 1971.

Summer, J. Tinnitus and the TMJ., ATA Newsletter, Vol 12,I, March, 1987.

Sweetow, R. W.,ed. Seminars in hearing, Thieme Medical Publishers, New York, 1987. 
Telles, J. I., \& Pollack, M. H., Feeling sick: the experience and legitimazation of illness.

Soc. Sci. Med., 15A, 243-251, 1981.

Thaler, R., Rosen, S. The value of saving a life: Evidence from the labor market. "Household Production \& Consumption", NBER, 1975.

Tinnitus, facts, theories and treatments, National Academy Press, Washington, 1982 .

Tonndorf, J. Stereociliary dysfunction, a cause of sensory hearing loss, recruitment, poor speech discrimination and tinnitus, Acta Oto, (91),469-79, 1981 .

Tyler, R. S., \& Baker, I. J. Difficulties experienced by tinnitus sufferers. Jrl Hrg Sp Dis, 48, 150-154, 1983.

Tyler, R. S., \& Conrad-Armes, D. The determination of tinnitus loudness considering the effects of recruitment. Jrl Speech Hearing Research. 26, 59-72, 1983.

Uhde, A. The need for health indicators. in A. J. Culyer (ed.), Health indicators, Oxford, Martin Robinson, 1983.

Uhrs,I. \& Uhrs, I., Tinnitus in connection with amalgam fillings, Goteborg, Sweden: Vasastadens Bokbinderi, 1986 .

Vernon, J. A., Schleuning, A., Odell, I., \& Hughes, F. A tinnitus clinic, Ear Nose \& Throat Jrl, April, 1977.

Vernon, J. A., \& Schleuning, A. Tinnitus: a new management Laryngoscope, 88, 413-419, 1978.

Vernon, J. A., Assessment of the tinnitus patient. in Hazell, J. W. P. (ed.) Tinnitus, Churchill Iivingstone, Iondon, 1987.

Vernon, J. A., \& Meikle, M. B., Tinnitus masking:unresolved problems, in D. Evered \& G. Lawrenson (Eds.) Tinnitus, Ciba foundation symposium 85. London: Pitman, 1981.

Verschuure, J., Ed. Audiology in Practice. Excerpta Medica, Amsterdam, the Netherlands, III/2, 1986.

Virtanen, H. Objective tubal tinnitus: A report of two cases. Jrl Laryn \& Oto,97,(9), 857-62, 1983 . 
Ward, P.R. Treatment of elderly adults with impaired hearing: Resources, outcome and efficiency. J. Epidemiol Comm. Health, Mar: 34(1):65-8, 1980 .

Weiss, A.D. \& Weiss, E. R. Acoustic trauma: Tinnitus and vertigo. in A. Shulman, (Ed.) Proceedings of II international tinnitus seminar, Jrl.Laryn.Oto., Suppl.9, 1984 .

Wood, K. A., Webb, W. I., Orchik, D. J., \& Shea, J. J. Intractable tinnitus: psychiatric aspects of treatment. Psychosomatics, 24 (6), 559-565, 1983.

Zola, I. K. Socio-medical inguiries:recollections, reflections, and reconsiderations. Philadelphia, Temple Univ. Press, 1983.

Zola, I. K. Denial of emotional needs to people with handicaps. Arch Phys Med Rehab, 63, 63-67, 1982. 
REFERENCE NOTES

1. Douek, E. Closing remarks at Ciba Tinnitus Symposium, 1981 .

2. Johnson, R. M. Personal communication, 1982, \& 1987.

3. Brummett, R., Personal communication, 1987.

4. F. B., Personal communication, 1985.

5. Johnson, R. M. Personal communication, 1982, \& 1987.

6. Mahr, T. Personal communication, 1987

7. Johnson, R. M. Personal communication, 1982, \& 1987.

8. Elkins, E. Personal communication, 1987

9. Axelsson, A., Prevalence of tinnitus, Unpublished manuscript, University of Gothenberg, Sweden, 1987.

10. Reich, G., Tinnitus in hearing impaired schoolchildren in Oregon, Unpublished manuscript Portland State University, Portland, Oregon, 1980.

11. Keane, J. G., Personal communication, 1986.

12. Glorig, A. Tinnitus - Impairment, Handicap, Disability Suggested guidelines for the establishment of criteria of evaluation, presented at Tinnitus Study Group at the Annual meeting of the Academy of Otolaryngology, Chicago, 1987.

13. Johnson, R. M. Personal communication, 1982, \& 1987.

14. Johnson, R. M. Personal communication, 1982, \& 1987. 
APPENDIX A 
AMERICAN TINNITUS ASSOCIATION

"DIRECT AND INDIRECT COSTS OF TINNITUS"

A PATIENT'S PERSPECTIVE

NOTE: This information will be held CONFIDENTIAL and will be seen only by the administrative and medical advisory staff of the ATA.

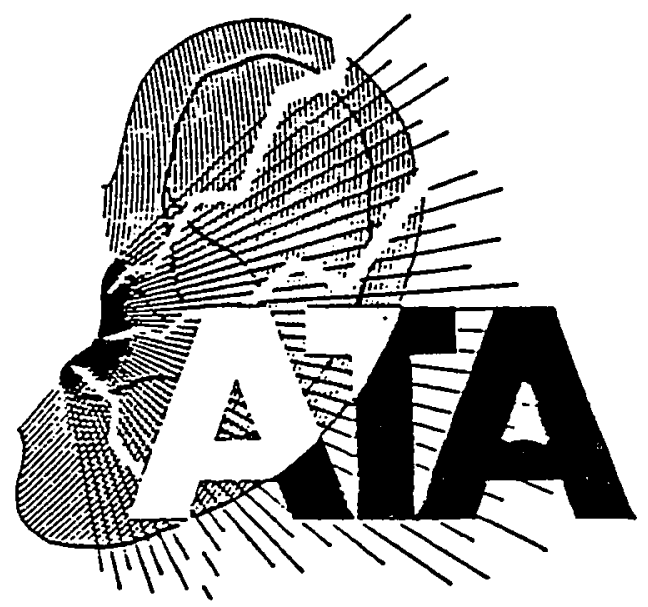

YOUR HELP WTTH THIS EFFORT IS GREATLY APPRECIATED! IT IS ONLY POSSIBLE TO OBTAIN THIS INFORMATION FROM YOU, THE PEOPLE WHO ACTUALLY HAVE TINNITUS. PLEASE TRY TO ANS WER EVERY QUESTION. IF YOU HAVE TROUBLE WITH A QUESTION, FEEL FREE TO WRITE AN EXPLANATION IN THE MARGIN, OR USE THE BACK PAGE TO ANSWER IN MORE DETAIL. THANK YOU!

(TURN TO BACK PAGE FOR SPECIAL ANNOUNCEMENT) 


\section{TINNITUS:THE BIG PICTURE}

SOME PEOPLE FEEL THAT TINNITUS IS A MAJOR HEALTH PBOBLEM, IN ORDER TO DOCUMENT THAT POINT WE NEED TO ASK YOU ABOUT TIE COSTS YOU HAVE INOURRED DUE TO HAVING TINNITUS. PLEASE REMEMBER TIAT THE QUESTIONNAIRE IS ANONYMOUS---NO ONE WILL KNOW YOUR NAME---BUT WE DO NEED All OF THE INFORMLATION ASKED FOR. PLEASETRY HARD TO ANSWER EVERY QUESTION EVEN IF YOU HAVE TO GUESS.

1. IIOW LONG HAVE YOU BEFN AIARE OF YOUR TINNITUS? number of years.

2. HOW LONG HAS THE TINNITUS BEEN A PROBLEM FOR YOU?

3. DO YOU HAVE A HEARING LOSS? yes, no.

4. HHICH IS MORE OF A PROBLEM FOR YOU, THE HEARING LOSS OR THE TINNITUS? Hearing Loss. Tinnitus

\section{TINNITUS COSTS}

5. HOW MANY DIFFERENT HEALTH PROFESSIONALS HAVE YOU SEEN REGARDING YOUR TINNITUS? Check all that apply to you from the list below:

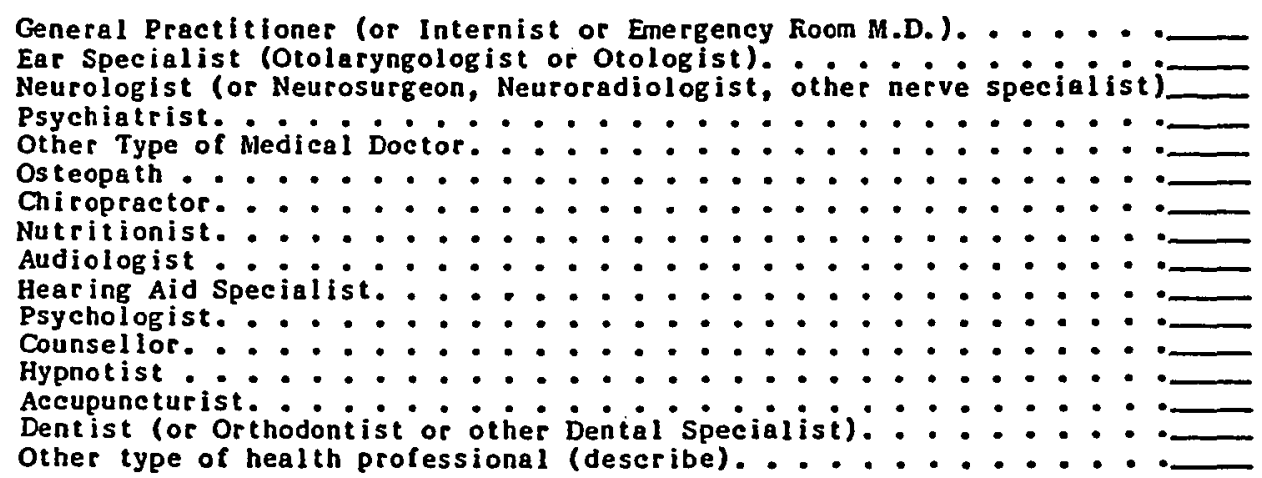

6. IN TOTAL, ABOUT HOW MANY VISITS REGARDING TINNITUS HAVE YOU MADE TO THE HEALTH PFOFESSIONALS LISTED ABOVE:

A) In the past year:

B) During the year you mest actively sought tinnitus help: What year was that?

C) During on "average year" for your tinnitus:

D) Total number since you first noticed tinnitus:

7. ROUGRY HOW MUCH HAS IT COST (EITHER FOR YOU OR FOR YOUR HEALTH INSURANCE COMPANY) TO PAY FOR VISITS TO THE HEALTH PROFESSIONALS LISTED ABOVE:
A) In the past year: 5
B) During the year you most actively sought help: s
C) During an "average" year: $\$$
D) Total costs since your tinnitus started: 
TINNITUS COSTS (continued)

8. SINCE YOUR TINNITUS STARTED, ILAS TIERE BEEN ANY YEAR OR YEARS IN WIICH YOU DID NOOI SEEK HELP FOR TINNITUS FROM ANY HEALTH PIBFESSIONAL? YES NO

9. HOW MANY YEARS haVe THERE BEEN IN WHICH YOU SPENT HQ MONEY ON TINNITUS-RELATED VISITS TO HEALTH PROFESSIONALS? (indicate number)

10. HOW MUCH HAVE YOU SPENT FOR PRESCRIBED DRUGS OR EQUIPMENT FOR YOUR TINNITUS? Please answer for an "average" year and for the year your costs were greatest. (Write in the year) Average year

Hearing aid(s)

(only if preseribed for tinnitus)

Tinnitus maskers

Tinnitus Instruments

(combined masker-hearing aid)

Medications (prescribed for tinnitus)

$\$$

Greatest year

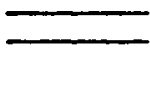

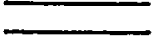

11. HOW MUCH HAVE YOU SPENT FOR NON-PRESCRIBED DRUGS AND/OR DEVICES USED FOR TINNITUS RELIEF?
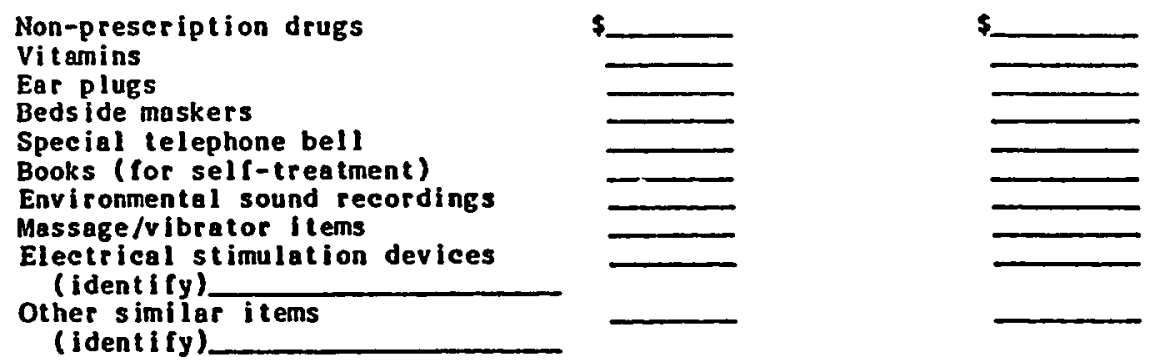

12. HAVE YOU EVER BEEN HOSPITALIZED FOR TINNITUS? YES NO

13. HOW MUCA HAVE YOU SPENT FOR HOSPITAL COSTS DUE TO TINNITUS? (Include the costs of hospital rooms, special treatments and tests done in the hospltal)

A) In the past year: \$

B) During the year you mostactively sought tinnitus help: \$

What was that year? 19

C) During an "average" year: $\$$

D) Total hospital costs since your tinnitus started: \$

14. HON MUCA. HAVE YOU SPENT ON TRANSPORTATION COSTS OR OTHER RELATED MEDICAL VIS IT COSTS IN ORDER TO GET HELP FOR YOUR TINNITUS?

A) In the past year: \$

B) During the year you mest actiyely sought tinnitus help: \$

C) During on "average" year: \$

D) Total tinnitus travel \& related visit costs: $\$$

15. OTHER HEALTH CARE COSTS NOT RELATED TO TINNITUS: About how much dId you spend last year? 
16. UNFORTUNATELY, MEDICAL SCIENCE DOES NOT YET HAVE A TREATMENT TO TURN OFF THE NOISES OF TINNITUS. Suppose, however, that such a treatment were available and that it was safe, easy, and effective. Assume that you would need one treatment each month, indefinitely. How much of your menthlyincome would you be willing to spend for treatment that would lead to:

a.) a $10 \%$ reduction in your tinnitus? $\$$

b.) a $30 \%$ reduction in your tinnitus? $\$$

c.) a $50 \%$ reduction in your tinnitus? $\$$

d.) a $25 \%$ reduction in your tinnitus? \$

e.) a $95 \%$ reduction in your tinnltus? \$

HEALTH INSURANCE:

17. WERE YOUR TINNITUS COSTS DURING THE PAST YEAR COVERED BY MEDICAL INSURANCE? NAME OF INSURER:

(Please remember to write in the name of your prepaid medical care plan if you subscribe to one, or write in VA (Veterans Administration). If applicable.

18. WERE TINNITUS COSTS COVERD DURING TIE YEAR THAT YOU MOST ACTIVELY SOUGTT HELP FOR TINNITUS? Yes No NMIE OF INSURER:

CHANGES IN SOCLIAL HABLTS:

19. IN YOUR OPINION WHAT ARE TIE GREATEST PROBLEMS CAUSED BY YOUR TINNITUS?

20. DO YOU ILAVE. SI.EEP PROR. BMS BECAUSF OF TINNITUS? yes , no.

21. IF YES, HAVE THESE INTERFERED WITI YOUR WORK OR DAILY ROUTINE? HOW? Explain brlefly

22. HAVE YOU HAD TO CONSULT WITH A PSYCIDLOGIST OR PSYCHIATRIST FOR HELP WITH TINNITUS OR RELATED STRESS? yes, no

23. HAVE YOU HAD TO CURTAIL YOUR SOCIAL ACTIVITIES BECAUSE OF TINNITUS? (check level that applies)

1. Never curtall activities because of tinnitus

2._ Curtail activities slightly

3._ Curtall activities moderately often.

4.__ Curtail activities quite often

5._ Virtually all social activities are curtailed. 


\section{TINNITUS SEVERLTY}

24. HOW WOUL YOU RATE THE SEVERITY OF YOUR TINNITUS (Check level)

1. Tinnitus is there if attended to but it is not very irritating

and can usually be ignored.

2.___. Tinnitus is often irritating but can be ignored much of the time.

3._._Tinnitus is difficult to ignore even with effort.

4._- Tinnitus is olwnys present at an irrituling level and often causes considerable distress.

5. Tinnitus is more than irritating, causes an overwhelming problem much or all of the time.

25. IOW HOULD YOU RATE TIIE DEGREE TO MIICI TINNITUS INTERFERES MTI YOUR LIFE? (check level)

1.___ Tinnitus causes little or no interference with work or social events.

2. Tinnitus causes sone interference, but $I$ can live with it.

3._Because of tinnitus it takes considerable effort to maintain normal work or social activities.

4. Tinnitus is a serious interference with normal lifestyle, can do only simple tesks.

5.__ Tinnltus renders me unable to perform any work or social activities.

26. HOW WOULD YOU RATE THE QUALITY OF TIE CONTACTS TTLAT YOU HAVE MADE IN ORDER TO GET HELP FOR TINNITUS? (check as many levels as appIy)

1.___Very helpful, treatment successfully reduced or eliminated

tinnitus.

2. Helpful and sympathetic but was unable to reduce or eliminate tinni tus.

3.__ Treatment offered but was ineffective or inappropriate.

4. No help offered other than being told "Learn to live with It."

5.___ Other comments about your satisfaction with the quality of care available for tinnitus. 
5

\section{GENERAL_QUESTIONS}

FINALLY, WE WOULD LIKE TO ASK A FEW QUESTIONS ABOUT YOURSEF TO HELP WITS CUR ANALYSIS OF THE RESULTS.

27. HIERE IS YOUR RES IDENCE LOCATED?

COUNTY

ZIP CODE

TOHN OR CITY IN WIICH (OR NEAREST TO)

YOUR RES IDENCE IS LOCATED

28. HAVE YOU CILANGED YOUR PLACE OF RESIDENCE BECAUSE OF TINNITUS?___ Yes,__no

29. AGE_, in years

30. SEX , M Or F

31. YOUR SCTDOLING LEVEL COMPLETED:

Grade school

High school

Vocational sehool

Four year college

Other

32. ARE YOU PRESENTLY: MARRIED

WIDOWED

DIVORCED__ NEVER MARRIED

OTHER_, explain

33.DO YOU HAVE CHILDREN? ___ yes, no__ how many? how many live with you?

34. HOW WOULD YOU RATE YOUR HEALTH IN GENERAL? (Check one) Excellent. Cood Fair Poor Very bad

\section{DISABULTX COMPENSATION:}

35. HAVE YOU EVER RECEIVED ANY DISABILITY PAYMENTS BECAUSE OF TINNITUS? Yes No

36. WHAT WAS THE SOURCE OF THESE PAYMENTS? (Check any that apply)

Worker's Compensation; In whet state?

VA service-connected disability

Social Security (not old-age benefits)

A legal settlement or court award for damages

Other (explain briefly) 


\section{EAMLIY LNCOME}

37.PLEASE ANSWER THESE QUEST IONS FOR YOURSELF and YOUR SPOUSE OR OTHER ADULT LIVING PARTNER.(If you have one) Check the categories that best apply to you.

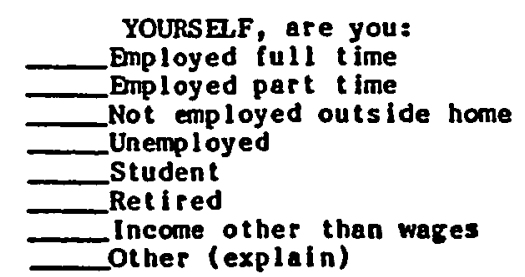

38. PLEASE CHEC THE CATEGORY THAT BEST DESCRIBES YOUR ANNUAL FAMILY INCOME. (these are the categories used in the $1980 \mathrm{U}$. S. census)

Under $\$ 10,000$ $\$ 10,000$ to $\$ 14,999$ $\$ 15,000$ to $\$ 24,999$

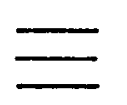

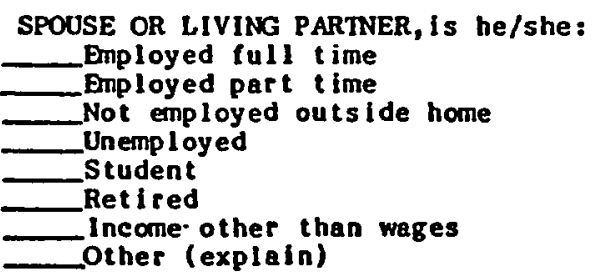

39. HAVE YOU EVER HAD TO CHANGE JOBS BECAUSE OF TINNITUS? yes, no 40. WHAT PERCENTAGE OF YOUR INOOME WAS LOST BECAUSE OF CHANGE? \%

41. HAVE YOU EVER HAD TO QUIT MORKING BECAUSE OF TINNITUS? If yes, are you: a) permanently unemployed? b) temporarily unemployed? yes, yes, ___ no For how long no. 2. MLAT PERCENTAGE OF YOUR INCOME IHAS LOST DUE TO QUITTING YOUR JOB? \$

43. IF YOU ARE A HOUSEWIFE, DID TINNITUS AFFECT YOUR ABILITY TO PERFOFM YOUR REGULAR DAILY HOUSEHOLD TASKS? Yes No

44. IF YES, DID YOU haVE TO HIRE SCMEONE ELSE TO DO THE hOUSEWORK? PLEASE ESTIMATE HOW MUCH THAT HOUSEHOLD HELP COST LAST YEAR.

45. Your ususl occupation when employed (or before reti rement)

Title

Kind of work

Type of compeny or bus iness

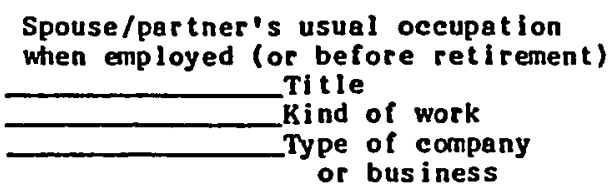

Spouse/partner's usual occupation Title

Type of company or bus iness

46. HAS ANYONE CLOSE TO YOU HIAD TO CHANGE ERPLOYMENT BECAUSE OF YOUR TINNITUS? (check answers that apply)

Yes, he or she went to work to provide extra income

Yes, he or she quit work to provide hame care for me

No, no one had to change their usual routine

Other, (please explain briefly) 
YOUR COMMENTS:

Please use this space for any additional comments you would like to make about the problem of tinnitus, about its costs or other impact on your life, or about your experiences in seeking

treatment for tiunitus:

Your help in completing thls research is greatly apprecialed. If you wish a suminary of results, please print your name and address on the back of your return envelope (NOT on this questionnaire). We will see that you receive it.

AS AN ADDITIONAL TIIANK YOU TO THOSE WHO RETURN THE QUESTIONNAIRE WE MLL ENTER ALL OF TIIE NAMES RECEIVED ON THE RETURN ENVELOPES IN A DRAWING FOR A COPY OF THE BOOK PROCEEDINGS OF THE II INUERNATIONAL TINNITUS SEMINAR. (IF. YOU WIN AND HAVE ALREADY PURCHASED THE BOOK WE WILL REFUND THE PURCHASE PRICE.)

(If you don't want the result summary, please write on the envelope, "Drawing Only".)

rev. $5 / 85$ 
APPENDIX B

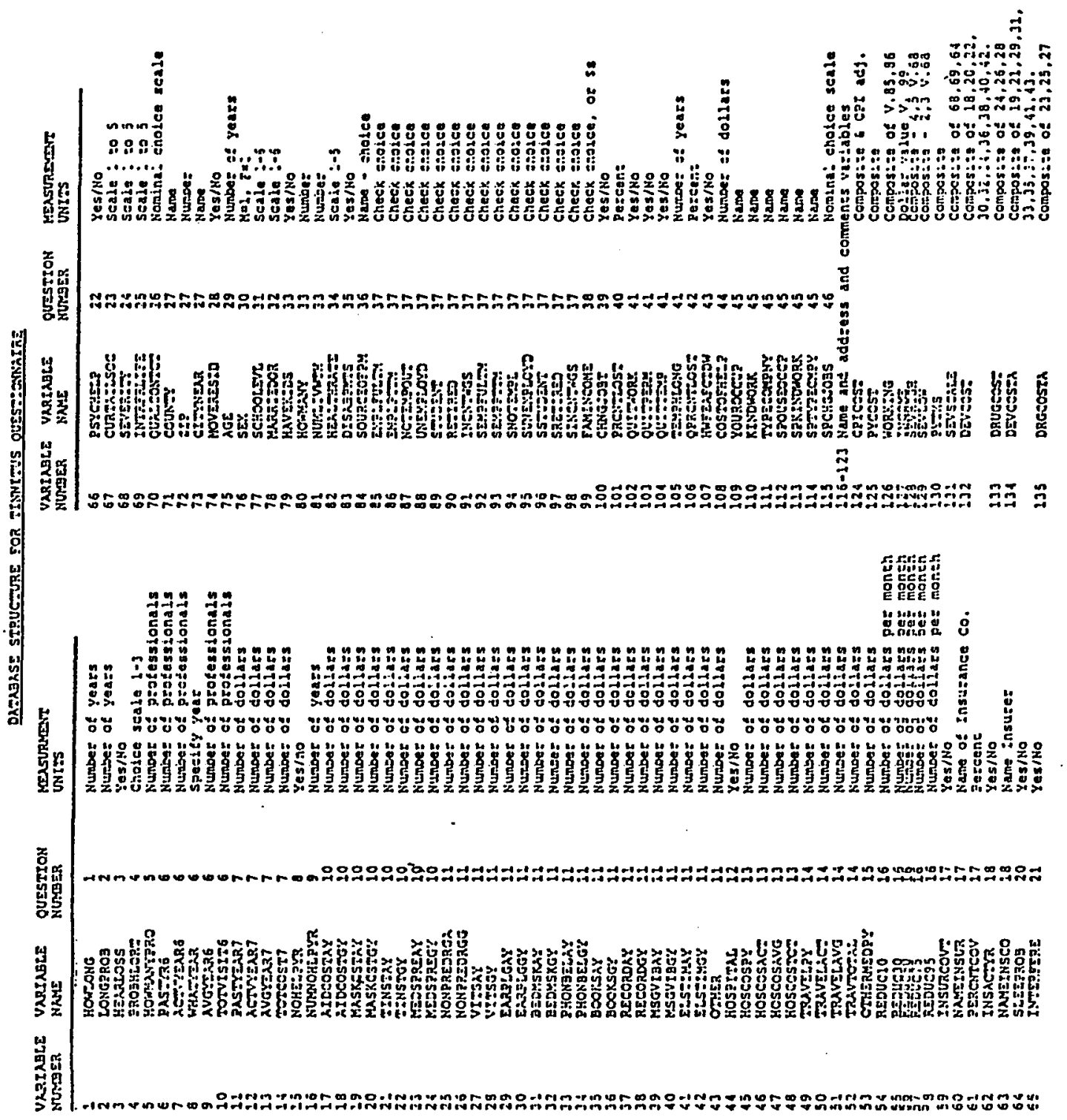


APPENDIX C

\section{PERCEPTION OF SEVERITY OF TINNITUS SCALE}

I. Do you have sleep problems because of your tinnitus?

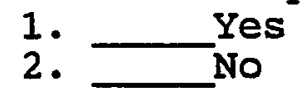

II. How would you rate the severity of your tinnitus? (Check level)

1. Tinnitus is there if attended to but it is not very irritating and can usually be ignored.

2. Tinnitus is often irritating but can be ignored much of the time.

3. Tinnitus is difficult to ignore even with effort.

4. Tinnitus is always present at an irritating level and often causes considerable distress.

5. Tinnitus is more than irritating, causes an overwhelming problem much or all of the time.

III. How would you rate the degree to which tinnitus interferes with your life? (Check level)

1.___._Tinnitus causes little or no interference with work or social events.

2. Tinnitus causes some interference, but I can live with it.

3. Because of tinnitus it takes considerable effort to maintain normal work or social activities.

4. Tinnitus is a serious interference with normal lifestyle, can do only simple tasks.

5. Tinnitus renders me unable to perform any work or social activities. 